\title{
HOMELESS MEN SEEKING SAFETY FROM TRAUMA AND SUBSTANCE USE: FINDINGS FROM A PILOT STUDY
}

\author{
By \\ Juliet L. Haynes, BSW Highest Honours
}

A Thesis submitted to the Faculty of Graduate Studies and Research In partial fulfillment of the requirements for the degree of Master of Social Work

\author{
School of Social Work \\ Carleton University \\ Ottawa, Ontario
}

July, 2007

(C) Copyright

Juliet L. Haynes, 2007 


$\begin{array}{ll}\begin{array}{l}\text { Library and } \\ \text { Archives Canada }\end{array} & \begin{array}{l}\text { Bibliothèque et } \\ \text { Archives Canada }\end{array} \\ \begin{array}{l}\text { Published Heritage } \\ \text { Branch }\end{array} & \begin{array}{l}\text { Direction du } \\ \text { Patrimoine de l'édition }\end{array} \\ \begin{array}{l}\text { 395 Wellington Street } \\ \text { Ottawa ON K1A ON4 }\end{array} & \begin{array}{l}\text { 395, rue Wellington } \\ \text { Ottawa ON K1A ON4 } \\ \text { Canada }\end{array}\end{array}$

Your file Votre référence ISBN: 978-0-494-33686-1 Our file Notre référence ISBN: 978-0-494-33686-1

NOTICE:

The author has granted a nonexclusive license allowing Library and Archives Canada to reproduce, publish, archive, preserve, conserve, communicate to the public by telecommunication or on the Internet, loan, distribute and sell theses worldwide, for commercial or noncommercial purposes, in microform, paper, electronic and/or any other formats.

The author retains copyright ownership and moral rights in this thesis. Neither the thesis nor substantial extracts from it may be printed or otherwise reproduced without the author's permission.
AVIS:

L'auteur a accordé une licence non exclusive permettant à la Bibliothèque et Archives Canada de reproduire, publier, archiver, sauvegarder, conserver, transmettre au public par télécommunication ou par l'Internet, prêter, distribuer et vendre des thèses partout dans le monde, à des fins commerciales ou autres, sur support microforme, papier, électronique et/ou autres formats.

L'auteur conserve la propriété du droit d'auteur et des droits moraux qui protège cette thèse. $\mathrm{Ni}$ la thèse ni des extraits substantiels de celle-ci ne doivent être imprimés ou autrement reproduits sans son autorisation.
In compliance with the Canadian

Privacy Act some supporting forms may have been removed from this thesis.

While these forms may be included in the document page count, their removal does not represent any loss of content from the thesis.
Conformément à la loi canadienne sur la protection de la vie privée, quelques formulaires secondaires ont été enlevés de cette thèse.

Bien que ces formulaires aient inclus dans la pagination, il n'y aura aucun contenu manquant.

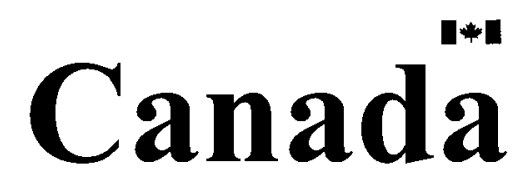




\title{
HOMELESS MEN SEEKING SAFETY FROM TRAUMA AND SUBSTANCE USE: FINDINGS FROM A PILOT STUDY
}

\begin{abstract}
Objective: Seeking Safety is a novel cognitive-behavioural model that addresses substance use and trauma. The Ottawa Area Mission, LifeHouse Addiction Treatment Program integrated Seeking Safety classes into its existing program structure. The purpose of this thesis research is an evaluation of the LifeHouse program with a particular emphasis on Seeking Safety. Method: The study included mixed methods: first, a quantitative comparison pretest and posttest, which employed the Trauma Symptom Inventory (TSI) and second, a qualitative exploration through semi-structured interviews. Eleven men completed TSI pretests and posttests between May 2006 and March 2007. Six of these men plus an additional four men participated in the interviews. In sum, fifteen men formed the participant sample for this research. Results: Seven themes emerged from the analysis including, Control, Trauma, Safety, Seeking Safety, Anger Management, Skills, and Motivation. The men who participated in this study reported diminished trauma symptoms at posttest. The men also provided positive feedback for LifeHouse program effectiveness through the participant interviews. A key finding from this analysis was an expressed need for Seeking Safety class repetition and reinforcement to increase coping skill retention.
\end{abstract}

Keywords: LifeHouse, Substance Use, Trauma, Men, Control, Safety, Seeking Safety, Anger Management, Skills, Motivation, Cognitive Behavioural Therapy, Coping, Mindfulness Based Practice. 
This research project is dedicated to my children Danika, Matthew, Kristina and Joseph who know the passion and perseverance of the journey.

I would also like to acknowledge the men who contributed to this study who shared their recovery experience in the hope it may benefit others. 


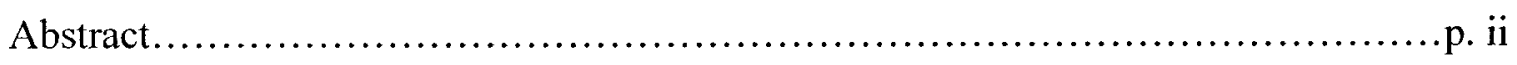

Dedication \& Acknowledgement................................................ iii

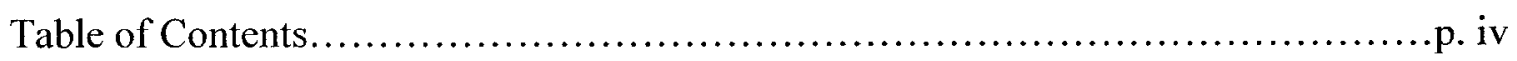

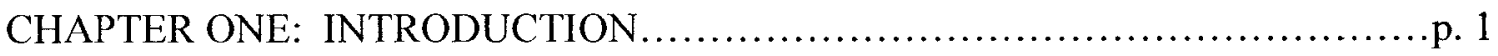

CHAPTER TWO: LITERATURE REVIEW

Part I: Contextualizing Addiction \& Historical Overview.........p. 14

Part II: Theoretical Framework..............................p. 29

CHAPTER THREE: METHODOLOGY...................................... 48

CHAPTER FOUR: DISCUSSION OF FINDINGS............................. 61

Quantitative Analysis.....................................p. 64

Qualitative Analysis...................................... 69

Conclusions...............................................p. 120

References......................................................... 131

Appendix A - Seeking Safety: Treatment Topics............................. 143

Appendix B - Research Instrument...................................... 144

Appendix C - Thematic Diagram (Themes \& Subcategories).................... 147

Appendix D - TSI Individual Tables..................................... 148

Appendix E - Information Letter..................................... 156

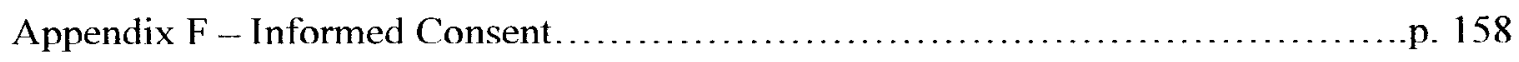




\section{CHAPTER ONE: INTRODUCTION}

Individuals residing in shelters for homeless and addicted individuals have varying complex and legitimate needs (i.e., homelessness, poverty, health concerns). And many of these same individuals face numerous barriers to achieving stability despite being clients of various health and social service agencies (VWSAC, 2004). Societal norms attach stigmas to individuals living in poverty in general and addiction in particular. Individuals living with no fixed address having exhausted all resources are vulnerable to criminal behaviour, violence and victimization on the streets. Moreover, individuals living with substance abuse are at increased risk for self-harm including susceptibility to illness and premature death (Tjepkema, 2004). Such complex issues may be indicative of historical trauma.

Individuals whose life experiences include trauma are ordinarily susceptible to substance abuse (Najavits, 2004; Muller, Kraftcheck, \& McLewin, 2004). Substance abuse is recognized as a vehicle for coping (i.e., self-medication; Martin, Weinberg, \& Bealer, 2007) among some individuals who experience pain and psychological stressors if the latter are chronic and of incremental severity (Najavits, 2002; Martin et al., 2007). Individual substance use potentially numbs and assists in avoiding negative emotions and/or cognitions. Such individual tendency toward numbing and avoidance is one of three criteria used in diagnosing posttraumatic stress disorder (hereafter referred to as PTSD). According to the Diagnostic and Statistical Manual of Mental Disorders (hereafter referred to as DSM-IV), reliving the traumatic experience and hyper-arousal are additional criteria used in PTSD diagnoses. Concurrent posttraumatic stress and substance use disorders will be discussed in more detail later in this thesis. Indeed, 
homeless individuals living with traumatic effects, PTSD and/or substance abuse experience societal judgement (e.g., stigmatization), fear and shame (Najavits, 2004). Moreover, with each "failed" recovery attempt individual self-esteem is compromised and internalized negative messages are reinforced (VWSAC, 2004).

It is often the case that psychoactive drug use is not tolerated in emergency shelters. Individuals may seek shelter in hospitals, treatment centers or recovery homes and even jail as a means to survive the cold winter months. Of course, this is but a temporary measure and finding an improved way to meet people's substance abuse treatment needs is a serious social, political, economic, and health care challenge. For example, 18,036 individuals were hospitalized for alcohol and drug dependence in Canada in 2001-2002 according to Statistics Canada (2004a). This represents approximately 58 per 100,000 individuals that were hospitalized in 2001-2002 (Statistics Canada, 2004b). A recent Substance Abuse and Mental Health Services Administration (2005) survey revealed "22.2 million Americans age 12 and older suffer from dependence on or abused illegal drugs (excluding alcohol) only; 15.4 million were dependent on or abuse alcohol alone" (as cited in Hoffman \& Froemke, 2007). A preliminary investigation revealed 800,000 Canadians had psychoactive drug (including alcohol) dependencies in 2002 (Tjepkema 2004). Indeed, addiction as a health and social concern is prevalent in North America. In fact, mental health and addictions affect one in five Canadians yet there is an absence of funding allocated to such care (CWHN, 2006). While one in five Canadians may experience addiction and/or mental health distress, their families and friends are also affected. Indeed addiction prevention, treatment, and relapse prevention warrant further study. 
Marginalized individuals possess fewer recovery options than those individuals having more adequate personal resources. Furthermore, the effects of substance abuse coupled with trauma extend beyond the individual, affecting the lives of family members, intimate partners and friends (Catherall, 2004). Substance abuse often leads to family breakdown, diminished productivity, job loss, healthcare expense, treatment and support, illegal activity, and imprisonment (Dziegielewski, 2005). Indeed, individual substance abuse is both influenced by and contributes to the sociopolitical climate.

While addiction is encompassed under the umbrella of mental health, it also influences physical health and immunology. For example, HIV/AIDS (e.g., human immunodeficiency virus and acquired immunodeficiency syndrome) and hepatitis $\mathrm{C}$ virus are diseases transmitted and contracted through injection drug use. Moreover, an Auditor General Report (2001) estimated 125,000 individuals injected illicit drugs, which resulted in $34 \%$ of all new HIV infections in 1999. Clearly, the intravenous drug user is vulnerable to contracting and spreading such disease, which further impacts society through increased healthcare and economic costs as well as productivity loss. In fact, the Auditor General of Canada (2001) estimated illicit drug use incurs a five billion dollar per annum economic expense (including health care, crime enforcement, chattel crime and lost productivity).

While the Auditor General Report (2001) describes drug use and ensuing societal harm such as crime, illness, and premature death, individuals engage in different forms of drug use for various reasons including stress, coping (i.e., anxiety and/or depression), medical use (e.g., pain), recreational use, and ensuing addiction. Public perception of drug use stigmatizes individuals citing self-induced illness, lack of willpower, and 
lifestyle choice as explanations for chronic drug use. Yet funding cuts to mental health and social programs have influenced poverty and marginalization including homelessness. Individual illicit drug self-medication is employed as a coping mechanism owing to an absence of health care programs and prescription drug plans (Davis, Rhodes, \& Martin, 2004; Bolam, Murphy, \& Gleeson, 2004; Capponi, 1997).

The current study emerged from a community request for a pilot project evaluation. Specifically, addiction counselors at the Ottawa Mission LifeHouse Addiction Treatment Program (hereafter referred to as LifeHouse) recently implemented a pilot project, based on Seeking Safety ${ }^{\prime}$, which employed a combined trauma and substance abuse focus (Najavits, 2002a). Addressing trauma and substance abuse treatment simultaneously is a novel approach to addiction recovery as contrasted with more traditional programs, which recommend treating the addiction prior to examining any concurrent disorders (i.e., trauma, posttraumatic stress disorder and/or mental health disorders; Najavits, 2002a). Fields (2007) defined concurrent disorders as, "[t]he terms dual diagnosis, comorbid disorders, and co-occuring disorders have been used interchangeably to describe the condition of having both a psychiatric diagnosis and a chemical dependency diagnosis" (p.304). For example, the concurrent disorders substance use and posttraumatic stress (linked to trauma) - are interwoven and as such have challenged mental health and addiction counselors to find a common ground for intervention. Clearly, there is a demonstrated need for an integrated program and service provision (Najavits, 2004; VWSAC, 2004).

The LifeHouse program includes group educational sessions, individual counseling as well as community volunteering. Seeking Safety was integrated into

\footnotetext{
${ }^{1}$ Seeking Safety will be discussed in more detail in ensuing sections of this thesis.
} 
LifeHouse educational programming to address trauma among substance users in treatment. Residents are admitted to LifeHouse only after achieving 72 continuous hours of psychoactive drug abstinence. The 72-hour interim period was implemented for detoxification. Detoxification is a designated minimum period for managing psychoactive drug withdrawal ${ }^{2}$. Following initial detoxification, residents work toward achieving stabilization. Stabilization is a core LifeHouse program goal, defined as maintaining psychoactive drug abstinence for a minimum one-month period. During stabilization, it is hoped that through drug abstinence, residents' emotional and cognitive states will be restored. The stabilization period includes a weekly educational session, which focuses on Anger Management; while an interim session is employed to establish Seeking Safety modules (Najavits, 2002). In addition to the educational sessions, residents are required to attend weekly bible study and local Alcoholics Anonymous (AA) and/or Narcotics Anonymous (NA) meetings. Finally, the participants engage in volunteer work as part of the treatment program.

Anger Management - developed by Barbara Armstrong (1996) for incarcerated men - was implemented into the LifeHouse program to teach recovering individuals new skills to handle life's stressors. Previously, these substance users relied on drugs and alcohol as a primary coping strategy. Once drugs and alcohol are removed, anger management skills training is offered as a substance replacement. Learning new skills for coping is a process that takes time. Therefore, LifeHouse immediately teaches skills to deal with potential frustrations that may arise. For example, individuals in early recovery may become angry owing to being in treatment and/or because of earlier, perhaps abusive

\footnotetext{
2 72-hours is a standard period of abstinence requested prior to admission to treatment. This guideline was established to avoid admitting people under the influence or in severe withdrawal as a way of protecting other individuals in treatment from being cued to use.
} 
historical events. Anger Management is a cognitive-behavioural therapy model which partializes individual reaction to events so as to identify the thoughts that lead to behaviours. Individuals who complete this class learn to respond to previously emotionally triggering events proactively rather than reactively.

The class entitled "Bible Study" is perhaps not the best-suited title as it is a class focused on discussing individual perceptions of spirituality and how these might apply to one's life.

Although it is a mandatory component during core treatment, it is a nondenominational approach and is not in any way, shape or form an attempt to convert clients to religion. It is a forum for clients to hear others share about spirituality and how it may have aided their recovery (LifeHouse staff, 2007).

The bible study class aims to assist individuals in linking,

mind and spirit in their daily life. This can manifest itself in a greater level of gratitude and an appreciation of the little things in life. This, [LifeHouse staff] feel, is a huge component of recovery and is a tool that can be utilized anywhere and everywhere to reduce stress. The other side is that if it awakens or reawakens a desire for spirituality, clients may choose to get active at a church of their choice in the community. This may increase socialization and assist with mental health issues such as depression and anxiety [including traumatic symptoms] (LifeHouse staff, 2007).

AA and NA meeting attendance is a mandatory component of the LifeHouse program predominantly because of its accessibility and meeting availability. For example, currently there are over 160 meetings scheduled each week in the Ottawa area alone, which makes this program readily accessible (http://www.ottawaaa.org/). Individual substance users may discover such meetings provide social support through relating to each others' common experiences. Such social support is considered fundamental to recovery. Subscribing to the principles of the AA and/or NA program including following the twelve steps is left to individual discretion. However, staff at 
LifeHouse recognized linking clients to established community support may increase potential for sustained sobriety. Volunteer work also connects individuals to the community and promotes "socialization, lifeskills, self-esteem and tangible [work experience] they [LifeHouse residents] can add to a resume" (LifeHouse staff, 2007). Taken together, LifeHouse clearly supports an abstinence model for substance abuse recovery.

As previously noted, LifeHouse counselors implemented a twelve-week pilot program entitled, Seeking Safety (Najavits, 2002a). Seeking Safety was created in 1993 as a program for women, but has since been broadened to include men (Najavits, Schmitz, Gotthardt \& Weiss, 2005; Najavits, 2007). It is a groundbreaking and empirically-tested program that seeks to address trauma and substance abuse treatment simultaneously (Najavits, 2002a; Najavits, Weiss, Shaw \& Muenz, 1998). Seeking Safety is a first stage trauma recovery program. First stage is interpreted as addressing the concept, safety as an initial healing objective. The program principles emerged from Herman's (1997) work, which emphasized safety, remembrance and mourning (i.e., exposure $^{3}$ ), and reconnection as themes for trauma recovery (Najavits, 2002a). While Seeking Safety was initially geared toward group counseling, it has been modified to suit individual counseling needs as well (Najavits, 2007). Taken together, proponents for the Seeking Safety program attempt to reduce individual "retraumatization" and ensuing substance abuse (VWSAC, 2004, p.1). This is potentially accomplished by attempting to normalize traumatic experiences through group therapy. The Seeking Safety class provides trauma symptom awareness, practical skills-building and peer support.

\footnotetext{
${ }^{3}$ Exposure therapy includes recalling and/or retelling the traumatic event in a safe environment with the objective of reducing fear associated with or reminiscent of historical trauma. Exposure therapy is used in conjunction with relaxation techniques.
} 
As previously mentioned, LifeHouse staff operationalized a first stage group emphasizing safety. The concept of safety has been well documented in the literature as a hallmark for trauma recovery (Najavits, 2002a; Herman, 1999). Indeed, "safety, compassion and honesty" are Seeking Safety program ideals (Najavits, 2002a, p.19). Cognitive-behavioural therapy (hereafter referred to as CBT) forms the theoretical basis and therapeutic intervention of the Seeking Safety program. CBT has been employed as an effective treatment for substance abuse and trauma (Hien et al., 2004). Psychotherapy and CBT and their connection to LifeHouse will be described in more detail later in this thesis. In essence, the Seeking Safety program aims to equip individuals with "safe coping skills" (Najavits, 2002a, p.5; Najavits, 2007, p.1). Such skills are used to navigate trauma and substance abuse recovery. Recovery is a term understood as "regaining something [individuals] once possessed but have lost or set aside" (Al-Anon, 1992, p.327). Recovery from substance abuse is a healing process where individuals engage in self-examination toward discovering their self-identity, no longer obscured by drugs.

Affect, behaviour and cognition are individually addressed through specific treatment program topics and complimentary skill sets. Such topics include "Taking Back Your Power, Detaching from Emotional Pain, Asking for Help, Setting Boundaries in Relationships, Getting Others to Support your Recovery, and Coping with Triggers" to name but a few (Najavits, 2002a; Najavits, 2007). In fact, the program includes 25 topics (see Appendix A), which are organized in "cognitive, behavioral, interpersonal" and case management categories (Najavits, 2007). Indeed, individuals are motivated toward behavioural changes by taking action in new ways. Such efforts are validated because even the smallest of actions is considered worthwhile in the healing process. 
Attitudes and beliefs are also examined and reframed to help foster a more positive worldview. Affect is linked to self-compassion and recognizing that substance abuse was employed as a survival mechanism to counter pain and suffering (Najavits, 2002a). Individuals may gain personal insight and awareness of trauma and substance abuse and find ways to forgive, make amends, and nurture themselves and others. Yet the program does not linger on past events, but rather is focused on the 'here and now' (Najavits, 2002b). Recovery is considered a lifelong process which, unfolds in a circular manner rather than following a linear format (Herman, 1997). Indeed, recovery from trauma and substance abuse relies on first establishing a trusting client-worker rapport in a client-perceived safe environment such as that provided by LifeHouse.

The LifeHouse counselors previously collected data that was generated from the pretests and posttests initiated prior to and following the Seeking Safety twelve-week pilot project. Moreover, the counselors have used the research compiled to date to determine that $85 \%$ of the men at LifeHouse living with substance abuse have experienced physical and/or sexual abuse or trauma ${ }^{4}$ (Thompson \& Hopton, 2006). Specifically, over the three year period between 2003 and 2005, LifeHouse statistics revealed an average of $35 \%$ self-reports for physical and/or sexual abuse (Thompson \& Hopton, 2006). Such statistics are consistent with Briere and Elliott's (2003) study, Prevalence and Psychological Sequelae of Self-Reported Childhood Physical and Sexual Abuse in a General Population Sample of Men and Women. The authors of this study discovered $36.4 \%$ or 169 men from a mixed gender, random sample size 1,442 reported

\footnotetext{
${ }^{4}$ LifeHouse does not collect data regarding the circumstances surrounding how the trauma occurred or how these men may have been abusive (i.e., physical, sexual, emotional) toward others. LifeHouse staff simply ask whether the men have experienced trauma at the time of initial assessment. More disclosures regarding traumatic experiences may emerge during individual counseling sessions.
} 
childhood sexual abuse and/or physical abuse. Indeed, men who have encountered physical or sexual abuse may be under-assessed (Najavits, 2004, p. 468). Accordingly, LifeHouse counselors calculated the figure, $85 \%$ by accounting for those men who did not self-identify physical and/or sexual abuse, but who have self-disclosed comparable traumatic experiences. Indeed a quarter of these individuals have suffered emotional abuse and/or neglect. Najavits (2003) estimated 12\%-34\% of men are living with concurrent trauma and substance abuse disorders. Clearly, such numbers, which reflect individual pain and suffering, demonstrate relevance for social work intervention.

This study aims to evaluate the LifeHouse program in general and the Seeking Safety Pilot Project in particular. It will be recalled that LifeHouse addiction counselors conducted a pilot program, entitled Seeking Safety (Najavits, 2002a). The counselors used the Trauma Symptom Inventory (TSI; Briere, 1995) to guide a pretest and posttest for program evaluation purposes (Briere, 1995). I have examined quantitative data collected by the LifeHouse staff. I have also examined the LifeHouse program participants' initial assessment forms. Finally, I have interviewed consenting participants who experienced LifeHouse Seeking Safety pilot project classes regarding their recovery experience. Indeed, I have provided a comprehensive program evaluation based on the data collected. In addition, I have analyzed men's trauma and substance abuse recovery experience, describing strategies and interventions found to be personally and practically useful in their recovery from trauma and substance abuse.

\section{Research Question: What is the effectiveness of the LifeHouse Addiction Treatment Program for LifeHouse participants?}


Key Concepts: Safety, Trauma and Substance Abuse.

Najavits (2002a) operationally defined safety as,

an umbrella term that signifies various elements: discontinuing substance use, reducing suicidality, minimizing exposure to HIV risk, letting go of dangerous relationships (such as domestic abuse and drug-using "friends"), gaining control over extreme symptoms (such as dissociation), and stopping self-harm behaviors (such as cutting) (p.5).

In another article, Najavits (2002b) defined safety similarly as,

An umbrella term that includes discontinuing substance use; reducing suicidal and self-harm behaviors, such as cutting; minimizing HIV exposure; ending dangerous relationships, such as with abusive partners and drug-using friends; and gaining control over extreme symptoms such as dissociation, or "spacing out" (p.136).

Such self-destructive behaviours may be reminiscent and replications of early childhood traumatic experiences (Muller et al., 2004). Indeed, the initial abuse becomes internalized so that the traumatized individual perpetuates the pain and suffering by hurting himself (Najavits, 2002a; Najavits 2002b; Muller et al., 2004). Clearly, selfdefeating thoughts and harmful behaviours may exacerbate or activate (e.g., trigger) continued traumatic experiences. Accordingly, the Trauma Symptom Inventory (TSI) was employed by the LifeHouse staff with LifeHouse residents to evaluate trauma, including acute and chronic traumatic effects emerging from sexual violence, accidents, combat, war, natural disasters and historical abuse (Briere, 1995). Likewise, Najavits (2004) described trauma, as "generally understood to be unpredictable and occurring from some force external to the patient - another person, a natural disaster, an accident, or combat" to name but a few (p. 469). Moreover, the DSM-IV definition of PTSD includes three criteria, (1) reliving the traumatic experience, (2) memory avoidance 
and/or numbing ${ }^{5}$, and (3) hypervigilance (e.g., hyperarousal) ${ }^{6}$. In addition, there must be a personal or witnessed physical threat, which caused substantial distress for the event to be considered traumatic. Finally, these symptoms must surpass one month duration to meet a PTSD, DSM-IV diagnosis (Fraser, 2003). Taken together, traumatic experiences shake the foundations of people's beliefs about safety and shatter personal assumptions of trust (Moran, 2005).

Substance abuse is often defined as an inability to control psychoactive drug use despite experiencing negative consequences such that drug use is considered a compulsive behaviour (Blume, 2005). The DSM-IV defines Substance Use Disorder in detail, noting substance abuse as the least severe and substance dependence as the most severe classification (italics added; Najavits, 2007, p.1). In either case, symptoms need surpass one-month duration (Coombs \& Howatt, 2005). Substance dependence may become incrementally worse over time as demonstrated by increased and persistent drug use. As well, significant time is spent in seeking drug-related activity so that engagement in additional activities is diminished. Enhanced cravings occur and chronic drug use is marked by withdrawal effect abeyance (Coombs \& Howatt, 2005). For the purpose of this study, trauma and substance abuse are operationally defined in the broadest sense. For example, trauma includes physical and/or sexual and/or emotional abuse as outlined in the LifeHouse assessment form. Moreover, LifeHouse clients self-identify whether a substance is problematic and/or and self-determine whether a life experience was traumatic.

\footnotetext{
${ }^{5}$ Individuals suffering from PTSD may use substances to avoid intrusive thoughts and/or memories. As well, individuals may use substances to avoid negative feelings.

${ }^{6}$ Hypervigilance and hyperarousal refer to the fight-flight theory where an individual may be overly attentive or guarded owing to exposure to perceived intense stress-inducing stimuli.
} 
A concise literature review including relevant theories will be explored in following sections of this thesis. A mixed methods approach was utilized to gather the research as will be outlined in the ensuing methodology. Both a quantitative analysis pertaining to the Trauma Symptom Inventory measure and qualitative analysis emergent from the semi-structured participant interviews will be presented. A summary including my interpretations of the findings and limitations of the study will conclude the thesis. 


\section{CHAPTER TWO: LITERATURE REVIEW}

I have divided the literature review into two parts, Part I: Contextualizing Addiction \& Historical Overview and Part II: Theoretical Framework. In Part I, I aim to provide a concise evolution of addiction, which gave rise to certain beliefs and associated theories regarding substance users. Some of the stigma surrounding drug users is rooted in this historical context. While medical interventions ought not to be dismissed, an alternative view is one of addiction being constructed as a moral problem, a social problem, and also a criminal offense. Such viewpoints will be outlined in this review. In Part II, I will highlight those addiction theories, most relevant to the LifeHouse program. In addition, the literature review provides an overview of trauma and posttraumatic stressors. Psychoanalytic theory, neuroadaptive theory and cognitive behavioural therapy will be discussed. I will also provide a critical examination of each of these theories. I will examine novel integrated treatment models which are aimed at trauma and addiction recovery respectively. Finally, I will highlight Seeking Safety as an integrative treatment which targets both trauma and substance abuse. Particular focus is given to recent Seeking Safety studies conducted to date, which allude to program efficacy. Finally, I will address gaps in social science knowledge and organized the current study accordingly.

\section{Part I: Contextualizing Addiction \& Historical Overview}

The following historical overview needs be considered as it forms the social context for the ensuing program analysis. Providing the historical context aims to enrich the readers' understanding of addiction. Addiction as a disease concept has a social history, which stretches from moral roots to scientific discovery. By maintaining 
addiction as a disease, professionals are able to pursue extensive treatment opportunities. And while treatment centres have wait lists and provide measures of success, no program has empirically supported absolute efficacy in cure provision (Truan, 1993). Interestingly, the models commonly cited and included in this review (i.e., the moral model, the disease model, the spirituality model, and the medical model) each focus on individual responsibility as the agent of change, which preserves the current social order and construction of addiction as an individual problem or deficit (Truan, 1993). Moreover, dominant public discourse supports the disease concept whereby individuals have inherited lack of control of their progressively worsening alcoholic disease (Levine, 1978). In sum, Truan (1993) advocated for a changed locus of emphasis where society's role in constructing addiction is examined.

Reinarman (2005) and Levine (1978) emphasized the historical and cultural conditions from which the disease concept emerged. Throughout the $17^{\text {th }}$ and $18^{\text {th }}$ centuries intoxicated individuals were not labeled alcoholics, but rather were recognized for choosing perceivably pleasurable overindulgence through alcohol consumption (Reinarman, 2005; Levine, 1978). In other words, "people drank and got drunk because they wanted to, and not because they had to" (Levine, 1978, p.144, italics added). It became apparent later in the $18^{\text {th }}$ and early in the $19^{\text {th }}$ centuries that not every individual who engaged in substance use became addicted, which gave rise to an individual-specific disease notion of addiction. Moreover, individuals described a desire or willingness to drink alcohol. This urge or compulsion to drink led to the conceptualization of addiction (Levine, 1978). Dr. Benjamin Rush, associated with the $19^{\text {th }}$ century Temperance Movement, introduced the notion of addiction as a disease of the will caused by alcohol 
consumption and remedied by abstinence (Reinarman, 2005; Levine, 1978). Temperance Movement crusades claimed the problem of addiction was rooted in the substance, alcohol (later this phenomenon was expanded to include additional substances; Levine, 1978). Indeed, alcohol was recognized as possessing addictive properties, which if consumed threatened to cause the gamut of social problems (e.g., dissolved marriage, job loss, crime, aggression, and so forth). The first temperance meeting in Nova Scotia, Canada in 1828 , coincided with urbanization. Temperance was a grassroots social movement initiated by agrarian Protestants and embraced by middle-class professionals (Csiernik, 2003). In examining the evolution of the disease concept construction and the associated cause of addiction Levine (1978) noted,

The Temperance Movement found the source of addiction in the drug itself - alcohol was viewed as an inherently addicting substance, much as heroin today. Post-Prohibition thought locates the source of addiction in the individual body - only some people, it is argued, for reasons yet unknown, become addicted to alcohol (p.144).

Moreover, individuals who are arguably compelled to drink may not wish to become inebriated, but rather aim to achieve sociable drinking or moderate consumption (Levine, 1978).

During the period of industrialization, families became strained under economic pressures which "increasingly depended upon self-control" (Reinarman, 2005, p. 310) "in order to survive and succeed" (Levine, 1978, p.164). Similarly, Dr. Rush discovered that individuals living with mental distress, who previously had been physically restrained and housed in asylums, could indeed be taught self-control through self-discipline (e.g., the moral model; Levine, 1978). At the same time, the socioeconomic milieu continued to support notions of individual loss of control attributable to alcohol consumption. 
Moreover the individual will and act of consuming alcohol was thought to increase personal susceptibility to ensuing addiction.

In addition, during the early late $19^{\text {th }}$ and early $20^{\text {th }}$ century (In Ontario and the Maritimes; Csiernik, 2003), Prohibition emerged with social reform linked to the negative image of alcohol. Alcohol consumption was linked to factory and locomotion accidents as well as productivity losses. Furthermore taverns had a reputation for rousing criminal behaviour, political and labour unrest and corruption (Levine, 1978). Prohibition became policy in Canada between 1898 and 1919, enforced by the War Measures Act and also the Doherty Bill. The Doherty Bill banned alcohol importation. Those individuals in support of Prohibition asserted alcohol was brazenly abused and the primary cause of social problems (Csiernik, 2003). Social order rested upon self-control owing to the emerging middle class' solution-oriented mindset and notion of a "free society" (i.e., freedom of choice; Levine, 1978, p.163). However, by 1921 all provinces with the exception of Prince Edward Island had rescinded Prohibition legislature (Csiernik, 2003). Even so, individuals traveled out of province to access alcohol, manufactured home brew, or relied on Temperance beer with a reduced alcohol content of $2.5 \%$. Physicians also prescribed alcohol for its perceived therapeutic benefits. During this period, the working class had begun to support the middle class notion for temperance, which eliminated a distinction between class-associated moral behaviour. Previously, the middle class had distinguished their status by framing intoxication as an immoral act committed by the marginalized.

French Canadians, British, Irish, Scottish and Welsh were dominant cultures in Canada. These groups combined drinking alcohol with socializing. They continued 
accessing alcohol through smuggling. The provincial governments recognized the economy generated through bootlegging. As such, alcohol became government regulated both as a social control measure and a revenue generator. Eventually, in 1967 the Canadian Temperance Federation folded.

Alcoholics Anonymous emerged in 1935 and along with the scientific push from the Yale Centre of Alcohol Studies (Jellinek, 1952) (re)conceptualized Rush's disease model (Levine, 1978). Alcoholism was defined as a progressive disease encompassing a physical allergy, a mental obsession and a soul sickness. While AA proclaimed no cure per se, the disease could be put into remission through continued abstinence combined with spiritually principled living. The disease concept including loss of control informed Alcoholics Anonymous' hallmark first step, where members declared personal powerlessnness over alcohol (Alcoholics Anonymous, 2001). Alcohol became readily available and socially accepted owing to the presupposition that addiction occurred only in isolated cases (Levine, 1978). The locus of the cause of addiction shifted from a problem residing within an addictive substance to a problem residing within an addicted individual. The first Canadian treatment centres were established in 1955 in British Columbia (Csiernik \& Rowe, 2003).

To this day, substance users locate addiction support through self-help groups such as AA and/or NA sometimes in lieu of medical intervention (Weinberg, 2000). In fact, despite addiction being constructed as a medical problem some medical professionals are averse to treating substance users owing to the chronic nature of addiction. Yet AA in general and its twelve steps in particular have become integrated “into mainstream medicine and psychotherapy" (Peele, 1987, p.24). Indeed, addiction 
has been widely portrayed and accepted as a disease requiring ongoing support. Moreover, without continued twelve-step program support, substance users are considered susceptible to going back out presumably to a lifestyle of unyielding temptation and certain resumed substance use. Weinberg (2000) described street life in general and a drug-using life in particular as degraded, devalued and subordinate to an AA program-oriented life. As well, a life in program is considered empowering and rewarding whereas conducting life outside program is perceived as lacking self-direction. Finally, Weinberg (2000) argued that for addiction to be defined as disease then diagnosable symptoms or identifiable precursors are also implied. Yet individual substance users are called upon to "reconcile the view that they can be socially empowered to overcome their drug problems with the view that those problems are caused by a disease" (Weinberg 2000, p.618). Adding to the nature-nurture debate, the disease model of addiction has grown to encompass behaviours which go beyond substances and extend to gambling, overeating, intimate relationships, shopping, and shoplifting among others (Reinarman, 2005; Ferentzy, 2002; Peele, 1989; Levine, 1978).

Sedgewick (1993) examined popular notions of control, powerlessness, will and desire as they apply to addiction in general and its derivative pathologies in particular (i.e., eating disorders). For example, Overeaters Anonymous is an off-shoot of Alcoholics Anonymous, employing the same twelve-step program to addiction recovery. Moreover, Sedgewick (1993) acknowledged that eating disorders are characterized by controlled caloric intake at regular intervals, food refusal, or food binging and purging. Yet food is readily accepted by society and viewed as a basic necessity. Alcohol too is widely available and socially accepted. However, illicit substances including opiates and 
marijuana have negative connotations. Accordingly, Sedgewick (1993) argued the addiction concept covers a broad spectrum of behaviours connected by the abstract notion of free will. Further, "the locus of addictiveness cannot be the substance itself and can scarcely even be the body itself, but must be some overarching abstraction that governs the narrative relations between them" (Sedgewick, 1993, p.131). Free will is the universal thread among the addictions.

Sedgewick puts forth the commonality among individuals living with addictions is their envisioning the addictive source as compensation for some inherent inadequacy (i.e., confidence, tension-release, esteem, and so forth). Interestingly, Sedgewick (1993) proposed individuals envisioning such rewards from addiction already possess these innate qualities. The widespread application of addiction as a chronic illness to any number of substances, behaviours, and/or feelings is linked to the social construction of an insufficient and impure free will (Sedgewick, 1993, p.132). Furthermore, free will has an ethical underpinning linked to the capitalist economy. Free will in a capital economy is presented as a counter construction to balance the absence of self-control and assumes addiction is a voluntary pursuit. Sedgewick (1993) pointed toward a late $20^{\text {th }}$ century addiction epidemic as arising from capitalism, consumerism, and the ever expanding global economy. Moreover, Sedgewick (1993) reintroduced the notion of habit as a behaviour or repetitive action, not in an absolute sense as with voluntary free will, but rather the interplay of self with body set apart from the world:

That is, the tradition of reflecting on habit, a version of repeated action that moves, not toward metaphysical absolutes, but toward interrelations of the action - and the self acting - with the bodily habitus, the apperelling habit, the sheltering habitation, everything that marks the traces of that habit on a world that the metaphysical absolutes would have left in a vacuum (Sedgewick, 1993, p.138). 
The habitual act of substance use is considered a way to free the true self - a rejuvenating retreat from the world, others' perceptions of us, and our belief system developed from other-influences (Sedgewick, 1993). In sum, addicts are framed as compelled toward substances (i.e., loss of control) and yet they are told they have the freedom to choose that drinking alcohol or using substances is a choice. Courtwright's (2001) book entitled, Forces of Habit, identified in detail the proliferation of drugs consumers are exposed to on a daily basis (i.e., alcohol, nicotine, and caffeine). Sedgewick (1993) advocated for a collective to challenge such economic power structures. Taken together, loss of control versus free will, a capitalist emphasis on consumerism, and an economy generated by addiction promotes continued favouritism for disease model construction.

Peele (1989) categorized diseases into three generations. Fïrst generation diseases were defined as having identifiable causes and "measureable physical effects", which provided diagnosis and prescribed treatment (p.4). Second generation diseases were described as variations of mental distress diagnosed by examining affect and cognition. Addiction was classified under a third generation of disease, which was directly connected to behaviour. Addiction can be overcome by arresting the behaviour, which is very different from cancer where a change in behaviour is not assumed to have an affect on the disease. Yet individuals continue to be labeled as "alcoholic or addict" following years of remission (Peele, 1989). Peele (1989) argued biological solutions for emotional and substance using problems "ignores the therapeutic needs" of substance-using individuals as demonstrated by increased addiction prevalence (p.13). Yet substance use is influenced by environmental and structural complexities, which are overlooked by traditional medical and disease models. In sum, while new developments in neuroscience 
(i.e., pharmacology) and psychology (i.e., psychotherapy) have emerged, these have not been effective in solving the drug problem. In the absence of a cure for addiction, the alcoholic-addict becomes a lifetime patient sanctioned to those in medical-power (Peele, 1989). Peele (1989) put forth an individual learning model where personal knowledge (i.e., values) and experience (e.g., an event or moment of clarity) are the best aids toward initiating addiction recovery. Contrary to notions of loss of control and powerlessness, Peele (1989) also suggested recovering individuals need to feel in control of their futures in order to sustain recovery. Moreover, recovering individuals become empowered through opportunities to practice self-efficacy (Bandura, 1977; Peele, 1989). Finally, developing coping through positive reinforcement (i.e., social interaction and work) combined with anxiety release fosters enduring personal change (Peele, 1989).

Reinarman (2005) viewed the disease concept as "a humane strategy for gaining access to treatment and other services, but at the same time a justification for punitive drug policies"(p.308). Indeed, viewing addiction as a disease enables a medical or penal solution for a social problem. Fook (1993) discussed formal and informal sanctions as aspects of social control. Formal sanctions enforced by dominant society's sociopolitical and economic climate govern human behaviour and maintain power imbalance (Fook, 1993). Likewise, informal sanctions (i.e., social norms) impose individual ways of being and create stigmas, which contribute to alienation and oppression (Fook, 1993). The notion of social control will be explored in the ensuing section.

Not only has addiction been classified as a disease, but it has also been constructed as a deviant and even criminal activity. Criminalization implies a social problem (Loue, 2003). Moreover it is not uncommon for criminals to be mandated to 
treatment as an alternative to incarceration (Peele, 1989). Canadian drug policy was influenced by sociopolitical events, which occurred in the United States. Taken together, drug policy in North America was organized around "issues of morality, racism, punishment, social control, discrimination and oppression" (Csiernik, 2003, p.273). The United States was the global forerunner in banning illicit drugs (Ferentzy, 2002). Dr. Hamilton Wright, in 1911 was the leading spokesperson who proclaimed substance use promoted criminal involvement and criminal activity (Streatfeild, 2001; Woodiwiss, 1998). In 1914 such perspectives led to the emergence of the United States Federally legislated, Harrison Narcotic Act (which emphasized opium and marijuana as illicit substances). This legislation had immediate consequences for addicted individuals as they were refused medical care and were no longer issued prescription drugs. As well, with the introduction of Prohibition, bootlegging became prolific and logically, substance-using individuals began purchasing drugs through illegitimate means. Indeed, "Prohibition had simply made consumption of alcohol more expensive, secretive, challenging and risky" (Woodiwiss, 1998, p.19).

At the turn of the $20^{\text {th }}$ century, race was also considered a factor pertaining to drug use and ensuing brain adaptation (e.g., damage). Taken together, "a stronger middle class ethos, wild frontiers, and a fear of races considered to be primitive or even animal like [e.g., people of colour and aboriginal peoples] all made for greater concern with selfcontrol, autonomy, and freedom" (Ferentzy, 2002, p.168). For example, opium was linked to Asian people, marijuana to Mexican, and cocaine to Black people living in the Southern United States. The Opium Act in 1908, followed by the Opium and Drug Act 
of $1911^{7}$ were created in response to hostility toward marginalized Chinese people in Canada (Csiernik \& Rowe, 2003; Csiernik, 2003). In 1907, such hostility was demonstrated by white labour activist-initiated riots who perceived competition with the Chinese for employment (Csiernik, 2003). In addition to race, a connection between drugs and sex emerged. Sexual relations and sexual violence were embellished to have occurred between white women and substance-using black men in particular (Streatfeild, 2001). As well, substance use was thought to promote promiscuity and sex trade involvement between white women and Asian men (Csiernik, 2003). Indeed, individuals of colour were labeled unpredictable and insane under the influence of drugs including alcohol. Moreover, alcohol was thought to have serious enough consequences, but cocaine was considered a dangerous hallucinogenic and delusion-evoking drug. Furthermore, psychoactive drug use received attention for fueling aggression, violence and superhuman strength. Such invincibility created regulations for added social control, a larger police force and the acquisition of more powerful weapons (Streatfeild, 2001).

In 1930, Anslinger was appointed the Commissioner of the Federal Bureau of Narcotics (FBN). Anslinger reinforced the association of drugs with moral degradation and racism. Yet an opposing argument was put forth by Coffee, a representative of Washington State. Coffee believed Harrison's Narcotics Act had been misrepresented and advocated a shift of responsibility from FBN to Public Health. Coffee's argument drew attention to the large Federal revenues acquired through the illicit drug business and identified FBN corruption. Anslinger retained his position with the FBN until the early 1960s. During this period he authored a book claiming illicit drugs were manufactured in China and funneled into the United States as an addiction-promoting tactic. Clearly,

\footnotetext{
${ }^{7} 1911$ legislature included cocaine and morphine and was expanded to include cannabis in 1923.
} 
Anslinger embraced racist views as illustrated by the excessive incarceration of people of colour who received extensive terms of imprisonment (e.g., up to 50 year terms) for minimal drug-related offenses (Woodiwiss, 1998). In 1968, the FBN was abolished owing to rampant internal corruption.

Similarly to the United States, Canada initiated The Narcotic Control Act in 1961. During the 1950s drug charges flourished in an effort to combat increasing drug prevalence. The controversial Le Dain Commission (The Royal Commission of Inquiry into the Non-Medical Use of Drugs) was established in 1969 and recommended a less punitive approach in favour of health promotion (Csiernik \& Rowe, 2003; Csiernik, 2003). Controversy emerged with the recommendation for cannabis decriminalization. However, no major policy changes emerged (Csiernik, 2003).

Drug charges continued to grow throughout the 1960s surpassing 40,000 per annum during the 1970s. Individuals began to question the utility for social control measures. For example, health interventions including addiction treatment and harm reduction were considered, particularly with the onset of HIV and hepatitis $\mathrm{C}$ virus. The Controlled Drugs and Substance Act of 1997 was a replication of earlier attempts to control drug use through the criminal justice system (Csiernik \& Rowe, 2003). Indeed, Canadian drug policy history has concentrated on the criminalization of addiction as demonstrated by sanctions which control and prohibit substance use (Csiernick, 2003).

President Nixon picked up where Anslinger left off initiating war on drugs in 1972 (Woodiwiss, 1998). More recently, the United States campaign against war on drugs, initiated by Reagan (Ferentzy, 2002) and bridging the years 1986 through 2003 , resulted in the incarceration of an excessive number of citizens and predominantly 
marginalized people of colour for drug-related offenses (Reinarman, 2005). Canadian Prime Minister, Brian Mulroney followed suit by announcing epidemic drug abuse in Canada. The Canadian Centre on Substance Abuse emerged in 1988 as a vehicle for addiction-related social and economic harm-reduction (Csiernik, 2003). In sum, the notion of waging war on drugs as a moral epidemic has incurred billions of dollars in enforcement expenditures often at the expense of vulnerable, marginalized and minority populations.

The National Drug Strategy in 1987, Canada's Drug Strategy in 1992 and the Controlled Drugs and Substances Act of the late 1990s were initiated to balance the supply of drugs and the demand for drugs (Collin, 2006; Csiernik, 2003). The revised Canada Drug Strategy of 2003 includes four pillars: prevention; treatment, harm reduction; and enforcement (Collin, 2006, p.3). In 2002, the Special Committee on NonMedical Use of Drugs recommended safer injection sites, methadone maintenance, needle exchange, and increased research funding. Harm reduction has gained attention recently owing to Vancouver-situated substance users who advocated for safer injection sites (Vancouver Area Network of Drug Users; http:/www.vandu.org/). In fact, the first medically supervised needle injection site opened in Vancouver in 2003 (Collin, 2006). While harm reduction is presented as value-neutral, such recommendations including crack pipe exchange programs are considered public health initiatives to prevent spread of disease (Collin, 2006; Csiernik, 2003). Certainly stigma surrounding intravenous drug use persists. Yet tobacco is the primary cause of premature death in Canada. Indeed, less than 100 Canadians die each year from heroin overdose as compared with 40,000 individual deaths as a result of tobacco smoking (Csiernik, 2003). 
Drug courts have gained interest in the past decade; the United States initiated drug courts during the 1980 s whereas the first Canadian drug court opened in Toronto in 1998. Along the continuum of harm reduction, drug court initiatives mandate addiction treatment for public protection as well as reducing costs to the criminal justice system. Relapse is considered a part of addiction recovery and providing individuals remain honest and accountable about their substance use, penalties may be avoided. Drug courts offer a five stage treatment program which includes assessment, stabilization, treatment (i.e., cognitive behavioural therapy and methadone, maintenance), and aftercare (http://www.ccsa.ca/pdf/ccsa-008697-2000.pdf). Taken together harm reduction policies provide an alternative to traditional abstinence models.

However, substance use is increasingly complex as new synthetic drugs emerge and associated trends develop (i.e., crack, ecstacy, and oxycontin). As well, individual substance users are at risk for HIV/AIDS, hepatitis $C$ virus, the reemergence of tuberculosis in addition to homelessness and mental health distress (Massing, 2000). Clearly, chronic drug use has an impact on individual health and welfare and speaks to a need for sociopolitical change as well as progressive treatment. Massing (2000) proposed a centralized system for individual assessment and individualized treatment selection. A key component of this system would be the involvement of addiction specialists and former substance users. Such a system would require a redistribution of political spending to balance demand (e.g., prevention and treatment) and supply (e.g., criminal justice). 


\section{Part I: Summary}

The preceding historical overview is connected to the current thesis research. Consistent with many addiction treatment centres and recovery homes, LifeHouse expects residents to remain substance-free for the duration of the program. While LifeHouse staff are supportive and aim to reduce stigma associated with substance use as well as diminish the impact of oppression, they do administer urine screens. Some would argue random drug screening as an act of social control. Yet such a measure while seemingly intrusive serves to safeguard other residents' recovery by lessening opportunities for relapse. LifeHouse also issues written citations to residents for lateness or missed groups among other program guidelines. Following a maximum of three citations, a resident is discharged. Granted, some individuals are mandated to addiction treatment and fulfill the obligation in an effort to reduce charges however, the men interviewed at LifeHouse were recovering of their own volition.

LifeHouse supports a disease model of addiction as demonstrated by references to "the bug" (i.e., addiction as a physical illness), cognitive therapy (Seeking Safety and Anger Management) to relieve the mental obsession, and chapel attendance to abate soul sickness. LifeHouse is host to the marginalized. The men who stay at LifeHouse may have frequented other treatment facilities and attained a reprieve from substance use and life on the street. LifeHouse staff borrow from historical theoretical frameworks while also remaining open to more progressive interventions. For example, LifeHouse aims to change drug-using behaviour by targeting individual thoughts through variations of cognitive therapy. Taken together, LifeHouse draws from both treatment models and 
social control models of addiction. The following section of this literature review will examine theory as it pertains to LifeHouse.

\section{Part II: Theoretical Framework}

LifeHouse offers an addiction treatment program to marginalized populations. In addition to addiction treatment programming, LifeHouse also assists residents in transitioning back into the community. For example, residents are connected to second stage housing and are provided ongoing recovery support through the LifeHouse aftercare program. The following theoretical framework demonstrates linkages to the historical overview provided in the previous section of this thesis. As well, the following theories have relevance to the LifeHouse program.

\section{Theories of Addiction}

I have provided an overview of the historical context of addiction treatment in North America. The following theories should be considered within the historical context. Detailed descriptions of the Temperance Movement, Prohibition and the social construction of the disease concept were outlined in the previous section and therefore will not be repeated here.

\section{The Moral Model}

The moral model emerged during the Temperance movement. Historically, alcoholism in particular and substance abuse in general have long been considered a moral issue among some members of society (Najavits, 2007; Health Canada, 2001). In fact, it has commonly been argued that alcoholics and drug addicts lack self-discipline (Doweiko, 2002). The moral model is based on the notion of free-will. Moreover, it is 
assumed that substance abusers are choosing to drink alcohol or use drugs and therefore can choose to stop (Coombs \& Howatt, 2005).

The Spirituality Model

Similarly, the Oxford Group used the issue of morality as a springboard for designing a six-step alcohol recovery program. The Oxford Group had its foundations in Christianity. One of its members, "Ebby" is noted as introducing Bill Wilson to the Oxford Group alcoholism recovery process. In 1935 Bill Wilson along with Dr. Bob Smith conceptualized Alcoholics Anonymous based on the Oxford model. Together Bill Wilson and Dr. Bob Smith expanded the original six steps to include twelve steps toward alcoholism recovery. The program of Alcoholics Anonymous, has influenced additional twelve-step programs including, Narcotics Anonymous (Alcoholics Anonymous, 2001). The Alcoholics Anonymous basic premise is to help the still suffering alcoholic by sharing personal recovery stories. Bill Wilson communicated his alcoholism recovery to Dr. Bob Smith and from this initial communication a fellowship among other recovering people emerged (Alcoholics Anonymous, 2001). Individuals are encouraged to develop a belief in a Higher Power and embrace the twelve steps as a principle-centered way of life. The Spirituality and Disease Models are interconnected.

\section{The Disease Model}

While Rush (1810, cited in Coombs \& Howatt, 2005, p.36) first introduced a disease model in the early $19^{\text {th }}$ century, Jellinek (1960) is more commonly credited with conceptualizing alcoholism as a disease. Alcoholism was considered an issue of morality among professionals and society in general prior to his work and in collaboration with Alcoholics Anonymous. Reframing alcoholism as a disease gave rise to substance users 
as people in need of medical treatment (Goodman \& Levy, n.d.). Jellinek (1960) classified alcoholic progression as (a) Prealcoholic (i.e., drinking to reduce perceived tension), (b) Prodromal (e.g., blackouts and alcohol preoccupation), (c) Crucial (i.e., loss of control and expression of withdrawal symptoms) and (d) Chronic (i.e., tolerance, obsession with alcohol and tremors; Doweiko, 2002). Essentially such classifications place alcohol consumption along a continuum including social using, abuse, and dependence. In ensuing research, Jellinek (1960) reorganized categories of drinking behaviour and identified these as alpha (psychological dependence), beta (physical illness and psychopathology), gamma (physical dependence), delta (loss of control) and epsilon (intermittent), which were perceived as non-discriminating and/or non-judgmental descriptors of those individuals engaging in alcohol consumption. In sum, addiction is considered a primary illness or condition, which can be arrested only through abstinence (http://silkworth.net/ask_billw/Q\&A1.html). Loss of control is a hallmark of the disease concept. Denial fuels such progressive disease (Denning, 2000).

\section{Medical Model}

The medical model supports a disease concept of addiction. Addiction is defined as the chronic, progressive use of alcohol and/or drugs despite negative consequences. Chronic drug use may develop into drug dependence as psychoactive drug tolerance increases. Chronic substance use leads to a physical tolerance marked by increased resistance to psychoactive drug effects (Eckardt et al., 1998). Physical tolerance is a process where alcohol and/or drugs once ingested create a craving for more of the substance. Psychological dependence ensues where individuals have a compulsive desire to use alcohol and drugs. Psychoactive drugs are substances that influence individual 
affect, cognition and behaviour through a specific mechanism of action. Such mechanism of action occurs in the central nervous system, which encodes euphoria experienced by psychoactive drug administration as reward. The perceived positive drug effects are positively reinforced and retained as memory within specific neurobiological sites commonly known as the reward circuit or pleasure center. These memories are powerful and become triggered by environmental cues, which promote repetitive drug use (Coombs \& Howatt, 2005).

Such genetic or biological determinants of addiction are individual-specific in that vulnerability to alcohol use and adaptive coping are partially determined by genetics. (Thaller et al; Ting-Kali, 2000). Genetic markers for alcoholism have been discovered (Schukit, 2002; Enock \& Goldman, 2002), which suggest such a predisposition to alcoholism. For example, individual risk to alcoholism is greater where parents and/or close relatives are also alcoholic. A similar genetic pattern is likely for individuals dependent on drugs. However, illicit drug studies are limited owing to changing trends in drug availability and use as well as the illegal nature of these drugs. In sum, individuals require the genes that carry alcoholism to become alcoholic; without these markers risk is greatly reduced if not, eliminated. Reviewing neuroanatomy or the central nervous system assists in understanding the diverse learning patterns and reinforcement which is integral to addiction development and recovery.

The Adaptive Model (The Self-Medication Hypothesis)

The adaptive model (Alexander, 1990) has been offered as an alternative to a disease interpretation of addiction. Where the disease model demonstrates addiction as the cause of individual problems, the adaptive model is recognized as the result of 
experiencing numerous problems. Adaptation refers to coping loss and ensuing selfmedication through alcohol consumption (Alexander, 1990; Catanzaro \& Laurent, 2004). This model encompasses biopsychosocial factors (e.g., genetic variables, concurrent disorders, family dynamics and individual character traits) as underlying stressors contributing to coping breakdown. Individual deficient or maladaptive coping is compensated through chronic alcohol consumption. It should be underscored, individual deficiencies should not be confused with blaming the individual, but rather the individual has not been equipped with adequate coping or life skills emerging from any number of variables (i.e., marginalization and parental role modeling). In fact, choosing to drink alcohol as a means of coping is considered a temporary strategy acquired through experience where other coping strategies have failed (Alexander, 1990; Catanzaro \& Laurent, 2004). It is also highlighted that there may be a preference for a particular drug, such as alcohol, yet substitutions are readily attained based on availability and perceived individual need.

\section{The Gateway Hypothesis}

Both predisposition and experiential variables can contribute to the development of affective (e.g., anxiety, depression) and substance use disorders. Age of onset as well as frequency of substance use is relevant criteria contributing to addiction (Kandel, Yamaguchi, \& Chen, 1992). Drinking alcohol to induce an anxiolytic (e.g., calming) influence and/or promote euphoria is a central nervous system learning process, which allows alcohol consumption to serve as a coping mechanism (e.g., self-medication hypothesis). Moreover, employing alcohol for tension release and to counter withdrawal effects perpetuates reinforcement (craving) in adolescents (Koval \& Pederson, 1999). 
Life transitions combined with peer influence will strengthen the likelihood for ensuing drug dependency in adulthood (Bentler, Newcomb, \& Zimmerman, 2002). It has also been argued that environmental cues (see Peroutte et al., 2004) favour psychoactive agent intake and once initiated genetic predisposition maintains such chronic drug use (Maes et al., 1999).

\section{Relevance to LifeHouse}

An examination of the LifeHouse addiction treatment program demonstrates features of the aforementioned theories in its programming structure. Take for example the parallel between the moral model and the Ottawa Mission's provision of shelter to homeless men willing to participate in the addiction program. Indeed, homeless men who are also living with substance abuse are confronted with societal judgement and stigmatization. Moreover, the stereotypical alcoholic is commonly perceived by society as the single man living on the street. Often the stereotype is followed by assumptions that if such an individual would quit drinking and get a job, he could turn his life around. LifeHouse extends such an opportunity, but without harsh judgement. LifeHouse does not employ tactics - tearing a person down through peer examination or digging their own graves as a symbolic fate of continued drug use - used elsewhere, which infringe on human dignity. At the same time, the LifeHouse program does include Bible study, which might be perceived as a social gospel or moral orientation. In addition, the LifeHouse program promotes AA and/or NA meeting attendance, which are considered spirituality programs. AA advocates a disease model of addiction - that alcoholism is an individual or family disease and that remission can be achieved through abstinence and spiritual growth (Alcoholic Anonymous, 2001). The LifeHouse program offers 
participants opportunities for building life skills by encouraging community volunteerism and participating in cooking classes. As well LifeHouse counselors have recognized the utility for fostering resident coping skills as demonstrated by the implementation of Seeking Safety classes. Taken together the LifeHouse program has borrowed from each of the above noted addiction theories to create an integrated programming structure.

Trauma should not be confused with posttraumatic stress disorder, but rather understood as an event that may preclude PTSD (Najavits, 2004). While experiencing a traumatic event may cause individual problems, "most people who experience a trauma do not develop PTSD" (Najavits, 2004, p.470; Kessler, Sonnega, Bromet, Hughes, \& Nelson, 1995). Posttraumatic stress disorder emerged as an AXIS I, DSM III disorder in 1980 (Najavits 2004; Herman, 1997), and was received with some skepticism by the psychological community (Pitman, 1997). The skepticism was in part attributed to the subjective PTSD self-identification coupled with a perceived categorical creation as a political decision to appease Vietnam War veterans (i.e., PTSD; Pitman, 1997). However, experiments have ascertained some central biological discrepancies (e.g., hippocampus deterioration) exist among those experiencing PTSD symptoms (Pitman, 1997). Conversely, it is argued some individuals possess a genetic blueprint, which may predispose vulnerability to such a post traumatic response (i.e., diminished coping capacity; Najavits, 2004; Martin et al., 2007). Taken together, it should be underscored that while neurobiological adaptations (e.g., hippocampus or memory) have been correlated with potential traumatic and ensuing posttraumatic stress response (True et al., 1993), such correlations should not be understood as causation (Pitman, 1997). 
Summerfield (2001) put forth post-traumatic stress disorder (PTSD) as a social construction rather than a scientific or medical discovery. As previously mentioned, PTSD emerged following the Vietnam War and veterans returning to the United States displaying various symptoms of stress. Such symptoms were formerly termed battle fatigue and war neurosis (Summerfield, 2001, p.95). This change marked a shift from individual blame to traumatic effects induced by exposure to war. Such a shift requiring a medical diagnosis also permitted compensation via disability pension. Yet, personal pain and suffering does not necessarily preclude a disease diagnosis especially in the case of socially constructed social problems such as alcohol and other drug addictions.

PTSD initially emerged as a consequence to severe and unusual stressful life experiences, yet the diagnosis seems to have expanded to include everyday occurrences. In fact PTSD is a disorder that arguably stems from social conditions and is even judiciously promoted to secure increased financial compensation owing to personal suffering and damages. In this way, PTSD can be linked to a market economy involving individual claimants, medical professionals, law and additional stakeholders such as social workers, therapists, psychologists, (i.e., professionals who have been created around PTSD treatment; Summerfield, 2001). In sum, Summerfield (2001) argued that proponents for a PTSD diagnosis are less concerned with individual distress in favor of medicalizing and perhaps even sensationalizing a socially-constructed phenomenon. In sum a DSM-IV diagnosis such as PTSD is not necessarily a disease. 


\section{Theories of Psychoanalysis}

Psychoanalysis and/or psychodynamic theory inform psychotherapy. Psychotherapy is defined as, "The treatment of mental and emotional disorders through the use of psychological techniques designed to encourage communication of conflicts and insight into problems, with the goal of personality growth and behavior modification" (http://www.thompsonbooks.com/foundations/FDNDF120.htm). While various perspectives for personality theory (i.e., trait theory, humanistic theory, and social learning theory to name a few) exist, the Freudian psychodynamic approach included mind structures (i.e., id, ego and superego), childhood experiences, and ego defense mechanisms (Carlson, Buckist, Enzle \& Heth, 2000). The personality is divided into three components, namely the id, ego and superego (Coombs \& Howatt, 2005). These different aspects of the personality compete and create conflict between the conscious and unconscious mind. This conflict is considered psychodynamic (Carlson et al., 2000). Furthermore, the pleasure principle was a term coined by Freud (1958; cited in Coombs \& Howatt, 2005) to describe individual motivation toward pleasure and away from pain. Such motivation is sparked by the id (Carlson et al., 2000). The id functions on unconscious and perhaps irrational instinctive drives. This has relevance for substance users' need for immediate gratification and is one explanation for irrational thoughts (Carlson et al., 2000). Conversely, the ego is considered conscious and rational thought. In addition to thinking, the ego is responsible for planning and self-regulating behaviour (Carlson et al., 2000). Therefore, the ego may delay gratification. Finally, the super-ego guides morals through feelings of guilt and ideals. According to Freudian 
psychoanalysis, individual affect, cognition and behaviour are motivated primarily by the unconscious, mind (i.e., id; Strean, 1996).

Moreover, Freudian psychoanalytic theory includes connecting individual pathology with earlier "psychosexual developmental stages" (Coombs \& Howatt, 2005, p.102). Painful and/or traumatic childhood experiences are anxiety provoking which create intrapsychic conflict. Various important ego defense mechanisms emerge to counter the id's drives and reduce anxiety. Repression as an ego defense is often linked to trauma survival. Similarly, substance users often rationalize and justify their substance use as an ego defense and attempt to make their behaviour more acceptable (Carlson et al., 2000).

Freud (1939; cited in Strean, 1996) recognized that "structural, genetic, economic, interpersonal and cultural" personality features are interwoven (p.524). In fact, Freud derived a metapsychological approach, which embraced such perspectives to yield a better understanding of human personality. Taken as a whole, the metapsychological approach provides scope for internal and external experiences, historical and current events, personal struggles and sociopolitical barriers (Strean, 1996). In essence, a neurosis emerges in response to individual distress. Indeed, neurosis includes individual pain and suffering by way of "obsession, phobia, or psychosomatic disease" (i.e., substance use and PTSD; Strean, 1996, p.535).

Cognitive behavioural therapy is a variation of psychotherapy and shares similar goals for fostering individual insight of thoughts, which are then used as a springboard for changing behaviours (Najavits et al., 2004). CBT, a key component of Seeking Safety focuses on individual attitudes, perceptions and actions and has demonstrated 
utility with substance abuse and trauma (Hien et al., 2004, Najavits, Liese, \& Harned, 2004) as well as additional disorders (i.e., schizophrenia; see Kingdon \& Turkington, 1994; Perris, 1989). Beck $(1963,1967)$ is heralded for cognitive-behavioural conception with depressed and anxious clients (Najavits et al., 2004). Historically, substance abuse was considered an indicator of underlying problems (Najavits et al., 2004). While substance use is recognized as a primary presenting problem, trauma may emerge as a precursor to alcohol or other drug use. As such, therapists employing CBT aid clients in recognizing triggering or automatic thoughts and developing healthier coping strategies (Beck, 1995; Najavits et al., 2004).

Critics of cognitive-behavioural therapy highlight the reoccurrence of depression and addiction relapse as examples, which demonstrate a need for further CBT research. Clinical trials have demonstrated positive CBT outcomes. However, CBT has not faired as well in practical settings (e.g., frontline work; Holmes, 2002). In fact, researchers have integrated mindfulness meditation (Teasdale, 2000; Leigh, Bowen, Marlatt, 2005; Marlatt \& Donovan, 2005) and additional CBT program enhancers (e.g., pharmacological agents; Martin et al., 2007) to promote positive addiction treatment outcomes. For example, anti-depressant medication is prescribed to stabilize mood while clients learn cognitive coping strategies. The medication is slowly weaned in relation to coping via an acquired cognitive skill set. CBT success is in part attributed to fostering a positive counselor-client rapport (Holmes, 2002). Similarly, the Seeking Safety program emphasizes the client's primary counseling need as a safe environment.

Motivational Interviewing (Miller \& Rollnick, 1991) and Stages of Change (Prochaska, Norcross, \& Di-Clemente, 1994) models are commonly used in conjunction 
with cognitive-behavioural models to assess treatment readiness. For example, clients enter various stages of treatment readiness including precontemplative, contemplative, determination, action, maintenance and relapse prevention (Miller \& Rollnick, 1991; Fields, 2007). The precontemplative stage is characterized by an absence of consideration for pursuing treatment. Followed by the contemplation stage where a decision is reached regarding treatment initiation. Next, determination involves individual preparation for treatment. The action stage is marked by individual action-plan conceptualization whereas maintenance represents operationalization of the plan. Individuals may experience fluctuation through the stages including maintenance and relapse as a natural part of the addiction treatment-recovery continuum (Di Clemente, 2003). Counselors employ motivational interviewing in developing empathic rapport with clients (Fields, 2007). Similarly, CBT emerges in an encouraging and supportive environment (Najavits et al., 2004). The counselor uses motivational interviewing to persuade the client toward substance abuse treatment (Fields, 2007) and determine CBT strategies. For example, one goal of recovery maintenance is to identify perceived "threats or temptations" (Di Clemente, 2003, p.190). CBT can be used to identify automatic thoughts, which may trigger drug and alcohol cravings and develop counters to effectively reframe the situation. Taken together, this approach has been criticized for allowing substance abusers to gauge personal treatment readiness, which may delay addiction recovery (Fields, 2007). Yet motivation is essential to sustained recovery. 


\section{Integrated Treatment Strategies: A Review of the Literature}

Biopsychosocial Model addresses substance abuse.

The biopsychosocial model (Engel, 1980) was developed in the 1980s. This perspective asserts individual vulnerability to addiction emerges from a genetic predisposition (biological), personality traits (psychological), and life experience including interrelationships (sociological) (Coombs \& Howatt, 2005; Goodman \& Levy, n.d.). The biopyschosocial model of addiction examines three facets of substance abuse. The biological aspect considers neural anatomy and brain function. Biological features include identifying any brain adaptations caused by psychoactive drug use, but also recognize the brain's ability to rejuvenate following drug abstinence (Martin et al., 2007). Certain individuals are equipped with a genetic blueprint, which may have an absence of neurochemicals including serotonin, which favours compensation through substance use (Wilson, 2007). Individuals initiate substance use to experience the euphoric effects and diminish negative affect such as depression and anxiety. Over time tolerance to substances develops so that individuals engage in repeated substance use to avoid aversive withdrawal effects (Martin et al., 2007).

Psychological characteristics of this model include affective disorders (i.e., "depression, anxiety or phobias") and mental disorders (e.g., borderline personality; Martin et al., 2007, p.34). Psychological dependence among alcohol and other drug users is linked to loss of control (Jellinek, 1952). Dodes (2003) concurred substance users are propelled toward drugs by psychological drives, which promote addictive behaviour.

Social factors pertain to peer-association and socio-economic status. Individuals are influenced by friends, which may lead to alcohol and additional drug 
experimentation. While a low socio-economic status should not be identified as the sole cause of substance abuse, marginalized populations may be exposed to a variety of factors (e.g., child maltreatment and parental drug use), which in combination create susceptibility for ensuing substance use (Martin et al., 2007). Social pressures increase with substance use, which contributes to financial, legal, familial and additional problems.

Self-trauma model addresses trauma.

The self-trauma model was introduced by Briere $(1992,1996)$ as an integrated treatment strategy for adults exposed to childhood trauma including maltreatment and/or neglect. Maltreated, neglected and/or abused children may not develop adequate coping skills (i.e., self-regulation; Briere, 2002). As well, these children are at increased risk for developing substance abuse and traumatic disorders (Schore, 1994). The self-trauma model combines trauma theory, cognitive-behavioural therapy and psychodynamic therapy in its treatment approach (Briere, 2002). Moreover, personal relational schemas, attachment experiences and ensuing emotional responses are examined as they relate to memories and current behavioural responses as a result of acquired learning (Briere, 2002). "The self trauma model suggests that a significant aspect of one's responses to a potential trauma is the degree to which the stressor overwhelms one's capacity to "handle" its effects through self capacities, especially affect regulation" (Briere, 2002, p.6). A "stress-induced sensitization to subsequent stressors" (Pitman, 1997, p.4) occurs whereby a conditioned emotional response is encoded and stored along neural pathways (Killcross, Robbins, \& Everitt, 1997). The memory retains experiences, which are influenced by personal perception or schemas (Briere, 2002). Indeed, emotion is 
emphasized as being equally important as cognition in trauma intervention (Briere, 2002).

Seeking Safety integrates both trauma and substance abuse.

In recent years there have been attempts to create an integrated program to address PTSD and substance abuse (see Back, Dansky, Carroll, Foa, \& Brady, 2001; Donovan, Padin-Rivera, \& Kowaliw, 2001; Triffleman, Carroll, \& Kellogg, 1999; Morrissey et al., 2005). Posttraumatic stress disorder and substance abuse are wellknown correlates (Najavits, 2007; Najavits, 2002b; Pitman, 1997; among others). Seeking Safety has been empirically tested with various groups including "women outpatients" (Najavits, in press, p.12; Najavits, Weiss, Shaw, \& Muenz, 1998), incarcerated women (Zlotnick, Najavits, Rohsenow, \& Johnson, 2003), marginalized women (Hien, Cohen, Miele, Litt, \& Capstick, 2004), a meta-analysis of women exposed to violence (Morrissey, Jackson, Ellis, Amaro, Brown, \& Najavits, 2005) and "outpatient men" (Najavits, in press, p. 13; Najavits, Schmitz, Gotthardt, \& Weiss, 2005). In addition, I have located one qualitative Seeking Safety program evaluation (VWSAC, 2004), which examined women with mental health disorders and substance use who have also experienced sexual violence. Taken together, these studies have demonstrated positive Seeking Safety outcomes. Of interest for the current study, Seeking Safety was initially developed as a program for women, which has been expanded to include men (Najavits, 2007; Najavits, 2002a).

At this juncture I will describe Seeking Safety studies performed to date. In the first study entitled, "Seeking Safety": Outcome of a New Cognitive-Behavioral Psychotherapy for Women with Posttraumatic Stress Disorder and Substance 
Dependence, 17 women completed 24 Seeking Safety group sessions. The women were divided into three treatment groups, which were conducted over a 12-week interim period. Each session was 90 minutes in duration. As previously noted, Seeking Safety emerged from CBT. The participants improved through CBT exposure in areas related to substance abuse, trauma, suicidal ideation and psychosocial adjustment to name a few. Improvements were measured by utilizing a pretest, posttest, and a three-month followup evaluation. Participants appeared to be engaged in treatment. Taken together, researchers concluded that Seeking Safety was beneficial to the participants and an effective treatment model. Limitations of the study included the absence of a control group, and lack of dropout accountability (Najavits et al., 1998).

A second Seeking Safety pilot study entitled, A Cognitive-Behavioral Treatment for Incarcerated Women with Substance Abuse Disorder and Posttraumatic Stress Disorder: Findings from a Pilot Study, examined 17 incarcerated women. Of these participants, post-tests revealed that nine women "no longer met the criteria for PTSD" and at three-month follow-up an additional seven women "no longer met criteria for PTSD" (Zlotnick et al., 2003, p.99). Taken together such numbers reveal program efficacy in reducing PTSD symptoms. However, approximately five women had returned to prison at three-month follow-up. Six women reportedly relapsed (i.e., used illicit drugs) within three months of leaving prison. While approximately two thirds of the sample returned to a problematic lifestyle, the researchers considered Seeking Safety as potentially helpful toward abating PTSD symptoms. Again, a limitation of this study was the absence of a control group (Zlotnick et al., 2003). 
A third study of interest for this thesis research, Promising Treatments for Women with Comorbid PTSD and Substance Use Disorders, had a larger sample, which involved 107 women of low socioeconomic status. The women were randomly assigned into one of three treatment groups (i.e., Seeking Safety, relapse prevention or community care). The cognitive behavioural groups (i.e., Seeking Safety and relapse prevention) demonstrated notable substance abuse and trauma symptom improvements at the end of three months. Yet the community care group did not effect change in substance use and participant PTSD symptoms were exacerbated over the same period. The researchers concluded that cognitive-behavioural therapy is an effective intervention for substance abuse and PTSD (Hien et al., 2004).

In addition, a fourth study entitled, Seeking Safety Plus Exposure Therapy: An Outcome Study on Dual Diagnosis Men, looked at five men and introduced exposure therapy in conjunction with Seeking Safety. The participants were able to choose personal treatment from these two therapy types. Male participants experienced 30 sessions of various treatment combinations. The researchers summarized participant improvement in areas including substance use, psychosocial functioning, PTSD symptoms and anger management to name a few. One obvious limitation for this study was small sample size (Najavits et al., 2005).

Finally, a qualitative study initiated by Sally Gose (2004) of the Victoria Women's Sexual Assault Centre (VWSAC) evaluated ten women's experience with the Seeking Safety program (i.e., VWSAC Seeking Safety Evaluation Report). The sessions occurred over two, twelve-week periods. Pretests and posttests as well as a focus group were utilized for data collection. Of interest for the current study was the use of 
summarized, transcribed interviews, which identified common participant themes. Detailed findings were chronicled in the final report. Women expressed appreciation for an integrated program which examined trauma and substance abuse. The researchers concluded that Seeking Safety addresses a broad range of topics relevant for women with complex needs including substance abuse and trauma (VWSAC, 2004).

The current study aims to contribute to the trauma and substance abuse treatment knowledge base by providing a comprehensive program evaluation pertaining to the relevance of an integrated substance abuse and trauma program for men. Of the five studies reviewed, only one of these focused on men. Clearly there exists a gap in research pertaining to Seeking Safety and program effectiveness for men.

\section{Chapter Summary}

It can be concluded that there are various pathways to addiction derived from both genetic and experiential influences. Individual central nervous system sensitivity and responsivity to significant life experiences are factors, which deserve consideration. Details of this investigation suggest that alcohol consumption (a) interferes with cognitive and social development (b) may indicate concurrent psychiatric disorders and (c) may be reinforced by peer and/or familial influence. Transition and traumatic life experiences are considered stressful and can be anxiety provoking. Accordingly, it was concluded that young alcoholic individuals who employ psychoactive drugs to cope with stressors during pre-adolescence and early-adolescence are likely to continue such pharmacological strategies in adulthood (DeWit et al., 2000). Indeed, dependence on alcohol appears to exhibit a progressive profile which emerges from chronic and consistent use to effect significant central nervous system adaptation and health 
challenges, which require individualized treatment plans (Rimondini et al., 2003). Seeking Safety as a CBT model is explored as one facet of LifeHouse program effectiveness. 


\section{CHAPTER THREE: METHODOLOGY}

The current study does not seek to replicate previous research performed to date, but rather eleven paired pretests and posttests were gathered by the LifeHouse counselors to measure program effectiveness. As well, I interviewed ten LifeHouse participants to gather more in-depth feedback regarding their experiences with the LifeHouse program. In particular, I sought to gain better understanding for men's experience with trauma and substance abuse recovery by exploring, through semi-structured interviews 'what works' with this population? Similarly to the VWSAC (2004) study, I identified common themes among individual recovery accounts. For example, the themes safety and skills emerged in both studies.

\section{Sampling Procedures}

Qualitative approaches often use purposive sampling methods. Purposive sampling is defined as participant-selection based on specific criteria (Brun, 2005). The selection of participants for this thesis research emerged from those individuals who were in the process of completing or had previously completed LifeHouse Seeking Safety classes. Program completion was indicated by the gathering of both a pretest and posttest administered by the LifeHouse counselors. The pretest and posttest data collection were based on the Trauma Symptom Inventory (TSI) created by Briere (1995). The TSI has been widely used in various settings: women with concurrent and eating disorders (Blinder, Cumella, \& Sanathara, 2006), adult children abused in religious institutions (Wolfe, Francis, \& Straatman, 2006), individual sexual abuse survivors with schizophrenia (Lysaker, Davis, Gatton, \& Herman, 2005), female veterans and group therapy (Weller, 2005), psychological effects following World Trade Centre attacks 
(Wilson \& Rosenthal, 2004), community violence and adolescents of colour (Rosenthal \& Wilson, 2003) to name a few studies. The TSI consists of 100 questions pertaining to acute and chronic traumatic effects emerging from sexual violence, abuse, accidents, combat, war, natural disasters and historical abuse (Briere, 1995). The TSI does not classify trauma according to DSM-IV criteria, but rather evaluates degrees of posttraumatic stress in individual lived experiences (Briere, 1995).

The TSI has been tested for reliability and validity. Indeed, the TSI contains three validity scales and ten clinical scales. Discriminant function analysis ${ }^{8}$ was utilized to calculate TSI criterion and construct validity (Byrne, 2005). TSI criterion validity was compared with similar scales (i.e., Brief Symptom Inventory and Impact of Events Scale). The TSI positively predicted $92 \%$ of PTSD cases (Byrne, 2005, p.2). T-tests ${ }^{9}$ were employed to measure the relationship between TSI trauma scores and four classifications of traumatic experiences (Byrne, 2005). Such comparisons revealed significant relationships among interpersonal violence and disaster exposure and higher TSI scores (Byme, 2005). Finally, reasonable convergent validity ${ }^{10}$, but weak reliability was discovered for discriminant validity ${ }^{11}$ (Byrne, 2005, p.3). Internal reliability was consistently high, scoring mean alpha coefficients ranging from .74 to .91 across ten clinical scales.

\footnotetext{
${ }^{8}$ Discriminant function analysis is described as similar to multiple regression analysis and is used where the dependent variable is dichotomous or binomial (e.g., male or female) as a statististical measure (Rubin \& Babbie, 1993).

9 A t-test is defined as a "statistical procedure that tests for mean differences between two groups" (Graziano \& Raulin, 2007, p.422).

${ }^{10}$ Convergent validity occurs where multiple studies employing various operational definitions produce identical conclusions (Graziano \& Raulin, 2007).

1 Discriminant validity refers to achieving comparable measures of the same construct, but differing measures among alternative constructs (Rubin \& Babbie, 1993).
} 
The three validity scales (e.g., Response Level, Atypical Response Level, and Inconsistent Response Level) are used to determine individual respondent consistency. Where there is too much variation among TSI responses, the respondent may be over generalizing in certain situations or denying symptoms. Too many inconsistencies will result in discounting the questionnaire (Briere, 1995). Ten clinical scales included (1) Anxious Arousal, (2) Depression, (3) Anger/Irritability, (4) Intrusive Experiences, (5) Defensive Avoidance, (6) Dissociation, (7) Sexual Concerns, (8) Dysfunctional Sexual Behavior, (9) Impaired Self-Reference and Tension Reduction Behavior (Byrne, 2005, p.2; Briere, 1995). Such scales provide an indication of trauma symptoms and particular areas for therapeutic consideration. These scales will be explained in more detail in the discussion of findings section of this thesis.

The current research project will focus on male participants who participated and in some cases completed the twelve-week LifeHouse Seeking Safety pilot project classes at various intervals between May 2006 and February 2007. Approximately, eleven individuals completed the program by the end of March 2007 as measured by the completed pretest and corresponding posttest evaluations. The LifeHouse Seeking Safety pilot project participant dropout has also been recorded. I employed two methods of data collection. First, I reviewed the LifeHouse program initial assessment forms and the Seeking Safety pilot project pretest and posttest evaluations. Second, I interviewed ten LifeHouse residents and explored their perceptions of the LifeHouse Seeking Safety pilot project. I posed a series of open-ended semi-structured interview questions (see research instrument, Appendix D) similar to those previously completed with LifeHouse staff on a quantitative questionnaire (i.e., TSI). Semi-structured interviews provided depth to the 
quantitative analysis. For example, the interviews revealed additional contributing factors, which influenced the project effectiveness (Rubin \& Babbie, 1993). Such contributing factors will be explored in the Discussion of Findings section of this thesis research.

\section{Data Collection}

I was provided with the quantitative data for those individuals who corroborated with interviews. I calculated individual trauma scores accordingly using the TSI manual. In addition to the results from these questionnaires, I also initiated a qualitative semistructured interview to gain a more in-depth analysis of concurrent trauma and substance abuse recovery in general and the LifeHouse program in particular. Qualitative approaches normally involve a small sample where interviews continue until redundancy is reached (Brun, 2005). I observed and interviewed ten men in the LifeHouse residence rather than in a clinical laboratory. While the TSI indicated indices of trauma and traumatic effects, the interviews provided context and scope for the participants' lived experiences. The interview questions extended beyond trauma including substance use, skills learned during treatment and motivation for continued drug abstinence. Clearly, a qualitative research design was appropriate for the current study, which explored program effectiveness.

Furthermore, I aimed to be consistent and objective by conducting semistructured interviews (Rubin \& Babbie, 1993). Semi-structured interviews consist of broad open-ended questions aimed at exploring individual experiences and/or perceptions (Tutty, Rothery, \& Grinnell, 1996). I drafted an interview guide encompassing neutral, open-ended questions (again see research instrument, Appendix D) to reduce interviewer 
bias. I asked the participants predetermined and ethically approved questions. The questions I asked were considered carefully in accordance with the LifeHouse assessment forms and Seeking Safety pilot project pretest and posttest guide. Interview probes were "limited to where they [were] indicated on the program schedule" (Rubin \& Babbie, 1993, p.376). The responses were recorded on a digital voice recorder. Indeed, "the aims and philosophical roots of qualitative inquiry mandate that the respondent's answers should be recorded as fully as possible" (Rubin \& Babbie, 1993, p.382). Accordingly, I used a digital voice recorder to capture the interviews. Recording the interviews allowed me as the researcher to engage in focused listening. In addition to recording the interviews, I also scribed rough jot notes as a back-up procedure (Rubin \& Babbie, 1993). As well, I included visual descriptions and additional observations in my notes. Such observations included non-verbal participant cues (i.e., fidgeting, and covering the face with the hands). The digital voice recordings were transcribed immediately following the interview for ease of analysis. Moreover, I recorded personal reflections following each interview as a means of self-examination and information processing. Clearly conducting a thorough data collection method by utilizing both quantitative and qualitative research designs assisted in answering the research question, What was the effectiveness of the

\section{LifeHouse Program for LifeHouse participants?}

\section{Measures}

The Trauma Symptom Inventory was the research instrument used by LifeHouse Staff to measure the variables of interest. Yet the TSI was limited in its scope as it only measured for change in traumatic effects and did not encompass additional factors of individual lived experience. Seeking Safety was implemented to provide support for 
individual trauma survivors as a feature of the LifeHouse Addiction Treatment Program. As such, I employed a semi-structured interview guide which aimed to examine additional facets of the LifeHouse program. Such examination was sought to provide depth to the limited analysis derived from the TSI.

I received 33 pretests which had been collected between May 2006 and February 2007. Of these, 21 respondents did not complete corresponding posttests (there was one posttest, but with no corresponding pretest) and were therefore considered LifeHouse program dropouts. The focus of the ensuing quantitative analysis consisted of the eleven respondents who completed both a pretest and a posttest. Of the TSI respondents, six were also included in the qualitative interview process. It is noteworthy to mention the nonprobability or nonrandom nature of the sample that completed both pretests and posttests. This sample was purposively selected from the participants who had experienced the LifeHouse Seeking Safety pilot project.

Interview Guide: See research instrument (Appendix B).

\section{Method of Analysis}

By taking jot notes and recording the interviews I collected comprehensive data for the purpose of analysis. I retyped the notes soon after the interviews as a way to improve recall of interview observations and occurrences (Rubin \& Babbie, 1993). I recorded dates and times in completing a log for data collected. Taken as a whole, the data collected was stored in a locked filing cabinet located in the researcher's personal home office. Transcriptions and working drafts were also secured by a computer password. 
I approached the bulk of information gathered with the desire to gain insight for each participant's unique lived experience and also identify where the LifeHouse program may or may not have been individually effective. This objective helped guide my focus in responding to the research question (Tutty, et al., 1996). I was also mindful of the rapport I had developed with the participants. For example, while I clarified my role as researcher with each of the men; an empathic rapport was maintained throughout the interviews. In fact, I have since been invited to and attended three participant LifeHouse program graduation ceremonies. Where I had originally understood that the participants I would interview had successfully completed the LifeHouse program, only one man had graduated and moved out at the time of the interview. However, to date all the participants but one have graduated. One fellow was discharged from the LifeHouse program for reasons other than relapse.

I organized the compiled information into themes and made inferences accordingly. I examined commonalities and developed classifications for similar participant responses. I aimed to elicit meaning from the data collected rather than imposing categorical assumptions to the process (Tutty et al., 1996). In sum, I employed an inductive approach to the data analysis, meaning I developed specific outcomes based on general observations (Rubin \& Babbie, 1993). Following the interview transcription process, I reread each interview and cross referenced the digital voice recording with the written transcription adding in anything that may have been missed during the initial transcription. I also jotted down notes - analytical memos (Tutty et al., 1996, p. 100; Babbie \& Benaquisto 2002) - including my thoughts and reflections as I combed each interview. Reflexivity is defined as the critical thinking required to examine the 
interaction occurring between the researcher and the data during analyses which aims to clarify researchers' views, motivations, and assumptions (Jackson, 2003) Indeed, "observations and analysis are interwoven processes in qualitative research" (Babbie \& Benaquisto 2002, p.375). It is not linear, but rather a circular process (Babbie \& Benaquisto 2002; Creswell, 1998).

I decided to use a computer word processing system rather than the traditional cut and paste method (e.g., scissors and paper) to organize the qualitative research. Therefore I transferred all the interview transcriptions into one document. In sum, I transcribed 94 pages of information. I used a word find feature (e.g., seek and find) on the word processor to search and locate words which held similar meanings and had emerged repeatedly through the interviews. For example, I searched for the words skills, tools, resources, and information to find common themes based on what I had reread. Such synonyms became "meaning units" (Rubin \& Babbie, 1993, p.386). I applied these meaning units to the seek and find word processing option and gauged their value according to the frequency with which they appeared in the document. I determined the prevalence of these similarities by discerning whether the themes were common among the respondents. Determining high prevalence of certain themes inspired reflection and critical thinking which informed the ensuing interpretation of findings ${ }^{12}$ (Babbie \& Benaquisto, 2002). I also used a thesaurus and addiction recovery language as well as my notes to search for similar meaning units. In this way I was constantly comparing and organizing the data by various categories according to similarities and also differences (Babbie \& Benaquisto 2002; Tutty et al., 1996). Differences were considered equally

\footnotetext{
${ }^{12}$ For example the research findings uncovered the rationale for participants' perceived value for anger management and revealed memory as a potential barrier to learning new cognitive strategies. These findings will be discussed in ensuing sections of this thesis.
} 
important to similarities because they prompted questions surrounding what additional features of these participants varied among the sample group ${ }^{13}$ (Babbie \& Benaquisto 2002).

At this juncture in the research - after I had noticed similarities and differences among meaning units - I began the coding process (Tutty et al., 1996). I used a focused coding approach which, "consider[ed] the utility of the themes and how they may be related" (Babbie \& Benaquisto 2002, p. 382). Initially I identified nine themes which were related to the research question and reflected participant responses. I colour coded the transcriptions according to each theme. I used colour coding to ensure I did not overlook any data. I transferred the colour coded interview segments into one document by cutting and pasting the word document into individual files according to theme. Some interview data seemed to fit into more than one theme and was categorized under each for further fine-tuning. I double checked the original document for any 'leftover' material, yet the themes I had selected indeed covered the interview data in its entirety. I incorporated the themes into a draft Discussion of Findings chapter. I read through the compiled information creating subcategories under each theme and consolidating quotes. I aimed to organize the themes in a way that would best reflect what people had said. I recognized where the data became repetitive and summarized the information accordingly.

In reorganizing the data I needed to pull apart some of the longer participant quotes and reinsert the data into different categories. I was mindful that this finer level of coding may not capture the broader participant context. However, it did reveal

\footnotetext{
${ }^{13}$ For example, different individuals described different learning styles and therefore had differing perceptions of the counselors' facilitation of the Seeking Safety pilot project and LifeHouse program.
} 
commonalities among participant responses, which spoke to LifeHouse Program effectiveness (Tutty et al., 1996). I aimed to emphasize the participants' voices in the presentation of the research. During this fine-tuning process I made new discoveries regarding the themes and made adjustments accordingly. For example, I noticed a continuum emerged between Seeking Safety and Anger Management classes, which demanded a new theme be created in order for revealing respondent feedback. This awareness emerged from the fine-tuning process and required reorganization of categories, but also collapsed previously overlapping themes (Babbie \& Benaquisto, 2002). By the end of this process I had narrowed the themes to seven distinct areas including a number of related subcategories ${ }^{14}$.

Indeed, while compiling the data and considering subcategories, I was also mindful of the research question. I aimed to paint a picture of the participants' way of life prior to entering the LifeHouse Program and reflect the changes experienced during addiction treatment. I created a visual thematic diagram (Appendix E) of the emergent themes, which assisted in organizing the flow of the analysis. In this way I answered the research question while also drawing connections among the themes (Tutty et al., 1996). Creating a diagram also helped me realize where there may have been gaps in the literature review. Taken together, the research question, the respondents' responses, and the TSI scores prompted a more in-depth literature search (Tutty et al., 1996).

As was previously discussed in the literature review of this manuscript, there exist many different theories pertaining to addiction. As such, my aim is not to utilize the data collected from this research to further develop theory on the nature of addiction, but

\footnotetext{
${ }^{14}$ Such themes and subcategories will be explored in detail in the ensuing Discussion of Findings section of this thesis research.
} 
rather to focus on features of addiction treatment recovery found to be valuable by the participants in the LifeHouse Program. In this way I hope to contribute to addiction research and the social work knowledge base by presenting ideas for working with individuals living with addiction. In the ensuing Discussion of Findings section of this thesis I seek "to communicate a telling and focused story that can be understood by those not directly involved in the research - one that summarizes the material and addresses patterns and themes that are sustained by the data" (Babbie \& Benaquisto 2002, p.381). By striving for consistency throughout the research process I have aimed to develop credibility in the presentation of the findings of this study (Tutty et al., 1996).

\section{Ethical Considerations}

I conducted research in accordance with social work ethical considerations. In fact, I drafted a complete ethics proposal including the participant information and letter and consent form. I provided the LifeHouse addiction counselors with the information letter. The counselors invited their clients to participate in my study. The prerequisites for participation included participation in the LifeHouse Seeking Safety pilot project and individual psychoactive drug abstinence. LifeHouse addiction counselors scheduled interview times, which were convenient to both the participant and researcher.

The interviews took place in a private office located at the Ottawa Mission in the

LifeHouse building. I reviewed the consent form with each participant prior to initiating the interview. I emphasized that participation was voluntary and that the participants maintained the right to withdraw at any time during and up to seven days post-interview. As well, the participants were free to decline answering any questions posed by the researcher. Moreover, should the participants have decided to withdraw from the study, 
they were also free to decide at that time whether the researcher might keep the interview digital voice recording and/or notes taken to that point or ask to have the same erased or destroyed. The participants were informed of the potential minimal risk associated with participating in the interview (i.e., relapse). However, this was an unlikely scenario and LifeHouse addiction counselors were available but were not required. In the case that a participant chose not to answer a question, the researcher would have noted "no response" on the interview record. However, all the participants agreed to respond to each question without consequence. The participants were advised of the approximate 60-minute duration of the interview. This proved to be an appropriate guideline given the interviews ranged from approximately 25 minutes to one hour 40 minutes in duration.

In addition to the interview, I asked the participants to release data previously collected by the LifeHouse staff. In particular, I was permitted access to the LifeHouse addiction program assessment records as well as the pretest and posttest evaluations (i.e., TSI) previously collected by LifeHouse staff. The purpose for the information provision was to better inform the current research project. As well, pseudonyms were used in this manuscript as well as the final report to aid in protecting personal anonymity and confidentiality. Indeed participants were invited to select personal pseudonyms. For example, participants who were quoted or paraphrased were concealed by a code name of their choice. Clearly, all interview notes, digital voice recordings, transcripts and associated working papers were retained in secure and locked storage by the researcher.

\section{Chapter Summary}

The current study was a mixed methods research project including quantitative and qualitative measures. Such thesis research was a program evaluation to determine 
LifeHouse Addiction Treatment Program effectiveness for LifeHouse participants. I compared pretest and posttest Trauma Symptom Inventory scales. In addition I conducted interviews. I compiled the interview data, identified similar information and organized these meaning units into common themes. I compared and contrasted similarities and differences among the emergent themes to develop subcategories. Taken together the themes and related subcategories form the basis for the ensuing Discussion of Findings chapter of his thesis. Similarly to previously outlined Seeking Safety research studies, I have drawn comparisons between the pretest and posttests and documented change. Accordingly, trends which parallel the previous studies emerged and contribute to an argument for Seeking Safety program utility. A discussion of findings will be explored in detail in ensuing sections of this thesis research. 


\section{CHAPTER FOUR: DISCUSSION OF FINDINGS}

\section{Introduction}

The LifeHouse Addiction Treatment Program's main objective is to provide an "intensive, six-month drug and alcohol rehabilitation program" (http://www.ottawamission.com/en/addiction.html). In addition LifeHouse staff work with program participants to increase self-efficacy and develop self-esteem through coping strategies among the homeless and those at risk of becoming homeless. LifeHouse staff strive to provide a safe recovery environment by supporting individuals with personal, financial, medical and legal challenges as well as providing opportunities for volunteerism. Basic living skills are fostered through cohabitation and sharing basic cooking, cleaning, laundry and budgeting responsibilities.

The LifeHouse Program includes four main phases of addiction treatment: (1) Stabilization, (2) Core Treatment, (3) Reintegration, and (4) Aftercare. These four phases are tailored to meet individual need. For example, individuals may require longer or shorter stays in stabilization and/or benefit from longer term aftercare. Participants are introduced to the Alcoholics Anonymous Twelve Step Program and Anger Management during stabilization. The Seeking Safety trauma class, group therapy, individual counseling, and community volunteer experiences are explored during the Core Treatment Phase. Following core treatment completion, LifeHouse staff work with participants on securing housing, and either work or education opportunities. Finally, Aftercare provides ongoing support through bi-weekly groups and individual counseling services. The LifeHouse Program receives funding support from the United Way and additional community partners. 
The following discussion of findings focused on men who participated in the LifeHouse program between May 2006 and March 2007. Six of the men who agreed to be interviewed also completed TSI pretest and posttests. The following chapter will explore common themes and related subcategories, which allude to LifeHouse Addiction Treatment Program effectiveness.

\section{Sample}

The sample consisted of men between the ages 23 and 52 years, with the mean age 33 years. The Lifehouse Addiction Treatment Program is located in Ottawa and men traveled from all over Ontario to attend the program. While there was limited ethnoracial diversity, most of the men came from poor, working class families. Education ranged from grade eight to some high school and college graduates. Most men identified as Christian while one individual qualified as embracing spiritual principles. Some of the men had psychiatric diagnoses including ADHD and schizophrenia. Most participants revealed historical abuse and/or familial substance use.

The participants described experimenting with different drugs and one individual reported using alcohol only. All of the men smoked cigarettes. Cigarette smoking is not uncommon among individual substance users. Euphoric effects achieved with alcohol, cocaine, and other drugs are increased with nicotine. Such euphoric effects become reinforced in the brain's reward circuit. Withdrawal produces cravings owing to neuroadaptation of brain chemicals including dopamine and serotonin, which effect mood (Sofuoglu, Dudish-Poulsen, Poling, Mooney \& Hatsukami, 2005). This is particularly true for individuals living with depression. Depression and addiction have been associated in the literature for a long time. A pilot study conducted by Back, Brady, 
Jaanimagi \& Jackson (2006) revealed $41 \%$ of participants responded to a concurrent treatment plan, which addressed both substance use and trauma. The men at LifeHouse are coping with multiple issues including polysubstance use and trauma symptoms. Such stressors compromise the brain and the immune system. While some men had previously attended addiction treatment programs, Lifellouse was a first experience for others ${ }^{15}$. Men present more treatment challenges than women who are more likely to sustain substance abstinence (Gallop et al., 2007). Ontario Disability Support Pension (hereafter referred to as ODSP) and/or Ontario Works (hereafter referred to as OW) benefits offset treatment costs. However, the men are required to perform volunteer work while attending treatment. The men are asked by LifeHouse staff to choose a local agency where they can dedicate two hours of service each week. For example, some men choose to work at agencies where they have received benefits in the past (i.e., food bank).

\section{Findings from Pre and Post-Program Questionnaires}

The TSI was conceptualized in response to a need for PTSD stressor assessment (Briere, 1995). Briere (1995) described 14 potential stressors, which contribute to PTSD including assault, combat, rape, accidents, and national disasters to name a few. PTSD symptoms add to additional life stressors and exacerbate substance use. However, the findings reveal a change in trauma symptoms according to the TSI pretest and posttests following Lifehouse Addiction Treatment Program completion. The data collected revealed overall improvement in trauma symptoms. The participants' traumatic symptoms also may have diminished in the absence of substance use, safe housing and predictable surroundings (i.e., treatment effects).

\footnotetext{
${ }^{15}$ It is important to note that relapse is understood as a reoccurring feature of addiction therefore is not indicative of failed treatment, but rather is reflective of neuroadaptation as a result of prolonged substance use (Hoffman \& Froemke, 2007).
} 


\section{Findings from Participant Interviews}

LifeHouse staff recognized that clients recovering from substance use also made references to historic traumatic events. Such an observation was consistent with current research which supports simultaneous addiction and trauma counseling (Back et al., 2006; Najavits, 2002). Indeed, findings confirmed LifeHouse program effectiveness as revealed by seven themes: (1) Control, (2) Trauma, (3) Safety, (4) Seeking Safety, (5) Anger Management, (6) Skills, and (7) Motivation. In addition to the themes, similarities and differences were grouped into subcategories (please refer to Appendix E for a thematic diagram). Taken together, such variables contributed to individual capacity for coping and intrinsic motivation for substance-free living. Developing a positive outlook and coping skills through cognitive therapy (i.e., Seeking Safety and Anger Management) contributed to individual perceived control, lessened trauma symptoms, established safety and increased motivation. Clearly, LifeHouse treatment initiatives provided a supportive environment through which men successfully achieved substance abstinence and respite.

\section{Quantitative Analysis}

The TSI includes ten clinical scales; (1) Anxious Arousal, (2) Depression, (3) Anger/Irritability, (4) Intrusive Experiences, (5) Defensive Avoidance, (6) Dissociation, (7) Sexual Concerns, (8) Dysfunctional Sexual Behavior, (9) Impaired Self-Reference and Tension Reduction Behavior (Briere, 1995). The Anxious Arousal scale measures anxiety and includes jumpiness, worry, self-harm and so forth. Such responses may indicate panic or PTSD. The Depression scale measures for mood, hopelessness, and suicidal ideation. The Anger Irritability Scale measures for irritability associated with PTSD, angry cognitions (i.e., perceptions and thoughts). The Intrusive Experiences scale 
includes respondent reports of flashbacks, nightmares, intrusive memories triggered by historic events and so forth. Such symptoms indicate traumatic reexperiencing of events. Defensive Avoidance (DA) is defined as pushing negative memories from conscious thought. DA should not be confused with disassociation or regression because it is intentional. Disassociation then is defined as an unconscious defense mechanism. Sexual Concerns range from negative thoughts and feelings to confusion to preoccupation and shame. The Sexual Concerns scale does not measure for sexual orientation, but rather sexual dissatisfaction. Dysfunctional Sexual Behavior includes indiscriminate sex relations, using sex to offset loneliness and risky sex. Impaired SelfReference describes respondents' feelings of inadequacy and emptiness. Respondents with significant scores are described as lacking self-knowledge. Tension Reduction Behavior includes coping strategies such as, substance use, cutting (self-mutilation), and suicide attempts, which are behaviours often associated with Borderline Personality diagnoses. Taken together these clinical scales are commonly cross-associated so that one respondent may have a combined significant score along two or more scales.

The scales are further classified according to trauma scales, self scales and critical items which are warning signs for detrimental events (i.e., hurting others or self). Counselors may be interested in distinguishing among these variables in guiding the client toward next steps. Any positive response for the critical items is worthy of followup. The following table demonstrates the sample results of the Trauma Symptom Inventory pretest and posttest mean scores ${ }^{16}$.

\footnotetext{
${ }^{16}$ Please refer to Appendix D for the individual test scores.
} 


\section{Sample Mean Scores}

\begin{tabular}{|l|l|l|}
\hline Subscale Name & Pretest (trauma score) & Posttest \\
\hline Anxious-Arousal (AA) & 61.27 & 52.64 \\
\hline Depression (D) & 62.73 & 52.55 \\
\hline Anger-Irritability (AI) & 64.09 & 54.18 \\
\hline Intrusive Experiences (IE) & 64.73 & 59.82 \\
\hline Defensive-Avoidance (DA) & 61.27 & 58.64 \\
\hline Disassociation (DIS) & 60.82 & 53.45 \\
\hline Sexual Concerns (SC) & 61.45 & 58.18 \\
\hline $\begin{array}{l}\text { Dysfunctional Sexual } \\
\text { Behavior (DSB) }\end{array}$ & $67.55^{*}$ & 54.18 \\
\hline $\begin{array}{l}\text { Impaired Self-Reference } \\
\text { (ISR) }\end{array}$ & $66.27^{*}$ & 59.54 \\
\hline $\begin{array}{l}\text { Tension-Reduction } \\
\text { Behavior (TRB) }\end{array}$ & $66.45^{*}$ & 52.27 \\
\hline
\end{tabular}

* indicates significance

At this point I will elaborate on the clinically significant sample mean pretest scores: Impaired Self-Reference, Tension-Reduction Behavior and Dysfunctional Sexual Behavior. Individuals experiencing an impaired self-reference are challenged in discerning personal needs, goals, desires and direction. LifeHouse provided a structured program including basic living skills, which assisted in developing stability. As well, individuals at LifeHouse gained self-awareness through class attendance and homework completion.

Tension-Reduction Behavior included self-mutilation, suicidal ideation, aggression, risky sexual behaviour often in an effort to diminish feelings of abandonment and loneliness. Individual substance users self-report contemplating and even attempting 
suicide. LifeHouse provided respite from street life as well as opportunities for stabilization and strategies for coping without substances. Tension-Reduction Behavior may be linked to Dysfunctional Sexual Behavior in using sexual relations as a selfsoothing technique. I am wondering whether specific substances used contribute to higher scores on clinical scales. For example, one participant commented that he used crack cocaine to enhance his sexual experience. This comment is consistent with the literature which suggests a relationship between cocaine use and sexual experiences.

Zanis, Cohen, Meyers and Cnaan (1997) studied 89 African American male veterans with a mean age of 39.2 years (as compared with LifeHouse participants who identified as Caucasian and a mean age of 33 years). Zanis et al. concluded cocaineusing homeless men were at greater risk for contracting HIV, particularly where concurrent psychiatric distress was a factor (i.e., PTSD and/or trauma symptoms). Such greater risk was attributed to an absence of condom use, multiple and same-gender partners, and sex trade involvement. Similarly, Royse et al. (2000) performed a study which examined 5225 homeless crack cocaine users; $67 \%$ of the sample was male, mean age 39.8 years. Some of these individuals were also IV drug users. This study raised awareness for the changing face of the homeless population; from the older, single white male to more diverse and heterogeneous populations. Individuals who are homeless were described as stigmatized, marginalized, and lacking social supports. The majority of the sample had experienced either physical or sexual abuse including rape. As well, up to three-fourths of the homeless population was diagnosed with substance use and concurrent disorders. Criminal activity including sex trade involvement was not uncommon. Crack cocaine was noted as a cheap "fix" and posed a HIV risk owing to 
crack's association with "increased sexual activities, including exchanging sex for drugs, infrequent condom use, and multiple sex partners" (Royse et al., 2000, p.285).

Additional scales which approached clinically significant scores included AngerIrritability and Intrusive Experiences. Irritability and angry thoughts were attributed to trauma symptoms. Such anger is often associated with poor frustration tolerance and may be perceived as outside an individual's locus of control (i.e., attributing blame to people, places, situations and things). Therefore potential for aggression should be considered and confirms the utility for an anger management component to LifeHouse program structure. Intrusive Experiences are spontaneous and unpredictable memories comparable with reliving traumatic events. Racing thoughts contribute to levels of anxiety and/or distress and can increase irritability. Individuals use substances to cope with negative affect including fear, stress, and pain. Only one LifeHouse participant claimed alcohol dependence whereas the majority of residents had used (crack) cocaine and/or opiates. Such perceived "harder" drugs are increasingly associated with trauma symptoms including PTSD (as compared with alcohol and/or cannabis). However, a family history of substance use is also a strong predictor for ensuing traumatic experiences (Najavits, et al., 1998). Typically substance-using families have an absence of nurturing and few protective factors to provide a buffer for traumatic events. The cessation of substance use might alleviate traumatic symptoms. For example, Back et al. (2006) noted diminished PTSD symptoms in relation to cocaine cessation. Such results substantiate continued support for the Seeking Safety concurrent substance use and trauma class offered through LifeHouse. 
Overall examination of individual tables (see Appendix D) revealed variable change among participants. While a standard guideline for program effectiveness is that a third of the participants are predicted to improve, a third to worsen and a third to remain the same, in this case participant one worsened and participant eight experienced no change. The remaining nine participants seemed to fall along a continuum of improving but still maintaining clinically significant symptoms, improving and overcoming clinically significant symptoms or experiencing varying symptoms.

\section{Qualitative Themes}

Qualitative research does not require a clearly defined and operationalized definition because it is left to the participant to define whether an individual experience was traumatic and whether substance use has become problematic. Clearly, these experiences and the following account are purely subjective. Homelessness is understood as the men currently living at LifeHouse will be looking for second stage housing or living with family members upon departure. The current study provided the writer with an opportunity to learn about the quality of the LifeHouse program from the participants' perspectives. Fook (1993) described the focus of qualitative research as developing an understanding of individual experience, but not "intervening in it" (Fook, 1993, p.74). I invited the participants to select individual pseudonyms. The ten participants chose the following names: Matt, Ty, Cosmo, Martin, Steve, 007, Ed, The Big Unit, Al and Ryan. Those individuals who did not choose a pseudonym were assigned a name to protect their identity. Therefore the names that appear in ensuing sections of this manuscript will preserve the anonymity of the participants. 


\section{CONTROL}

Substance users have been profiled as losing control over their drinking and/or drug use. Schaler (2007) asserted that loss of control is essential to a disease model argument. In other words, alcoholics and/or addicts no longer have a choice and therefore use substances compulsively. Whether loss of control is linked to predisposition and/or disease (Jellinek, 1960, 1952), neuroadaptation (Hoffman \& Froemke, 2007), an empowered choice (Dodes, 2003) or a response to environmental stressors (Peele, 1985) the theme of control emerged in participant interviews.

The participants revealed their initiation into alcohol and substance use as being influenced by family and friends. Some men revealed older siblings and cousins as introducing them to substances, others described family parties (i.e., Christmas and a wedding reception), while still others spoke of their parents' drug use, "my father was a drinker". As such, individuals reported drug use was influenced by familial role modeling and/or peer pressure. Not surprisingly, the participants also described a variety of drug use. Over time, individuals experimented with various drugs including alcohol, marijuana, cocaine, heroine, morphine, ecstacy, and oxycontin.

I was allowed to drink every Friday but my parents just thought I was a teenager. So I would work in the middle of the week to get money for alcohol at the end of the week and it took me awhile before I became a drug addict actually. I took drugs to become more controlled in my substance abuse (The Big Unit).

Indeed, each individual disclosed his preferred drugs, but substitutions were not uncommon.

Dodes (2003) proposed individuals are compelled to substance use because they feel empowered while under the influence; drugs including alcohol compensate for any 
perceived inadequacies. Therefore, individuals possess a psychological motivation or drive toward substance use. LifeHouse participants disclosed initiating drug use for a sense of power and control; for a sense of belonging. One participant summarized his reason for substance use, "I just couldn't be comfortable in my own skin". Accordingly, individuals used substances to boost self-esteem and/or self-confidence. Furthermore, consistent with Peele (1985), individuals also reported substance use to escape life stress and trauma and to avoid negative affect,

I dealt with everything with drugs and alcohol. I was an alcoholic, but I didn't know what an alcoholic was and I wore it as a badge of honour. It was a problem according to society, but it wasn't a problem for me. I've been very successful; I made over $\$ 100,000$ a year. I had a car. I had a house. I had this. I had that. It was just that I didn't realize the real effect. I mean I should have done so much more, but I know it always kept me back, but I never identified it as keeping me back...It was a way of dealing with my feelings; anytime I felt discomfort, I immediately corrected it with substance. My belief system - I was self-centered, instant gratification. I drank and used to escape. Because I mean it works for a period of time $(\mathrm{Al})$.

According to the DSM-IV, substance abuse is defined as a behaviour emerging from three areas; habit-drinking, drinking to cope, and/or loss of control. An individual is diagnosed substance dependent in the face of loss of control, preoccupation with using to the exclusion of other activities, and the presence of tolerance and withdrawal (i.e., neuroadaptation; Martin et al., 2007). Individual predisposition for alcoholism promotes dependence among substance abusers whereas in the absence of genetic markers, substance-abusing behaviour may be extinguished. In effect, substance-abusing individuals are thought to be able to return to social drinking following a one year period of abstinence, which distinguishes them from substance dependent individuals who return to an identical and increasing level of alcohol consumption following a period of 
abstinence. Similarly, Peele (1985) asserted addiction is defined by individual behaviour, continued substance use despite negative consequences, and by the individual's personal admission. Accordingly, LifeHouse allows individuals to self-define whether substance use is problematic. Individuals self-define substance use as problematic through disclosing poverty owing to the financial cost of substance use and an absence of social support owing to exhausting such resources. In some instances, individuals have stopped using substances without support however; they are challenged to maintain any kind of enduring abstinence without implementing significant lifestyle changes offered through addiction treatment.

\section{(i) Disease}

Lost control occurs owing to neurological changes in the central nervous system which promote cravings for continued substance use despite negative consequences. Owing to the progressive nature of the disease, individuals become obsessed with thoughts of using and following initiation of the substance, they are compelled to drink and/or use more. The disease concept proposed by Jellinek (1952) classified drinkers into different categories. Accordingly, the gamma alcoholic is characterized by loss of control.

I got the bug - that's what they [Alcoholics Anonymous] call it. Yeah they have three different types of alcoholics - the chronic alcoholic, the problem drinker, the fall down - I know I'm not the fall down. I'm not like that. Like, I picked up [alcohol]. I put down. There's been consequences and then there hasn't been. And then there's this allergy and I still don't get it but ah maybe 'cause I don't have it. (c.g., I'm not convinced I'm an alcoholic). I mean it's not really destroyed me completely. I'm not a fall down. I can function (Ed).

Likewise, Steve contemplated the notion of the 'bug', "... it might be my fault, but I do have the bug and that with the trauma, I don't think I had a chance". Schaler (2007) 
proposed resolving the underlying problem (e.g., trauma) would alleviate the propensity for substance use. Individuals drink or use drugs to avoid negative feelings. Individuals may become substance free once perceived negative circumstances are overcome and new coping strategies are developed.

When asked questions pertaining to their drinking history, the men expressed choosing alcohol or drugs for the euphoric effects. For example, the men interviewed used substances to gain "power and control", "escape", for attention, to be noticed, to fitin, and "to be accepted". Given such motivations, beliefs about the effects of substance use seem to imply choice. However, perhaps there is a point in an individual's using where having choice becomes blurred. For example The Big Unit shared that "choice of friends [influenced my using because]... most of them were using and no matter how bad I didn't want to use that day, I would". Similarly, 007 may have initially chosen to smoke marijuana, but didn't realize until years later the full consequences of this action,

I didn't believe it was really affecting my life. But it was. You know as I look at it now, it was. Because ah I lost, with it I lost ah I lost the will to ah overachieve. The overachiever went away. And you know I'd rather do it an easier way. 'Cause I know I could have done a lot more in life, if I hadn't had it [used marijuana].

Such examples depict some of the subtle ways men have lost control of their using which is linked to the disease notion of lost control.

The biopsychosocial model (Engel, 1980) was developed in the 1980s. This perspective asserts individual vulnerability to addiction emerges from a genetic predisposition (biological), combined with personality traits (psychological), and life experience including interrelationships (sociological) (Coombs \& Howatt, 2005; Goodman \& Levy, n.d.). Certain individuals are equipped with a genetic blueprint, 
which may have an absence of neurochemicals including serotonin, which favours compensation through substance use (Wilson, 2007). Individuals initiate substance use to experience the euphoric effects and diminish negative affect such as depression and anxiety. Over time tolerance to substances develops so that individuals engage in repeated substance use to also avoid aversive withdrawal effects (Martin et al., 2007). Accordingly, withdrawal effects are a reason individuals are susceptible to relapse. Moreover, with each successive relapse, the central nervous system is further sensitized. Individuals perceive increased cravings for substances in the face of stressors. Cognitive therapy including Seeking Safety seeks to promote coping strategies, which help diminish the strength of stressors by altering individual perception of the same and therefore lessen cravings for drugs.

\section{(ii) Progression}

The notion of progression or a gradually worsening condition is closely linked to the disease model (Peele, 1985). Consistent with the literature, participants recognized individual substance use increased over time, "I thought I could still control this you know. I didn't have the full-fledged desire to quit everything. I had the desire to slow down. And after the last three years, I realized there's no slowing down. It's just the progression".

I remember vodka, the first time I drank vodka. I got sicker than a dog. And it seems like anytime I ever drank vodka after that I got sicker than a dog. And I just quit drinking vodka. Whisky I know I would black out or get into a fight. I didn't know enough to stop. So with my drinking I ended up as beer drinker. When I was drinking beer it seemed okay you know I'd wake up the next day - no black eyes no, no broken arms that's okay - I'll drink the beer you know, but even drinking beer made me sick after a few months. You know you try every little method, like maybe I should eat a little bit before I drink. Another method [was to] drink water after you drink you won't wake up with such a hangover you know that 
kind of stuff. But with drinking I never liked the hangovers. I never liked the dries in the morning, the pasties you know, and all that stuff, and when I found marijuana that was my miracle drug. I gave up on the drinking. I didn't drink that much after that.

That first toke would give me instant gratification and then after that it was rotten taste and I'd have to leave it for two hours before I could get that instant gratification again, but the addict doesn't allow you to leave it. Basically it's like let's try it again. You think an hour or two; you think five minutes is an hour. Your time is way off. You can't think. No kidding, you think five minutes is at least 20 minutes. It must be time to do another one. So you do another one. Meanwhile it hasn't even been two minutes. Before you know it, it's gone and you have to go back and make some more [money] to get some more [dope]. That's what a coke addict does, smokes 24 hours a day (007 paraphrased).

\section{(iii) Choice}

An individual living with substance use may continue using substances even though he has come to realize drug use is no longer working in his favour (i.e., abating negative feelings; avoidance). At this point, he may attempt to quit, but because all his "beliefs, values, habits, and physiological responses" are intricately woven, the pull toward using substances may be "quite powerful" (Schaler, 2007, p.xvi-xvii). The participants expressed various views regarding choice and substance use. Some men felt they had a choice whether to use or not, others felt that through abstinence they had gained freedom to choose alternative ways of living, still others felt they had a choice regarding pursuing addiction treatment or continued substance use.

You could be ten years clean - live a great life for those ten years, make a wrong choice, use that night, and it's over. [The] disease is very cunning and if you don't stay on top of it you know what I mean, if you don't have a foundation that is very strong... [you will relapse]. That's real, right? I don't want to ever feel the way I felt shooting in my arm, living in crack houses, pretty much doing whatever to stay high. Awful. And I'm not saying that people who relapse are wrong... I just don't want to be that though. It's my choice. 
While physiology or predisposition may influence susceptibility to drug addiction, individual attitudes and choice are motivating factors in the pursuit of substance use (Schaler, 2007). "I think that's where I differ from a lot of the people ... maybe they have been through serious trauma stuff. I don't know; it hasn't surfaced. I think a lot of my stuff has been my choice" (Ed). Choice seems to also be a factor in individual recovery as some LifeHouse participants revealed, "Sobriety has offered a choice", "remember where I've come from, what I've have been through ... [I have] choices" and "I came here to do what I have to do. It's a choice".

According to Schaler (2007) "addiction treatments don't work" (p.4). As well, he questioned Alcoholics Anonymous and other spiritually-principled twelve step recovery models capacity to combat a disease. Moreover, the addicted individual embraces the manifestation of disease because he recognizes his recovery depends upon such acceptance. Individuals need to believe the treatment is going to work in order to be motivated to apply new knowledge and skills. Finagarette (1988) argued individual acceptance of a disease actually provides a choice for treatment whereas a moral failing renders individuals helpless. Schaler (2007) proposed that an individual living with substance use may have an underlying problem that once resolved will be able to overcome addiction. For example Ed reflected, "I learned more about the disease. I'm not so sure about the allergy. I think we all have choices".

In sum, there are different pathways to becoming substance dependent and differing approaches toward becoming substance-free. The LifeHouse program is abstinence-based and requires individuals to participate in a variety of activities thought to promote healthy lifestyle change and balanced living. Those individuals who are 
willing to embrace the ideas presented at LifeHouse and successfully integrate new philosophies into daily living may be equipped with improved capacity for coping. Others who do not fully subscribe to program structure may require future and/or alternative treatment opportunities to facilitate similar coping skills. Individuals are interviewed regarding motivation during the initial assessment phase of treatment. Clearly, individuals exist who may benefit from engaging in treatment, but addiction recovery seems to be most effective for those motivated to change.

\section{(iv) Acceptance}

According to Hayes (2004), acceptance is defined as taking that which is offered. Acceptance can mean different things to different people. For example, the Alcoholics Anonymous text (2001) described acceptance as overcoming an inner disturbance evoked by people, places, things or situations that are not in accordance with individual preferences. Therefore accepting a situation does not preclude being in agreement or liking it. Some LifeHouse participants embraced acceptance as a strategy for coping with substance dependence and abstinence.

I don't think you have to buy into the Higher Power, but realizing you put out the action but you can't control the outcome realizing that the problem is inside of me which is very good because it's the only thing I can change - I can't change you - I can't change the weather but, I can sure change my thinking... I can't control anybody but I can influence people.

I think drug addicts have a better chance at recovery than alcoholics because alcohol is everywhere and acceptable. Where drugs are not acceptable when you are putting a needle in your arm you know you're doing wrong where sitting in a bar having a couple of drinks you don't think you're doing wrong $(\mathrm{Al})$

It is interesting to note that Schaler's (2007) research suggests most [individuals] will mature out of their addiction with the passage of time (p.28). Similarly, Peele (1985) 
suggested individuals with a preference for alcohol may mature out or achieve natural remission. Much has been studied on resiliency and preventative strategies including at risk adolescents and harm reduction strategies. However, such interventions will not be covered here. LifeHouse embraces an abstinence-based program including a twelve-step class. Moreover, many individuals recognized the utility for AA membership as a form of support post-treatment. Support systems will be discussed in ensuing sections of this manuscript.

\section{TRAUMA}

Some participants identified previous traumatic experiences whereas others did not identify traumatic occurrences unfolding in their lives. Still others had experienced events, which may be defined as traumatic by counselors and yet the individuals either did not perceive as traumatic or denied trauma as occurring in their lives. Considered together, the TSI scores clearly depicted trauma symptoms across participants, which suggest at least some coping disturbances.

I don't believe I had trauma, I got beat up by my old man. I protected my brothers. I protected my mother. I consider it a normal reaction to an abnormal situation. Now also because my hometown was immersed in alcohol abuse and it had a very high level and the way the other children were treated it was just the way it were so I didn't consider myself being treated any different. Everybody's old man hit them (Al).

The majority of participants interviewed disclosed traumatic experiences which occurred prior to substance use. LifeHouse residents self-determine an experience as traumatic. Traumatic events included abuse, bullying and accidents which will be explored in more detail below. A few individuals came to the realization they had experienced trauma during childhood but, had not recognized it as such until LifeHouse program exposure. For example, one interviewee related feeling rejected by significant 
others which contributed to low self-esteem. Another individual expressed feeling overly-sensitive to criticism as emerging from a historically critical environment, "I grew up in a family where you didn't talk about anything. I never did deal with it (e.g., trauma)".

A few participants began contemplating the existence of personal trauma while at LifeHouse, "I think that we all do have trauma in our lives if we're willing to search for it". The men identified traumatic effects as feeling helpless, suicidal and disillusioned. Substance use was a coping strategy employed to forget painful events. In some cases, the men denied memories of childhood, "We try to tap into this block - this memory block in my life and I just can't if I pushed it down so much over the years and something happens one day or nothing happens and maybe. There's a bunch of dead time I don't remember in my life".

Gender roles were another factor which contributed to psychological distress,

I'm surprised they didn't have Seeking Safety a long time ago because I've been screwed up for a very long time and a lot of it has to do with trauma and I never dealt with it properly, especially growing up in a family where we didn't talk about anything, especially being the only boy in the family you know - come on tough it up be a man - you don't talk about stuff. You don't cry. And I never talked about it with anybody; never.

One participant described sexual experimentation with other people his age during childhood. While he now recognizes such experiences as common, he previously carried shame for engaging in same gender sexual experiences. Another man revealed he was teased as a child by family members and in the school environment which exacerbated low self-worth. He used fighting as a survival strategy, "I learned how to be aggressive, protect myself, fighting a lot and so that was traumatic". Some men also described 
traumatic experiences while in jail, which encompassed rapes, gangs and fights. As well, two of the men reported being threatened at gun point by dealers.

In addition, the participants spoke of losses experienced over their lifetime. Specifically, the men disclosed loss of relationships with family, partners, and children, loneliness, and broken dreams.

I was mentally, emotionally, but never physically abused. My parents were always fighting. I had no stability. My mom and dad finally breaking up, meeting her husband, moving to a different city away from my family, and bouncing back and forth were all traumatic. I was just devastated at that time (Matt).

One man shared, "I have had a lot of losses; my friends through accidents, suicide and when I was younger; he was 15 and I found him". In addition to accidental deaths (e.g., overdose) and suicide, men recalled motor vehicle accidents that were also considered traumatic.

Taken together, the men's experiences echo the LifeHouse staff's assessment for a need for trauma programming. Traumatic effects were a reoccurring phenomenon among this group. Having a safe forum for which to communicate their experiences was new to the men yet, they expressed trusting rapport with LifeHouse staff. LifeHouse offers a three month core program and follow-up aftercare. Such continuity of care is vital for individuals coping with multiple stressors (i.e., trauma and substance use). Adapting to new situations and developing new strategies for coping not just with current life events (proximal), but also unresolved historical (distal) issues presents distinct recovery challenges. 


\section{SAFETY}

Herman (1997) proposed a clinical environment which embraces safety. Establishing a trusting rapport with trauma survivors is essential to first-stage trauma recovery. The LifeHouse program structure offers a safe refuge free from potentially harmful street life. LifeHouse staff maintain clear boundaries with the participants in an effort to diminish transference and countertransference. As well, staff contain individual disclosure during group sharing while supporting open dialogue in individual counseling. In this way client safety is fostered and trust develops through acceptance and a nonjudgemental attitude. The participants expressed feeling safe and recognized the counselors as supportive and calm. Staff genuineness was highly valued as well. One individual reflected the mutual understanding among the participants that they will be talking with each other and matching level of vulnerability in group, which helped reassure his feeling safe. It is interesting to note that this individual disclosed coming from a family where a no talk rule was firmly in place and yet he feels comfortable sharing with the other participants and counselors at LifeHouse. Some reservation emerged pertaining to new individuals entering the group following a period in stabilization, but who relapsed shortly after entering LifeHouse. While the residents don't always feel connected or share a common bond with each other, they do feel safe discussing the Seeking Safety literature. Accordingly, a lot of what was discussed was surface stuff or pertained to safe coping (e.g., cognitions) and safe behaviour. Conversely, one participant expressed his preference for being completely open with the group yet counselors suggested he disclose less in group and more in individual work. 
The participant had experienced treatment in a different recovery home where complete disclosure had dramatic effect.

Um to be honest, um a couple of staff, I feel, I believe their motives are all right - they're here to help, but whether it's a boundary thing or an ethical thing, I guess I have seen that kind of, but not to the degree of here. There is no emotion do you know what I mean? This is the line but it's pretty good because it's predictable - you're going to get the same answers. It's good, but it's also to connect - trustwise, fully trust it doesn't matter about trust because whether you trust someone or not you've got to do what you've got to do... whether I trust her (the counselor) or like her or not, put what I can into it and she's going to do whatever she can to help. But like it is pretty intimidating because there's no feeling or emotions or you know, certain things. No casual talk you know...just business...I mean talk to us about life, your views, what's your point of view not about what you are supposed to say you know what I mean. It's not like I'm going to...For me anyway, it's important to me - how do you feel about...you know what I mean, that's all. I don't want to know your number, your personal life, but just - what's your opinion? When I ask that [she says,] I'm not inclined to answer that. You know for me it's strange... boundary... I don't know is that just me? (Matt)

Another participant was impressed by the LifeHouse counselors' openness toward new ideas and their provision of different tools. As well he felt the counselors had an opendoor policy.

A participant observed bible study and volunteer work in addition to other programming as keeping him busy and safe from the temptation to use drugs. This is consistent with findings pertaining to heroin addiction recovery and using volunteer work to curtail boredom (Mullen, Hammersley, \& Marriott, 2005). Another individual referred to the Alcoholics Anonymous textbook, "You know in the Big Book it says you know you want to stay safe and not go around to where there might be using and stuff. It tells you in there not that you have to stay away from where there is alcohol....just gotta check your motives before you go there". Overall, the LifeHouse addiction treatment 
program was considered a safe harbour by the participants, "while I'm here there's no triggers for me".

LifeHouse is located downtown in an area where drug and alcohol use is prevalent. The LifeHouse residents could potentially access drugs and witness drug use any time of the day or night. However, some men did not recognize these cues as triggering. For example, one individual had witnessed a group of men sharing a quart of beer. While the image was still in his mind, he denied being triggered claiming he would never behave in a similar fashion (i.e., share his booze). Yet other individuals preferred to alter the route they walked to avoid potentially triggering stimuli (e.g., drug paraphernalia). Relapse prevention includes safety planning such as weekend safety planning. LifeHouse supports the men in creating a daily plan to build in structure and protect against risky situations. As well alternative plans are discussed to guard against unexpected events. Seeking Safety provides such planning tips and alternatives.

\section{(i) Trust}

Matching emotional risk through self-disclosure during group time was perceived as trust-building and therapeutic. As trust developed among group members, feelings of isolation diminished. For some people relating to others helped normalize personal struggles. Others chose not to contribute to the group discussion. One individual speculated lack of sharing was related to trust. Age differences for some of the older guys also presented a trust issue whereas the younger guys saw the older guys as good to share and identify with. "It's really great to have a good group of guys in the house and I don't think it would matter who was in the house I think it would be a good group of guys because we're all in it together we're all brothers". Some participants found 
bonding occurred more in the class room whereas others established a rapport during smoke breaks shared on the front porch. "It is definitely a bonding experience. We bond more in those classes than we do at night."

Another individual preferred to maintain boundaries letting "people in only as much as they have to be". Still another person chose to listen and gauge the group before feeling comfortable. "We all have different backgrounds and different stories, but the feelings and emotions are pretty much the same. Like hurt's hurt right"? LifeHouse staff make every effort to be supportive and allow time for individual contributions. Some men are naturally quiet and more reluctant to jump in. Yet the counselors pause to enable each voice to be heard which has the effect of bolstering confidence and role modeling patience. Self-efficacy and improved frustration tolerance are desired recovery traits.

\section{SEEKING SAFETY}

Seeking Safety was introduced as a cognitive-behavioural therapy to addiction treatment. There is vast literature available asserting cognitive therapy as an effective intervention for addiction (Marlatt \& Donovan, 2005), trauma (Najavits, 2002), depression (Beck, 1967), and schizophrenia (LaFond, 2002; Kingdon \& Turkington, 1994). The LifeHouse participants revealed such psychiatric diagnoses during the interview process. In addition, LifeHouse staff previously assessed for participant trauma symptoms (i.e., assessment and TSI) and determined Seeking Safety might benefit their clients.

LifeHouse staff selected Seeking Safety classes carefully based on the limited timeframe permitted by the three month core treatment and some overlap between features already integrated into LifeHouse program structure. For example, LifeHouse 
has a popular Anger Management class which focuses on similar themes as those presented in Red and Green Flags, Coping with Triggers, and Healing from Anger (Najavits, 2002). In addition, Case Management and Community Resources are a focus of individual counseling sessions. Also, Respecting your Time is offered during reintegration in situations where residents appear to be struggling with less structure. Finally, the Life Choices Game was omitted owing to time constraints. While Seeking Safety pertains to trauma and substance use, the men recalled that trauma was emphasized whereas substance use was not as prevalent.

Generally speaking, the LifeHouse participants recognized the Seeking Safety classes as being offered from genuine caring and concern. The efforts demonstrated by LifeHouse staff were appreciated by the program participants who understood the counselors as promoting positive change. "This course provides insight and just to know "there is a reason that you're not crazy is such a Godsend; that is so helpful". However, in some cases individuals did not identify trauma,

We are obviously here because of substance abuse and we are comfortable with that. I mean sometimes even when the word trauma comes up the group avoids it. Now I don't think I had trauma, but I could see where a drug addict... you know, you wear substance abuse as a badge of honour whereas trauma makes you a victim so screw that (Al).

Still other individuals felt substance use was not sufficiently integrated with the trauma class and that more emphasis on substance use would have increased the utility of the course.

Moreover, some individuals were surprised by Seeking Safety because they entered a drug and alcohol program and did not anticipate experiencing a trauma class. "I had a hard time identifying with this because trauma is different things to different people 
and I think that, teaching us that has really had an impact in what I share about because if its important to me well then it's important to me" (Ryan). "If you say you have experienced trauma then you have and that's accepted. That is good because then people don't feel stupid for sharing a little thing" (Steve). Individual participants were encouraged to share their traumatic experiences in a general way while reserving in-depth processes for individual counseling. Learning professional terminology and affirming skills already used were cited as benefits to Seeking Safety participation. One person described the experience of thinking about trauma as painful but helpful in that the issues were normalized through others relating. He felt more positive and a better person for the experience. Others recognized changes in their thinking and behaviour which they attributed to the Seeking Safety classes. Such awareness speaks to the effectiveness of the LifeHouse program and emerging cognitive change.

The men understand the purpose for Seeking Safety; all the different ways possible to stay safe and to think before they act on anything and they also recognize their own power (e.g., empowerment and/or self-regulation). Al reflected, "You can only take the clients where they want to go." Al also cautioned, "The counselors have to be very careful because they are opening doors that they better know how to close them". The men commented on the genuine concern, support and help exemplified by LifeHouse staff. They recognized the effort being channeled into new programs and overall participant wellbeing. The men felt encouraged to follow the program structure because the staff were enthusiastic about the potential participant benefits.

The men gained a better understanding for effects of trauma including feelings of helplessness, depression, suicide ideation, memory suppression, anger and resentment. 
One individual reflected on his childhood, "I'm over sensitive about some things and I know that it comes from criticism." The Big Unit shared he found Seeking Safety classes "purifying and settling to go back into the past and understand why we are the way we are." The men learned their reactions today may be linked to events which occurred in childhood. Prior to treatment, "I felt like killing myself. I just didn't like my life. "I didn't really live. I never really enjoyed life you know. I did survive obviously I'm here". Seeking Safety helped restore hope. "It hurt a lot to stay safe and go back and think about this stuff, but it's really helped me. You have to do it or you're not going to become a better person. You can be positive". One individual commented that practicing Seeking Safety coping strategies is becoming almost habit. "I'm only seeing big major changes in how I think and how I behave." Other individuals expressed Seeking Safety strategies are commonsense and that they "do a lot of this stuff naturally." Yet the same individuals appreciated learning clinical terminology as this might be useful in talking with professionals (i.e., social workers, psychologists, psychiatrists, physicians, and so forth).

While the men found role playing reinforced the ideas presented in Seeking Safety, they felt relating the techniques to safe and unsafe behaviours less worthwhile; "I think that if we didn't do the practical try outs then probably nobody'd try it". The men appreciated the Seeking Safety class; Honesty (Najavits, 2002), identifying the impact of a "web of lies". They recognized the importance of being honest with oneself. Seeking Safety also assisted with diminishing feelings of shame surrounding trauma and substance use," it made me feel what I went through was not that unusual". The men made references to changing their thinking in order to change their (addictive) behaviour, 
which can be interpreted as them understanding the Seeking Safety cognitive premise. Grounding and countering were two key benefits which emerged from Seeking Safety and Anger Management classes. These skills will be discussed in more detail in ensuing sections of this manuscript.

Overall, participants recognized some of their trauma and substance use symptoms diminished by using skills developed through Seeking Safety classes. For example, one man learned to cope with rushing thoughts (e.g., racing and/or overwhelming thoughts) by talking with somebody to regain equilibrium. Learning skills which required action (i.e., talking with a friend, journaling, attending an AA meeting) provided concrete examples for proactive next steps and were easier to implement than attempting to "think myself out of feeling a certain way, which of course is complicated." The same individual learned to be more compassionate with rather than critical of himself. In sum, he learned new ways of relating through new thought processes and new patterns of behaviour. Similarly, another participant gained insight regarding current reactions to certain (triggering) situations as emerging from earlier life events. Such awareness provided a gateway for reassessing the situation with a fresh perspective or perceptual change via the Seeking Safety model.

\section{(i) Feedback for increased effectiveness}

The men identified with and were more attentive to substance abuse information as compared with trauma. The long check-ins and questionnaires pertaining to safe coping detracted from the class. Following through with the homework or commitments (Najavits, 2002) provided practical reinforcement of class materials. Such provision of homework is consistent with the literature which emphasized post-class (e.g., 
extracurricular) skills rehearsal was linked to improved coping (Carroll, Nich, \& Ball, 2005). However, few if any of the men completed these applications. Gonzalez, Schmitz, \& DeLaune (2006) recommended providing rationale for homework completion, exploring barriers to completion and fostering intrinsic motivation toward assignment completion. Reviewing and reinforcing assignments during individual counseling has demonstrated positive treatment outcomes (Gonzalez et al., 2006).

The participants expressed gaining insight to the root causes and conditions beneath the addiction. Seeking Safety seeks to address traumatic experiences, which may have influenced substance use. However, men identify transferring substance dependence to food dependence for example. This is consistent with the literature which described displacing addictions in lieu of uncovering the original problems (Dodes, 2003). One individual made the connection between trauma, substance use, and anger, "I just knew that something was not comfortable inside me and I'd just have to go crazy. You know here it's addressing it, okay you feel this way, but why?" Yet another individual learned that by changing his thinking he could change his behaviour, but did not recognize a link to an earlier event,

You see you act like this, this is your consequence, but they never got in depth like, why'd you act like that in the first place? Now they wouldn't go back and try and figure it out like why are you acting like that? It was almost like don't worry about why you are acting like that - it was think before you act.

Assisting clients in making these connections provide a rationale for Seeking Safety. Increased understanding of the purpose behind treatment may increase client motivation. 


\section{(ii) Program Intensity}

The men expressed a difference between the intensity of Anger Management and the less intense pace associated with Seeking Safety. While the calm atmosphere seems appropriate for a trauma class, the participants seemed to enjoy learning in a more dynamic environment. Some of their comments included references to the classes not being "very powerful" or "powerful enough" but rather "quiet and docile". One individual expressed wanting the class to "hit home", but recognized "a lot of light bulbs haven't gone on".

[Seeking Safety] needs something like thought stopping something that is powerful enough that when you get a thought you can stop. If you brought that mentality into that class you would hit people very hard. And they would really understand why they do what they do. I would grasp it a lot better than just, you know you are using drugs, you went through this, blah blah blah and blah blah. I don't know it sounds like my mom nagging at me.

The men relayed feeling excited leaving other LifeHouse classes and would welcome the same energy being adopted in the Seeking Safety class. Matt said, "There should be more impact on me. A week [between classes] is too far apart".

Treatment is to tackle the hard things. If you're ashamed about so many things you're going to use again; the only way I think it would help is to feel (deal with) the pain and the remorse and the guilt and those things openly you know and some people aren't read for that and some people are and then they pull back, you know what I mean there's different people at different stages.

Some men revealed a preference for discussing more "emotional" and "powerful"

concerns with their "primary counselor 'cause you don't know how the group will perceive what you just said you know react". Individual counseling sessions were emphasized as a safe forum for exploring trauma more in-depth. One-to-ones provide opportunities for the individual to isolate areas that he wishes to talk about and for the 
counselor to "hit it home". "Something I've been able to do in this place is see things at face value and start bringing things slowly to the surface and dealing with them." Taken together, Seeking Safety group classes and individual counseling compliment each other and promote increased opportunities for processing traumatic experiences. "If there are any core problems, then you deal with it on your one on one, talk about it and be honest how you truly feel, but I think talking about it in group it is more effective because there are not two eyes just looking at you, there's 20 eyes" (Matt).

The men often said they intended on checking their notes or planned on referring back to the handouts to prompt recollection of class topics. The quotes, which accompanied the lessons helped with memory recall. Ryan recalled his favourite quote,

Watch your thoughts; they become your words. Watch your words; they become your actions. Watch your actions; they become your habits. Watch your habits; they become your character. Watch your character; it becomes your destiny (Frank Outlaw as quoted in Najavits, 2002, p.244).

However, individuals felt there was an over-reliance on the literature and that more group discussion and role playing would have been useful.

Najavits (2002) outlined "case management strategies" which compliment and reinforce Seeking Safety skills (p.74). For example, the clinician should "have a sense of urgency and concern" in developing measurable and attainable therapeutic goals (p.75). In addition, the clinician should hold the client accountable to reaching them which in turn fosters motivation. This may be challenging to achieve in a group setting and perhaps easier to follow in individual counseling as presented in the Seeking Safety manual. Furthermore, rather than maintaining a neutral stance, Najavits (2002) encouraged clinicians to provide guidance and genuine care (e.g., attunement) for the clients owing to a diminutive inclination to ask for help. 


\section{(iii) Program Initiation / Timing}

Individuals are introduced to Seeking Safety upon entry into the LifeHouse program. While men can remain in stabilization for approximately 30 days, some men revealed experiencing a shorter stay; as few as three days. These individuals described being in "the fog" upon admittance to LifeHouse and as such were not able to absorb much of the information being presented in class. One individual who had been at LifeHouse for 60 days still felt as though the fog had not yet lifted. Apparently one man entered LifeHouse while another individual was sharing his life story. The new person's immediate reaction was, "is this what I'm going to be doing all the time? I can't do that." The men suggested implementing a transition from stabilization into Seeking Safety so "you know what to expect". Ryan suggested "The program should be more repetitive. Not pushed, but repetitive in like ...being totally aware of what you are being taught. ...people are at different stages when they come in - they may be clean but the mind is still clouded". Having people who are at similar stages of recovery might be difficult to structure as there is a constant influx of graduations and new entries. Apparently class discussions including questions, arguments, and cross-talk waste time, which can be frustrating for those trying to learn from the program.

\section{(iv) Memory}

Memory and/or remembering seemed to be a consistent challenge among the participants. Understanding how addiction affects memory is essential to developing effective treatment programs. Memories are developed from experience and become reinforced over time. Memories are encoded as either negative or positive according to individual perception of the stimulus. Memory is effected by chronic substance use and 
stress including post traumatic stress (Rothschild, 2000). Rumination will also exacerbate impaired memory. Post acute withdrawal symptoms will also impede memory for up to one year following substance withdrawal (Hoffman \& Froemke, 2007). It is not surprising that the men expressed difficulty remembering the cognitive strategies presented in the Seeking Safety classes. In some cases the Anger Management skills were recalled as Seeking Safety skills. In any case the men indicated a need for a more dynamic group, repetition, and reinforcement. The individuals who identified specific Seeking Safety classes they had found particularly useful described the class taken during the current week, or classes they had taken more than once. After taking the class a second time the skill was better understood. As well, interacting with the information presented through role plays and practical application helped reinforce the skills rather than just reading the material.

I've worked on it but I can't remember it. I've read on it, worked on it, but if we haven't worked on it for a long time it is hard for me to remember. Whatever we were taught - I remember bits and pieces. I might remember it or something might happen that triggers it which makes me remember what skill we used and I do it, but I haven't practiced it (007).

Many of the men mentioned they wanted to refer to their notes to refresh their memories prior to the interview. The men commented that in certain situations, Seeking Safety skills were recalled. For example one person recalled using the grounding technique of "counting colours" when overwhelmed with "rushing thoughts". Perhaps such skills could be the springboard for reenactments in the class setting, which might provide both an alternative learning method and reinforcement. Physically engaging in the action might have the added effect of cueing thoughts for future interactions. In this way participants might begin generalizing newly acquired skills developed through 
Seeking Safety class participation to outside experiences (Carroll et al., 2005). In addition perhaps the skills could be reinforced by integrating themes with other program classes. For example, Seeking Safety and Anger Management classes seemed to overlap. Indeed, the interviews revealed participants interchanged terms and combined ideas developed in both classes.

Throughout the interviews, when asked about Seeking Safety, the participants referred to and drew comparisons to Anger Management. In particular, they expressed enthusiasm and interest in the delivery and/or presentation of the class. As well the skills acquired by the men seemed to be a blend of Seeking Safety and Anger Management. Moreover, Seeking Safety appeared to compliment and reinforced ideas learned from Anger Management classes. The men speculated that the counselors might be more familiar with the Anger Management Model and some of the men had previous experience with Anger Management classes whereas Seeking Safety is relatively new to both parties.

\section{ANGER MANAGEMENT}

The men would like a more intense trauma program in keeping with the intensity administered in Anger Management. The common refrain seemed to be less emphasis on reading and checking feelings and more emphasis on highlighting the key points. The men wanted to focus on the substance of the course rather than the check-ins, safecoping, and checklists. They wanted to be challenged to follow-through on the commitments. "Most of us have a high-octane life; we want it [the message] to be drilled into our heads" (Ryan). They want the class to be presented in a more "direct" fashion to be able to "grasp" it. 
In addition to Seeking Safety, Anger Management had an effect and was repeatedly referred to as having an impact on thought and behaviour changes. The participants referred to Anger Management and attributed key learning derived from Anger Management classes. "I think there are other programs here that are very powerful. The Anger Management Program for me answered the question why I am the way I am". The Anger Management class was considered "commonsense" and assisted individuals in becoming "patient", "tolerant" and "calm".

While Seeking Safety and Anger Management have a different focus (e.g., trauma versus anger), the men recognized that in some cases their anger has emerged from trauma. They revealed having developed "resentments growing up" and coming into LifeHouse "resenting everything". However, through experiencing LifeHouse, the resentments were diminishing, "I'm finding myself not being so resentful anymore which definitely is life-changing for me. I have a little bit of happiness in my life right now". Another individual recognized his sadness had emerged from unresolved anger connected to past trauma and/or grief, "I punch holes in the walls but it's not because I'm mad it's because I'm sad". Interviews provided context for such strong emotions. For example, this participant had previously shared he has kept everything inside - suppressed his feelings - owing to messages learned in childhood (i.e., don't talk, don't trust, don't feel).

Countering was a specific skill acquired through Anger Management that participants named as particularly useful. Countering was described as a sequence of identifying triggering (angry) feelings, identifying the cause of the emotion and using self-talk to redirect next actions. One participant expressed that with practice countering was becoming more of a habit where he does not need to "fake it" but rather it is 
becoming an "immediate reaction", "I'm only seeing big major changes in how I think and how I behave". The participants recognized living with others can be challenging because conflicts emerge, you can't see yourself, but you see things that tick you off about other people and um that usually means that you have some kind of issue. The men recognize and own underlying character traits which might not have been revealed without group living, "I haven't worked through it yet, but it's really good to see different walks of life too; like respect everybody. You wouldn't normally have anything in common with them, but you have the opportunity to really broaden your opinion and vibe for people". The men learned to be less reactive and impulsive through recognizing concern for others perspectives and perceptions - that people "don't automatically see things the way I do".

Finally, length of class warranted mention, "Like Anger Management there, like the moment we start getting tickled by it you know; class is over". Overall, the participants requested longer classes, but with an added smoke break, "Sometimes there are very emotional things that will pop up and many times with Anger Management especially, I want to go outside and pop, smash, bang. I get scared or angry or hurt and I need to go for a smoke then. I think smokes [cigarette breaks] are a good thing. You know, break it up; move your legs."

Taken together Seeking Safety and Anger Management seem to be the core psychoeducational classes at LifeHouse. While Seeking Safety aims to provide some catharsis, it is limited owing to the group context and counselors containing tender issues. The men have acquired a skills base, which provides alternatives for coping with previously stressful and/or triggering situations. The challenge for the men is their 
motivation to change - to choose these coping strategies over substances, which are familiar and requires less effort. Program effectiveness is demonstrated by the men's articulation of acquired skills. The participants also offered suggestions for program improvements.

\section{SKILLS}

The skills men learned in LifeHouse emerged from Seeking Safety and Anger Management. In fact there seemed to be interplay among these two classes which compliment each other and could perhaps be organized to reinforce each other. As well, the participants of this study emphasized thought-related skills as most valuable, which is interesting as Seeking Safety is a cognitive therapy which aims to reframe thinking connected to substance use and trauma. I have organized the skills into six subcategories as follows: (1) grounding to the here and now, (2) asking for help, (3) self-care, (4) thought-stopping, (5) self-awareness, and (6) relaxation. Relaxation has emerged in relation to mindfulness, the most recent LifeHouse program initiative.

While the men disclosed they had previously acquired some of the skills presented in Seeking Safety, the classes put names to the skills, which clarified their meaning. The men said the skills can be used "to take your mind off what you are actually feeling". For example, one individual holds onto something that is personally valuable - the key tag presented at Narcotics Anonymous meetings which represents 30 days clean, or a photograph of a loved one. When faced with an unsafe situation, these items help him remember where he's come from and what he's been through before he makes a choice for next steps. Some of the common skills which emerged included improved self-talk by either "changing the tape" or "talking to yourself compassionately" 
or reading recovery literature. As well, changing thinking, taking ownership (taking your part), talking about it (phoning people, going to an AA meeting, journaling), and asking for help were noted as beneficial recovery skills. In addition, there are certain skills that bring individuals back into the moment (i.e., grounding and breathing).

I don't think you have to buy into the Higher Power, but realizing you put out the action but you can't control the outcome. Realizing that the problem is inside of me which is very good because it's the only thing I can change; I can't change you, I can't change the weather, but I can sure change my thinking. Fortunately you are able to pick your own higher power from your own choice.

\section{(i) Grounding to the here and now}

The men interviewed highlighted Detaching from Emotional Pain (Grounding) as the most valuable Seeking Safety class experienced (Najavits, 2002, p.125). Grounding is also referred to as centering, distracting, and/or healthy detaching (Najavits, 2002) from emotional triggers. Grounding is considered a straightforward technique that with practice has been useful in coping with PTSD. Grounding is also thought to be useful in diffusing emotional triggers associated with drug use. Clearly, in order to apply grounding strategies, individuals must first be aware of their triggers. Typical triggers included bars, drug paraphernalia, or witnessing drug use. Withdrawal (Sofuoglu et al., 2005), negative emotions (Baker, Piper, McCarthy, Majeskie \& Fiore, 2004) and selfdefeating thoughts have also been recognized as triggering relapse (Witkiewitz \& Marlatt, 2004). Dodes (2002) asserted that a decision to drink or use drugs emerges out of a sense of helplessness or lack of control with another facet of the substance user's life and that the decision to initiate drinking or using becomes empowering.

While the skill, grounding was presented according to three types (i.e., mental, physical, and soothing; Najavits, 2002), the men emphasized physical and mental 
grounding applications. For example, Ty shared, "I think grounding is very important because it's in the moment. One of the [skills] was physical grounding where you touch something" (e.g., the floor). The next step in physical grounding included connecting the individual to the ground or another object through touch as a way to (re)focus thinking on the here and now or present. Mental grounding involves surveying immediate surroundings for example, "I'm sitting there and my name is [...], 'kay there's my chair, 'kay there's metal there, there's a knot there (e.g., mental grounding). You start thinking about using then [look outward] there's a computer, there's a lamp, there's a calendar, there's a clock you know things like that". Clearly, grounding was a skill the men embraced and demonstrated with competence. Grounding required an immediate action, which seemed easier for the men to recall than some of the other concepts presented through cognitive therapy.

A few of the men mentioned experiencing rushing thoughts (e.g., racing or overwhelming thoughts). These men applied Seeking Safety skills by recognizing the overwhelming thoughts were temporary and using self-talk as a soothing grounding technique to get through the uncomfortable moment and move on.

One thing I know is that triggers are mostly emotions or feelings and the one thing that helps me the most - no matter how strong they are or how weak they are or what it is - knowing that they won't last... Sometimes they last longer than others... but I think the only reason that they last longer than others is because I don't talk about it. You know talking about it right away, journaling about it, pray, talk to a different person...

Another individual experienced 'using' dreams, and used self-soothing techniques to become grounded (i.e., achieve equilibrium). Ty expressed using the soothing grounding technique, "put yourself in a happy place". Thinking about some favourite pastimes or comfort items was noted as a strategy for implementing soothing grounding. Ty has 
found listening to favourite music helped distract from negative people, places, situations, and moods. In sum, this Seeking Safety skill aims to help individuals recognize that negative feelings are temporary and do pass; that the individual is in control of his thinking and can overcome negative feelings by redirecting his thoughts (Najavits, 2002). Accordingly, some of the men use counting as a soothing grounding technique,

I count cars you know when I'm walking down the street or getting funny feelings or anything. I count my fingers. I count whatever is there when the thought comes up. I do things like that and the thought's gone again you know. And then you're back on your beam so to speak. And the more I do that the easier it is (007).

Clearly, grounding strategies are left to individual interpretation and definitely require rehearsal. Different stressors provoke varying degrees of perceived pressure where individuals may have to expend increased energy and concentration to be able to overcome triggering situations. A willingness to practice, reinforced through role play might increase the utility of this exercise.

\section{(ii) Asking for help}

Asking for Help (Najavits, 2002, p. 164) and talking about thoughts and/or feelings were also mentioned as useful skills acquired through the LifeHouse program. For example, Matt said "the one thing that stands out - how to ask for help. It is not easy for me to come out and ask because sometimes I don't know exactly what to ask for and I don't know if it's the right person to ask for help from or the right time". Asking for help is linked to trust. Individuals who have experienced trauma may not have received the support needed at the time of the traumatic event, or may have been taught - don't talk, don't trust, don't feel - through messages modeled in their families of origin (Najavits, 2002). In some cases it is easier to ask for help from virtual strangers (i.e., at 
an AA meeting) or while in LifeHouse, the addiction counselors. Asking for help is connected to boundary-setting in that individuals need to discern appropriate people, places and times for personal sharing. Developing the skill for asking for help requires taking risks therefore; practice acquired through role plays is thought to be particularly useful. Role plays help individuals consider a plan including who he will talk to, what he will say, predict outcomes, and recognize the reality (Najavits, 2002). Indeed, individuals who request assistance from others are motivated to change.

(iii) Self-care

Seeking Safety acknowledges themes including Taking Good Care of Yourself, p.174; Compassion, (p.182); and Self-Nurturing, (p. 337) as integral to healing from trauma and substance use. LifeHouse residents emphasized thought-altering themes more so than self-care strategies however; the following points were raised during interviews:

The Seeking Safety classes provide coping strategies for "how to deal with problems, but at the same time not to feel bad about yourself" (Cosmo). "We learned how we need to be more compassionate with ourself and learn to love ourself and forgive ourself and forgive others as well. I really like that part". Others echoed Cosmo's observations pertaining to forgiving self and others as a way to heal from trauma and substance use. One individual related his experience with shame and guilt to forgiveness. He explained guilt as a personal feeling for a wrong done to others whereas shame is a consequence to being humiliated by others. Ultimately he is learning to forgive himself by recognizing his reactions are linked to his childhood environment and development, "some of those coping methods really don't work and that's why I'm at LifeHouse" (The Big Unit). Guilt was perceived as being more readily overcome than shame. For 
example, The Big Unit spoke of making amends to others he had harmed saying, "it might be a big deal in my mind but the other person has probably forgot about it". Talking about healing from shame was understood as a deeper issue and was therefore not discussed during the interview. The process of coming to love oneself, seems connected to forgiving oneself and achieved through positive self-talk (i.e., developing compassion for oneself). Gerzon (1997) for example, discussed the impact of positive affirmations as compared with negative self-talk. Negative self-talk emerges as a consequence to individual automatic thoughts stemming from core beliefs (Beck, 1995). Indeed, Seeking Safety aims to equip individuals with coping strategies which foster healthy belief systems and improved cognitions through adapting self-talk. Adapting selftalk requires practice and includes using kinder more respectful language as if talking to a child who has made a mistake (Najavits, 2002,).

\section{(iv) Thought stopping}

Thought stopping is presented here as connected to tapes or scripts. Tapes (automatic thoughts) are considered analogous to self-talk (Beck, 1995). Negative selftalk is rooted to core beliefs developed and reinforced in childhood (Briere, 2002). The men are developing skills to interrupt thoughts (e.g., "thought stopping") and reframe the thought (e.g., "flip the thoughts") from perceptions of worthlessness to affirming selftalk. One individual expressed "half the battle is recognizing those tapes, which is identifying feelings, crap and the other part is really being able to counter that tape." Matt provided a practical application for thought interruption/thought stopping - he described going to Loeb to buy a cake mix - reciting all the steps necessary - "I'll just go to IGA to buy a flour mix and I'll need some money, just a second where's my bank card, 
do you know what I mean just whatever, do you know what I mean? That's a skill". For example, Matt may have experienced difficulty cooking the dinner for the other guys in LifeHouse. He may have become self-critical remarking, "He is so stupid". This remark may be reminiscent of his childhood where he was told he was stupid and would never do anything right. At this juncture, Matt would become aware and stop the negative self-talk or old tape. The cake mix sequence helps distract thoughts, which provides Matt with an opportunity to change his outlook to more positive messages. Such techniques are consistent with Beck (1995) who outlined a step by step cognitive format for reframing automatic thoughts.

\section{(v) Self-awareness}

Seeking Safety classes helped foster improved self-talk. One individual commented, "You have to treat yourself better inside and the outside, the outside will come", which he recalled from a quote taken from the Seeking Safety class, "If we change within, our outer life will change also" (Jean Shinoda Bolen as quoted in Najavits, 2002, p.331). While some of the men expressed their intention to revisit Seeking Safety classes during reintegration and aftercare, to date nobody has repeated the classes. While living in LifeHouse, the men avoid "high risk situations" and therefore may not have the opportunity to practice all the Seeking Safety skills. Overall, the participants recognized developing more tolerance and an open mind as beneficial to treatment. Such selfawareness helped participants gain a sense of humour and a broader life perspective "like it is not everybody else in the world that's the problem, it's me, and ah it's not a series of unfortunate occurrences". One man owned "self-created chaos." 
Some of the specific skills which emerged from Anger Management classes, but were associated with Seeking Safety as well included countering, which involved first identifying a using thought or negative feeling and second, flipping it to a contrary positive statement. Another skill was known among the men as "emptying the slush bucket or flushing the toilet", which was described as not allowing negative feelings to build up and overflow, but rather talk about them to keep emotional health in balance. Employing acronyms were useful to some for example, "HALT which means hungry, angry, lonely, and tired". One individual referred to a handout which included 27 emotions, "I never even knew there was 27 emotions. So I check them off each day. What did I feel today? Why did I feel that?" Clearly, LifeHouse participants have gathered some skills through program participation, which they have found effective in diminishing negative affect and substance use. Greater insight might be attributed to motivation and/or improved brain functioning as a consequence to arrested substance use.

\section{(vi) Relaxation}

Mindfulness has received increasing attention for health benefits including stress reduction. LifeHouse's recently implemented mindfulness class has been received well by the residents. "There's another class here called mindfulness". Mindfulness compliments the Seeking Safety notion "of trying to stay in the moment" which The Big Unit commented is his "biggest problem; focus[ing] on the moment [because I'm] feeling guilty about the past or worrying about the future or worrying about things I really don't need to worry about". The men are also participating in yoga classes as part of mindfulness practice. Ty uses music to just "zone out' and "think about good things, think about the future, think about you know where I'm going to be next week" as a way 
of achieving positive thoughts and relaxation. Relaxation achieved through mindfulness helps the mind slow down. The brain releases endorphins and enkephalins which help soothe and further heal the mind.

\section{MOTIVATION}

Drinking alcohol or using substances has been described as an action and intentional behaviour (Schaler, 2007). An intended action implies choice and therefore dismisses alcoholism and/or addiction as a disease. Dodes (2002) asserts addiction emerges from a psychological drive toward substances, initiated by free-will as compensation for perceived inadequacies. Whether one argues addiction is a disease or not; sustained recovery requires motivation. Treatment is not necessarily for those who need it, but for those that want it. Indeed, LifeHouse participants commented that any program will work if you believe, desire, and are willing to do the work.

\section{(i) Willingness}

Demonstrating willingness toward changing thinking and behaviour (abstaining from drug use) is observed and noted during the initial LifeHouse intake process. Individual willingness to engage in treatment is a key factor in addiction recovery. Participants agreed, referring to individual "mindset" or "determination" as a factor in overcoming addiction. The men emphasized, "to try to quit" because "you get out what you put in... if you put in a $100 \%$, you get a $100 \%$ back." One individual expressed that by giving his all, paying attention during classes, communicating feelings and thoughts he might avoid experiencing the pain of relapse. Other individuals described a willingness to "dig trenches", "scrub the floor with a toothbrush", and even "push a stick across the ground with my nose" if that would help sustain their clean time. While 
LifeHouse does not endorse self-degrading tasks, volunteer work and community service work were considered a way to "get our minds off ourselves". In addition to willingness, treatment readiness was acknowledged as a factor in individual recovery, "I think any program will work if you are ready to work it. I don't think it is necessarily the program. [LifeHouse] is a good program, but I don't think it's the program that makes the person recover, [but rather] whether they are ready or not". Indeed, LifeHouse provides the men with current and innovative treatment strategies. The staff also has a sincere desire to offer the men counseling support and program structure that will facilitate effective treatment.

\section{(ii) Practice}

Implementing or practicing the skills developed through LifeHouse was essential to change.

If I don't put something into action then I haven't learned anything. I can say I've learned a few things because I'll notice I'll be in bed at night and I'll be using the grounding techniques and I'll be using Anger Management tactics for something. As long as I apply these things to my life, it can only get better. If I stop doing the things that I've been doing now then I'm sure it will stop (Ty).

Obviously individuals who are proactive regarding recovery sustain abstinence. Journaling, talking with others, and developing a spiritual program through fellowship in AA, NA and/or a church group enhance new ways of thinking and behaving. Furthermore, establishing structure through routine is considered a mainstay of addiction recovery.

\section{(iii) Routine}

Formulating a daily plan helped develop structure and organizational skills. The men expressed the importance of balanced living; physically, mentally, emotionally and 
spiritually. Taken together, a balanced life was described as a healthy foundation for sustained recovery. The participants visited the gym for physical activity, aimed to eat properly, and established a regular sleeping routine. The men were also encouraged to develop hobbies to fill their leisure time. For example, LifeHouse staff has a self-help library available to the men where they are encouraged to select a book and complete it prior to program graduation. One man proudly shared with me that he had read his first complete book while at LifeHouse. In addition, LifeHouse staff have offered alternative types of support including art therapy and cooking classes, which may inspire continued interest for some. A few of the participants owned guitars and played music while at LifeHouse. Emotional growth is fostered through self-examination. Mindfulness and yoga practices as well as chapel services are available for spiritual development.

Physically, I go the gym that helps out. Emotionally, I talk about my problems. Mentally, I'm learning to read - I'm not learning to read but I'm actively reading. And Spiritually, I'm trying to understand who I am so...sometimes people in NA don't have the answer; your friends don't have the answer. Like I can't go to NA and ask about the bible. So if I come to fellowship in a church where someone knows the bible and is interested in it then I can go up to them and ask them. That' helped me - it has already. All those things are helping me (Matt).

A routine, which encompasses a holistic approach, is developed with each individual while at LifeHouse. It is hoped the men will continue such daily practice as they reintegrate into the community.

\section{(iv) Desperation / Hitting Bottom}

The men noted that recalling the quality of their lives while living with active addiction was a motivating factor in remaining substance-free. They recounted losing relationships, jobs and material possessions, and having health complications as a result of drug use. Where the men had initially used alcohol and other drugs to build inner 
"courage", "self-confidence", and "self-esteem" they spoke of the "progression" of alcohol and drug use, which dominated other aspects of their lives.

Marijuana was fine. I could get up and be walking around, play my guitar, get into drawing you know. With marijuana I loved it when 1 was younger. I lived for it. Ha ha - I thought it was the magic drug. You know I thought it made me an artist. I thought it made me play guitar like Stevie Ray Vaughan (007).

I had like some debts to pay off so I was working fulltime and I lived... I couch crashed... I stayed in and out of the men's shelter um grinded it out without a place even though I worked fulltime. It's funny cause the money that I saved on rent I used on eating out and it almost worked out to the same amount of money (The Big Unit).

I'm tired you know. 28 years old and tired it says a lot in itself. I want to move forward in life. I want to do something. I'm not exactly sure what, but I want to do something. I want to be able to help out. Give back what I have taken over the years. I don't want to ever feel the way I felt shooting in my arm, living in crack houses, pretty much doing whatever to stay high.

Such past negative experience has helped some individuals to commit to a recovery program, "I've had enough of the insanity, seen too much stuff, I've done too much drugs, and I just hate it". In some cases, the guys remembered the friends they have lost to drug overdoses and HIV/AIDS. Pursuing recovery is perceived as honouring these friendships. One individual also volunteers at a drop in for individuals living with HIV/AIDS because it helps him recognize the reality, "that could be me".

\section{(v) Relationships}

Perhaps connected to the loss of relationships was a desire to rebuild or foster trusting connections with others. The participants discussed maintaining relationships with the counselors and other supports in the area, which they anticipate will have a positive influence in sustaining sobriety. The men seemed fairly realistic in recognizing that trust among family and friends takes time to develop. Clearly relationships with 
their children were important. The men talked about being role models, and support for their children as they grow up. I just want to give to my daughter something that I didn't get. While some individuals wanted to get clean and sober to be better fathers one man considered,

I love my kids, I loved them as well when I was using before so my kids can't be that powerful thing anymore. So like I have to say really God and self-will. Because I can not end up back down there. I can never get back to drugs, and crack is not an option. I can never, never, never, ever. Um like I don't want to destroy my life again (Ryan).

The residents I interviewed expressed a sincere desire to remain substance-free. However, literature by Hoffman \& Froemke (2007) suggests many of the wellintentioned do relapse.

\section{(vi) Higher Power / Church}

The pull toward substances is strong so often people turn to faith in the belief that a Higher Power might provide a reprieve. According to Vaillant (1995), abstinence requires individual discovery for a substance replacement. For example, associating substance use to negative experiences, developing a social support network, and cultivating hope through spirituality. Spirituality is a fairly new term emerging in social work literature and is distinguished from religion. Whereas religion may include spiritual practices including rituals and customs, spirituality encompasses a broad range of religious beliefs according to individual perspectives (Leigh, Bowen, \& Marlatt, 2005). LifeHouse offers opportunities for participants to explore spirituality through bible study, chapel service and AA's twelve steps. Addiction recovery through AA is offered as a daily reprieve contingent on one's spiritual condition (AA, 2001). Kaminer (1993) observed twelve-step groups and noted individual eagerness to believe in a Higher 
Power. Spiritual beliefs may also substitute for substances in that individual attention is distracted from alcohol and drugs.

Attendance at Bible Study and Chapel is a mandatory aspect of the LifeHouse program. "These sessions are [Christian-based] interdenominational and are not designed to 'convert' participants but rather provide an introduction to spirituality. We have had men from all walks of faith enjoy and learn in these sessions. The greater concern from our end is participants that have been victimized by members of the church not feeling safe" (LifeHouse staff member). The men seemed to accept chapel attendance and shared that the bible study class seemed to be more of a general discussion rather than pertaining to bible readings. To elaborate, the men described bible study classes as providing "a thought for the day" and a forum for "open conversation on health, hope, faith, peace and war". Bible study was also linked to daily living according to scripture. One fellow commented,

It just gives people a chance to disclose some spiritual progress and get some insight into the word, God. People don't necessarily have to acknowledge their Higher Power. Why not believe in it? You know it's so much less stressful than if you don't believe in God and... and we can't do anything right apparently ha ha so we're powerless over our addiction; we know that.

Powerlessness was linked to contact with a Higher Power, which is certainly associated with twelve step programs. However, at least one individual developed a more secular belief system, which worked for him. LifeHouse staff are from diverse backgrounds. Moreover, there does not appear to be any pressure to convert or even adopt a faith. There exists different avenues for addiction recovery and some include adopting a faithbased set of principles. Whatever process motivates people toward change warrants merit including religion, spirituality and faith. 
Most of the men identified as growing up in Christian families. One fellow described his family as embracing spiritual principles (e.g., "the golden rule, do unto others"), but not being anchored to one particular faith. "I always believed in God. I've always had a God relationship. I haven't practiced it a lot throughout the years, but I've always talked to God and always believed there is a God and that someday it would all work itself out". "I do have good faith."

The men demonstrated a belief in a Higher Power by interpreting messages as God's will. For example one man talked about his daughter who encouraged him to stay in Ottawa to get well even though remaining in Ottawa would mean they would not see each other as frequently. The man interpreted this interaction as "The Higher Power working through my little girl".

It all has to do with letting a Higher Power [of your own choice] into your life. To restore my peace and to give me the promises. And the promises mean those things like joy and peace and you know all those things. And to me that is the only way to recovery. This program just allows you to break down and put things into manageable parts. It doesn't work for everyone, but for someone like me...I definitely think it is a great thing to have in any program.

I pray every night and every morning. I pray everyday. Twice a day and that's not me... I came here with the intent of giving it a $100 \%$ and if it doesn't work I have no problem dying on drugs. Like I didn't want to come here at all, but I figured I should because I had some kind of guilt when I was out there using. Once I stayed clean I said well let's give it $100 \%$ and if it doesn't work then I won't get depressed about being high all the time anymore. That's why I'm here... but it's working! I feel really, really good and that's not me. I don't pray. I don't want to be clean, but now I do? I think that's why these people talk about spiritual awakenings because there is nothing else that could make me the way I am right now (Steve).

Individual sobriety becomes related to the strength of their belief. Indeed, developing spiritual beliefs can foster hope through self-acceptance. As well, a spiritually principled 
life promotes cognitive change (i.e., changed attitudes through embracing spiritual principles).

\section{(vii) Fellowship}

The men described Alcoholics Anonymous (AA) and Narcotics Anonymous (NA) as providing a network of social support. Such fellowship commenced while residing in LifeHouse, but extends beyond addiction treatment programming. In this way, the men view $\mathrm{AA}$ and/or NA membership as adding an important cornerstone to recovery through continued support. While LifeHouse provides an aftercare program, some of the men planned to relocate and see AA and/or NA as helping them remain abstinent, "AA has really been the solution for me".

I've found there's a lot of similarities to what they teach us here (at LifeHouse) and what I do at the meetings, but the meetings is where I have to focus all my attention because these people are not going to be here for me in Ottawa, but they (AA) will so. I never got anything out of AA meetings before in my life until right now and I can't describe it.

The men described feelings of hope and inspiration linked to meeting other individuals who have overcome addictions, listening to stories of life changes, observing smiling faces and warm embraces,

I really see people that have made many differences in their life - good people there who have made it. You know, that's why I want to go. Because it's good people. And then watching the fellowship, hugging each other, seeming happy, you know smiles on their face and pretty cool - sharing their feelings um people talking about the gifts of recovery cause they stayed clean and talking about the things that have happened in their lives.

Benefits of the program are thought to emerge through working the twelve steps with the help of a sponsor. "There's a twelve-step process that guarantees if you work those steps your life will change and apparently you can't imagine". 
I went to the right meetings because it took awhile to find the right meetings where there was some good sobriety and people were talking about step stuff you know. It just seeing that people who were sober had made it you know. It was a big influence for me it kept me going you know. It definitely has been a vital necessity for me. AA meetings. Especially just for the fellowship to feel belonging.

The fellowship offered through meeting attendance is considered valuable because people identify with each others' experiences and offer support, "Like my Dad once told me, life is too short to make all the mistakes yourself, why not learn from someone else. You just learn from people who have been there" (Ty). The participants share a general consensus that $\mathrm{AA}$ and NA members share similar substance using histories therefore can relate to each other. They recognize AA and NA as a fellowship of people living with recovery and willing to help others along. People have had success by living the AA program, "so why not hang out with people that have gone there and who are where you want to be and who can relate to who you are and care about you and if you want to change they're the ones that are going to live it and know how to get there."

Initially the men had reservations about $\mathrm{AA}$ and/or NA meeting attendance. A common perception "was a bunch of people sitting in a circle, bitching about how they couldn't drink anymore". Typically AA and NA meetings are open to men and women. Therefore another attraction to the meetings is for social activity dubbed mating and dating. The men talked about feelings of loneliness.

At the beginning I went to the meetings because of the girls, but if that got me to a meeting then that's what kept me clean, but then I learned there was more to it. There are girls you can become friends with actually. 'Cause loneliness is another thing that is hard, you know what I mean. You can always go for a walk with a girl or go to a movie with a girl. You don't actually have to have anything but that. I've never experienced that before. So there's sorta a few girls that I like that are there for me you know what I mean like who are there to pick up the phone. Guys are not always easy to talk to. There's so many things you know. I've always 
grown up around women. I feel more comfortable. I can be more myself. (Matt)

"Every time I go to a meeting I kinda drag myself there, but I get there, I get involved, I leave, I feel so much better, peaceful. I feel great!"

In addition to self-help group support, the men find support through friends and family, spiritual advisors, counselors and even former school teachers. Some individuals have realized that returning to the city where they were previously using substances may threaten their sobriety and so have opted to stay in Ottawa, "This is where I need to be; Ottawa. I have a support system here." "I've made the decision that Ottawa is where I need to be to change my life. I can't do it back home". If I stay on this path a lot of friends I've deserted will be there for me. My family will support me". In sum, the men recognize that changing the people they associate with and developing a positive support system is an essential part of their recovery program.

\section{(viii) Change}

Recovery from addiction requires individuals to make many changes in their lives. Obviously, they need to change their environment including friends and where they spend leisure time. Developing coping strategies and self-regulation techniques are also required. Often, developing new ways of managing problems and feelings take time to cultivate. Addiction treatment programs aim to provide a safe, supportive environment in which to change thinking and behaving. "I think I'm confidant and strong, but also afraid you know of change. I came here to do what I have to do. It's a choice." "There's a twelve-step process that guarantees if you work those steps your life will change and apparently you can't imagine." The men have spent time reflecting and developing a new outlook toward life. With a new awareness has come the realization that they can 
control and change their attitudes to better cope with life. Seeking Safety is a cognitive therapy, which aims to reframe thinking, core beliefs, and attitudes. One individual recalled, “...realizing you put out the action but you can't control the outcome, realizing that the problem is inside of me which is very good because it's the only thing I can change I can't change you I can't change the weather but I can sure change my thinking."

You know it came to me I had almost an epiphany one day it was like, people don't change, you just stop being the person you'd been pretending to be for so long. Because I was a good person. I've always been a good person, but I did bad things, made bad decisions in life. You know we make 5000 decisions a day or more and I made a lot of bad ones. You know, it doesn't make me a bad person. Um but I think over the years, with living on the street, doing what I had to do I created this persona. I created a person that doesn't even exist you know. And so when I thought about it one day you know I don't have to change, I just have to drop this arsehole or jerk that I've created and the real Ty will come out. And that's what I've been able to - you know I could go on forever about how much I've changed in this place you know. And many times through this place I've felt like leaving, eh. I didn't believe what the counselors were telling me; and I didn't believe this and I didn't believe that. I just thank God that I stayed it through because the things I never thought, I never thought these things would happen - you know, you don't see them, you don't know they're coming - you don't know when you're going to change you know (Ty).

The men are more conscious of patience, tolerance and consideration toward others rather than being focused on themselves and personal troubles. "I couldn't do that before. I always had to push people and push people and try to solve problems". The men commented that they are increasingly content with themselves and no longer demanding to be the centre of attention. As well, the men felt more at ease spending time on their own (e.g., reading, or going to bed early), rather than needing constant interaction with others. In addition the participants were contemplating goals for their futures. "I'm not entirely changed, but I mean the program has given me the time to work on a lot of things. So I see myself as a calm much calmer individual who does not 
feel he has to result to using (substances) to solve his problems." "My life is changing through sobriety and the LifeHouse program. I am definitely not so negative. I was down on myself all the time. It's like all that false pressure is gone." "Like everything's changed about you and it's really good and your eyes are clear and you seem together and you know what I mean. And the thing that I found that I noticed about myself is the selftalk's improving and the counter, like the countering, like before I'd snap. So, l'm only seeing big major changes in how I think and how I behave".

The men mentioned feelings of anger and frustration are diminishing in relation to patience and tolerance increasing. "I'm finding myself not being so resentful anymore which is definitely life-changing for me. I have a little bit of happiness in my life right now. And I know it is only going to get better. ...you know I could go on forever about how much I've changed in this place. And many times through this place I've felt like leaving eh - you don't know when you're going to change" (Ty). The guys examine their motives when feelings of anger emerge as a means of self examination and to reduce substance use cravings.

The men truly recognized their own growth and recovery progress with the admittance of new people arriving from stabilization. Their initial reaction was "almost quick to judge", but then they realized, "that was me three months ago, which helped me realize what I've done to change".

\section{(ix) Education /Work}

Surprisingly, education and work was not an expressed motivating factor for sustained abstinence. Few of the men mentioned careers, retraining, or education. A couple of the younger men spoke of going to college and studying to become counselors 
themselves. Education and employment were also linked to broadening support systems. One individual was looking forward to returning to a position he had held for numerous years. A few men chose volunteer positions that were either related to work they had performed in the past or were jobs they envisioned attaining in the future. One individual spoke of acquiring a trade as a young adult that he wished to return to following treatment.

\section{(x) Hobbies}

The men at LifeHouse are encouraged to find hobbies to help balance their leisure time and give them pleasure. One individual spoke of building model cars when he was younger. Another individual selected art classes and even contributed to the mural painted on the Mission chapel wall. "Just going to [AA and/or NA] meetings isn't my style. I like doing art; it takes me out of myself. It helps me". A few guys played the guitar and sang while others preferred to write. Someone else embraced the idea for studying languages. Yoga classes were recently implemented at LifeHouse which some of the men mentioned. "I have so many things I would like to do it would be like limitless". Good, "clean fun" is something the men would like to participate in. One enthusiastic individual hopes to "make a motivational tape for myself" because he is confident in his ability to motivate others and would like to improve his self-talk through encouraging self-affirmations.

\section{(xi) Volunteerism}

While some of the men appreciated the opportunity to give back to the community via volunteer work, choosing places that had personal meaning for them, most of the men had difficulty with the notion of "forced volunteerism". One man 
offered, "We're not really allowed to volunteer - we are forced to volunteer", but I think that's great. Honestly - to give back to the community. I think everyone should give back to the community somewhere. ...I don't like the way they got it now where people got to do it all on their own time." Another individual expressed his views as,

Ah working for free. I've never really had a job. I did a good job and didn't even get paid. That's a moral-builder. And then when you start getting paid for a company then maybe you'll really enjoy it. It's good that they (LifeHouse) force you to do it 'cause I hate working I really do; and for free, I actually feel good after I do it... and you get used to it, right? It feels kind of like having an ego like working for free you go around telling people that you are working for free...(Cosmo).

According to one individual there is an intrinsic reward associated with altruistic gestures including volunteerism, "I've volunteered all my life and I disagree with being forced to volunteer. That's my opinion 'cause it's not volunteer work. I think it's an excellent idea - I volunteered before and I'll volunteer after 'cause I think there's a payback and it makes you feel good"'(Al).

The men were somewhat upset by a recent change in the program schedule, which required a shift in volunteer commitments. The schedule change interfered with some people's initial placements so that they needed to search out alternatives.

The [place I originally volunteered is] only open during the day and they (LifeHouse staff) have changed all the schedules around so I'm not able to do that anymore and it's a pain in the ass. But if they give us time like they did in the past it would be a lot better. Because now it (volunteering) is more of a chore than anything. At least give us one afternoon in the week to have free time. They give us free time, but they want us to volunteer for two hours and by the time we get over there...it's not working out very well. So I'm very frustrated with the program because of that.

\footnotetext{
${ }^{17}$ It is noteworthy to mention that "force" is understood to mean that the men are required to volunteer as a component of the LifeHouse Addiction Treatment Program, which ought not be confused with coercion or physical force.
} 
The schedule change was owing to a mindfulness class recently initiated at LifeHouse, which appeals to some of the men. However, some of the men are finding it challenging to organize AA and/or NA meeting attendance, sponsorship-meetings, and volunteer work around the new schedule expressing that daytime volunteer hours provided more variety and opportunities to connect to future work (e.g., "more towards my future"). "I wish they (LifeHouse staff) were more flexible instead of painting us all the same colour. I can see some people need rigidity and other people need flexibility. But they treat us the same right across the board."

In addition to being kept busy and having an opportunity to give back to the community, a secondary benefit emerged for some individuals who found support systems within the agency they serviced. As well, the men offered the experience of volunteering has helped them develop humility, "It's humbled me that I can walk into a church and ask can I help you for two hours?"

The men transition to a reintegration phase following core treatment. During integration the men have more freedom owing to fewer classes. Increased free time is an opportunity for the participants to plan their time and apply new skills to real life situations while still living in a supportive environment. One individual recognized the degree of personal change in accordance with patience and tolerance developed for new LifeHouse residents. Such self-awareness made him conscious of the ongoing dedication required to stay on track, "Cause a lot of the times you'll go through life and change and you don't even know you have. And then you'll end up being the same person you were slowly but surely if you don't, you know, keep working whatever it is you're working. 


\section{(xii) Growing / Growth}

Some individuals believed they were outgrowing substance use perceiving much of their prior using experience and attitudes as negative. "LifeHouse is a great program. There's a lot here a lot of growth that has happened here". The men expressed a desire to reexperience the Seeking Safety classes to reinforce and build on their learning. LifeHouse seems to offer "well rounded programming" including implementing new classes to fit with client expressed need. For instance, one individual was struggling with cooking and so a cooking class was established for everyone's benefit. LifeHouse has a positive reputation according to some participants. For example, one individual's sponsor had known someone who had remained sober for over 5 years to date following the Lifehouse program and this fostered a belief and hope in program effectiveness, "There's something here".

\section{Conclusions}

The findings from the current thesis research have added to the theoretical base by considering neuroadaptation (i.e., memory and learning) within a broader social work context. In addition, this study has added to the addiction literature by examining concurrent substance use and post traumatic stress disorders, which may be used to inform social work practice. Combined quantitative (TSI) and qualitative (interviews) methods provided an in-depth analysis of findings collected from the LifeHouse Addiction Treatment Program. The participants gave detailed accounts of their individual and collective experiences including substance use, abstinence, and recovery through the LifeHouse program. Treatment effectiveness was examined through seven themes and related subcategories. 
Many individuals entering treatment are among the most marginalized in society. While the men living at LifeHouse during the time of the current study unanimously identified as white (e.g., Caucasian) males, their socioeconomic histories were somewhat diverse. A few men had been raised in middle to upper-middle class, nuclear families. However, the majority had experienced living in large families and/or sole support families of low socioeconomic status. The men from economically disadvantaged families typically had less access to education and more exposure to environmental stressors (family breakdown, relocation, abuse, to name a few). In addition, participants reported that where alcohol and/or marijuana were socially accepted among parents and peers, they were also likely to drink and/or smoke. Indeed, individuals have a tendency toward emulating activities of others in their social group. Such environmental and social conditions likely contribute to compromised health (McCutcheon, 2006).

\section{Contribution to Knowledge Base}

Chronic substance use is one way people cope with societal pressure. However, substance abuse is often viewed as a cause of social problems rather than a consequence to structural barriers (Johns, 1992). I spoke with a few of the men at the time of their LifeHouse program graduation. These men were enthusiastic about their recovery and gave motivational speeches to incoming LifeHouse residents. In some cases the men planned to enter transitional housing owing to low income and lack of alternatives. Transitional or second stage housing is often located within access of substances and such an environment may present recovery challenges. Clearly lack of safe and affordable housing is a structural issue that contributes to homelessness and a likely return to substance use. 
Addiction is apparent in society as demonstrated by long treatment wait lists. Treatment is a medicalized solution to a societal problem. A medical conception of addiction situates the problem within the person; an illness, to be cured. However, the cure seems to be elusive as no one treatment has been effective for all. However, individuals are taught coping strategies while in treatment, which may contribute to longer term rates of abstinence. Self-confidence improves with increased coping. Valliant (1995) proposed substance users with bolstered self-efficacy and raised esteem will be motivated to sustain abstinence. LifeHouse staff recognizes intrinsic motivation is essential to addiction recovery. As such potential clients are interviewed while they are detoxing in stabilization to determine motivation. Treatment begins following the detoxification process. Addiction recovery requires continued self-examination and a lifetime commitment toward personal change (i.e., beliefs and behaviours).

Cognitive therapy (i.e., Seeking Safety) has been widely researched and has demonstrated effectiveness in changing belief systems (Beck, 1995), modifying behaviours (Najavits, 2002), and preventing relapse (Larimer, Palmer \& Marlatt, 1999). However, owing to memory lapses during the first year of abstinence, some individuals new to recovery may respond better to working on cognitive strategies following the post acute withdrawal phase. The LifeHouse participants embraced practical tips and reinforcement through interaction (e.g., role plays and visual tools). Such interactive approaches may have served a dual purpose as individual participants had different degrees of literacy. In addition, the educational classes were naturally being reinforced by cross-referencing coping strategies particular to both Seeking Safety and Anger Management. Some of the coping strategies are similar and naturally overlap therefore, 
highlighting these connections may further increase learning. Taken together, the emphasis on cognitive strategies helped participants to identify unhealthy belief systems and provided skills for change through heightened self-awareness. The men identified LifeHouse program effectiveness through an acquired skills base and increased insight.

I'm off the street. LifeHouse here slowed down my mind a lot drastically I mean I can't even begin to tell you. The only way I can describe it is like a glass, drop it on the ground and it shatters into millions of little pieces and now instead of shattering it breaks off into a couple of big chunks.

All the men interviewed completed the LifeHouse program and were substance free at graduation. Only one participant was discharged and that was for reasons other than relapse.

Traumatic experiences often include or evoke a sense of loss and/or grief. Individuals experiencing a loss may go through a grieving process before identifying needs. Likewise, arresting substance use may be perceived as a loss. Individuals use substances to avoid negative and/or painful feelings. Negative feelings are also linked to relapse. Addiction recovery is not merely about stopping the substance use, but rather is concerned with identifying human needs. Such needs are not necessarily material or economic needs - but rather additional human needs - emotional needs which were interrupted as a result of the trauma. Ideally, fulfilling emotional needs by initiating healthier behaviours may replace the perceived need for substance use.

\section{Findings}

The following summary of conclusions provides a personal interpretation of LifeHouse effectiveness and direct participant benefits based on the research findings (Tutty et al., 1996). First, the TSI scores demonstrated trauma symptom improvements at 
posttest as compared with pretest. Second, individual participants identified with the notion of progression and eventual lost control of their substance use. These same individuals adopted coping skills (i.e., Seeking Safety and Anger Management) presented by LifeHouse staff to effectively adjust their lifestyles and arrest their addictions. Grounding and countering were two skills which had particular utility for the participants. Third, through their experiences at LifeHouse, the participants developed an awareness of how trauma had influenced their using and conversely how addiction had increased susceptibility to trauma. Fourth, LifeHouse provided a safe environment where the men related to each other. In this way, the LifeHouse program assisted the participants in working through isolation, shame and stigma associated with trauma and substance use. Fifth, the participants described feeling motivated toward continued substance abstinence, acknowledging the value for structure, spirituality, AA and/or NA fellowship, and personal growth through goal attainment as the rationale for such commitment. Indeed, according to this thesis research, LifeHouse was effective in providing a safe refuge and opportunity for recovery from substance use.

\section{Limitations}

A primary limitation of this study was the fairly homogenous sample in that all the participants identified as white males. Although the absence of a control group might also be considered a limitation of the quantitative part of the study, qualitative research does not require the use of a control group. In fact, the combined quantitative and qualitative sample size of 15 was larger than similar Seeking Safety studies (see implications below). Perhaps another limitation of this study was the nonrandom sampling selection of participants. The sample was extracted from LifeHouse residents 
willing to participate in interviews conducted in January and February 2007. Finally, the positive participant feedback pertaining to the Anger Management class was unanticipated and presented opportunities for further exploration. Had I been more aware of its impact prior to the study I would have included more interview questions directed at Anger Management.

Lifehouse staff offer a dynamic and progressive program structure. Accordingly, the staff are open to and interested in revising featured programming. To this end, additional clinical inventories might be worthy of examination. For example, the TSI is limited to traumatic symptom measures. Perhaps a measure of coping or self-efficacy or memory would have relevance for the LifeHouse Addiction Treatment Program ${ }^{18}$.

\section{Implications for Social Work}

The TSI was administered as a pretest and posttest evaluation to measure trauma symptom change. I believe the TSI would have increased utility at the time of the pretest. Rather than using the TSI to measure symptom change, the TSI could be used to tailor individual counseling and screen for Seeking Safety. The TSI scores could be calculated at program admission to better determine counseling strategies and fit with program. Each individual has different scores and combinations of scales which indicate individualized or differentiated needs. Some participants did not identify with experiencing trauma, so perhaps they were not ideally suited for Seeking Safety. Of course, screening might also influence or bias the counseling focus. Using the TSI at

\footnotetext{
18 The TSI was the most commonly used self-report instrument used among the International Society for Traumatic Stress Studies' members where 23\% report administering the instrument according to a websurvey conducted by Elhai, Gray, Kashdan, \& Franklin (2005). The Clinician-Administered PTSD Scale rated highest of all surveys at $32 \%$ (Elhai et al., 2005).
} 
treatment onset is worthy of consideration. In addition, a TSI posttest might indicate more counseling might benefit participants and provide opportunities for next steps.

Seeking Safety was originally conceptualized in 1993 for use with women, and has since been expanded to include men (Najavits et al., 2005 \& Najavits, 2007). The current study adds to earlier research which suggests Seeking Safety is an appropriate and effective design for men. In fact this thesis research explored 15 participants' feedback. Such a sample size was greater than a previous study on men that examined only five outpatients (see Seeking Safety plus Exposure Therapy: An Outcome Study on Dual Diagnosis Men, Najavits et al., 2005). While Seeking Safety has been implemented with women and men, I am wondering whether a similar program would have utility for youth. As well, Seeking Safety was designed for group and individual work therefore I wonder whether the program could be adapted to crisis telephone line work. The sample examined in this study identified as white, I am curious whether a similar program could be developed to include diverse communities for example, aboriginal populations and gay, lesbian, transgender, transsexual, and/or questioning individuals.

Seeking Safety was a cognitive approach implemented at LifeHouse which aims to replace negative and/or catastrophic thinking with positive coping strategies. Over time and with practice, coping skills become reinforced. Seeking Safety as a first stage trauma recovery program aims to foster a sense of safety among individual participants. Perhaps aftercare may provide a segue to $2^{\text {nd }}$ stage trauma recovery by examining remembrance and mourning (i.e., exposure and grief therapy; Herman, 1997). Providing continuity of care through longer-term aftercare provision is recommended to sustain recovery among marginalized groups (Hyucksun Shin \& Amodeo, 2007). In addition to 
aftercare, stabilization programs are thought to increase longevity of recovery in homeless populations (Kertesz et al., 2003). LifeHouse's core program is bracketed by both aftercare and stabilization thus providing a complete treatment opportunity.

Traumatic experience seems to precede addiction. As well, addiction increases vulnerability for experiencing trauma. Therefore social workers need to develop an understanding for the relationship between trauma and addiction as well as possible courses of intervention. In addition, sexual abuse is under reported and therefore, may get missed during assessment. Social workers might use this knowledge to inform their practice. For example, clinical settings employ psychosocial assessments which may be intrusive. Social workers practicing in such environments may find ways to soften some of the more tender questions recognizing that up to $36 \%{ }^{19}$ of men living with addiction may have also experienced sexual and/or physical abuse.

Given the participants' recent graduation from the LifeHouse Addiction Treatment Program, a follow-up study is recommended to better gauge longer-term sobriety than the few months the current study examined. Indeed addiction treatment success is difficult to measure. After all, one day of abstinence may be defined as a success for an individual daily drinker. LifeHouse counselors consider the Seeking Safety pilot project successful owing to the diminished number of client-discharges attributed to psychoactive drug relapse. Indeed, only four residents have been discharged to date since the Seeking Safety pilot project's inception May, 2006 (Thompson \& Hopton, 2006).

\footnotetext{
${ }^{19}$ Please refer to the introduction for research which supports this statistic.
} 


\section{Recommendations}

Owing to clinically significant TSI scores which indicated sexual dysfunction and sexual concerns in conjunction with risks associated with IV (intravenous) substance use, a harm reduction and safer-sex awareness component is recommended as an adjunct to the Seeking Safety class. Similarly, HIV testing and counseling might be considered or referred. While substance use and concurrent disorder programs are a start toward addressing particular treatment challenges, acknowledging the need for cocaine and opiate-specific treatment and conducting research for more sophisticated interventions would likely benefit chronic substance users. Treatment and aftercare compliance might also improve with more advanced and progressive programs (than those traditionally organized around alcohol models of intervention). As well, research which examines the relationship between particular substances and trauma symptoms might uncover individualized treatment needs.

While the duration of treatment may vary, traditional addiction programs offer common and generalized themes. Psychosocial interventions including psychodynamic approaches might be adapted to individual recovery and are worthy of further examination. Pharmacotherapy might also be considered in reducing withdrawal effects and achieving neurochemical rebalancing. For example, methadone, LAAM (levomethyl acetate hydrochloride), buprenorphine (Royse et al., 2000), naltrexone and acamprosate, (O’Brien, 2005) have been used to reduce relapse among chronic substance users. As well, cannabis (when used intermittently or moderately) was introduced as an innovative and perhaps radical treatment alternative in reducing cravings among cocaine using individuals with ADHD (Aharonovich et al., 2006). Participants received CBT as one 
feature of this treatment, which may have contributed to positive outcomes. In sum, human beings are complex and present varying treatment needs. While some argue "You can't treat a drug problem with a drug", others support medication in reducing cravings and withdrawal effects as a way to lessen relapse (O'Brien, 2005, p.1423). Medication may diminish initial withdrawal effects however; chronic substance users require longer term counseling support. Psychotherapy used in conjunction with medication helps develop and reinforce new behaviours that compensate for neuroadaptation created by chronic drug use. Neurochemicals often rebalance following substance cessation and over a six-month to two-year period. Medication may help prevent relapse by stabilizing mood fluctuations.

\section{Concluding Remarks}

Examining trauma and substance use provides an opportunity for integrating socio-political, psychological, and biological understanding of addiction. Given that substance abuse and traumatic experiences are reinforced through experience and reward (Pitman, 1997), it stands to reason that such learning can be reshaped or reframed through therapeutic intervention. Coping strategies learned through Seeking Safety, Anger Management and cognitive behavioural therapy have provided an alternative to substance use for the LifeHouse participants. The proposed research contribution is important for addiction treatment because positive treatment outcomes build counselor confidence in the program's capacity for effecting change. Positive outcomes also increase participants' confidence or belief in program effectiveness (VWSAC, 2004). Indeed, the social cost to substance use including alcohol, cigarettes and other drugs in 2002 was calculated at 39.8 billion dollars (Collin, 2006). Interestingly, licit drugs - alcohol and 
cigarettes - contributed to $79.3 \%$ of social costs whereas illicit drugs accounted for $20.7 \%$ of health care, legal system, and lost productivity costs (Collin, 2006). While increased research funding is necessary for developing additional, progressive treatment options to better support the individual, the sociopolitical environment is also worthy of examination. 


\section{References}

Ad Hoc Working Group on Women, Mental Health, Mental Illness, and Addictions (CWHN; 2006). Women, mental health, mental illness, and addiction in Canada: An Overview. Retrieved 30 December 2006 from, http://www.cwhn.ca.

Aharonovich, E., Garawi, M.A., Bisaga, A., Brooks, D., Raby, W.N., Rubin, E., Nunes, E.V., \& Levin, F.R. (2006). Concurrent cannabis use during treatment for comorbid ADHD and cocaine dependence: Effects on outcome. The American Journal of Drug and Alcohol Abuse 32 629-635.

Al-Anon Family Groups (1992). Courage to change: One day at a time in Al-Anon II. New York: Al-Anon Family Group Headquarters, Inc.

Alcoholics Anonymous (2001). Alcoholics Anonymous: This is the fourth edition of the big book, the basic text for alcoholics anonymous. USA: Alcoholics Anonymous World Services, Inc.

Alexander, B.K. (1990). The empirical and theoretical bases for an adaptive model of addiction. The Journal of Drug Issues, 20(1), 37-65.

American Psychiatric Association (1994). Diagnostic and Statistical Manual of Mental Disorders $\left(4^{\text {th }}\right.$ ed.). Washington, D.C.: American Psychiatric Association.

American Psychiatric Association (1980). Diagnostic and Statistical Manual of Mental Disorders $\left(3^{\text {rd }}\right.$ ed.). Washington, D.C.: American Psychiatric Association.

Armstrong, B. (1996). The Violence Reduction Program.

Report of the Auditor General Canada (2001). Illicit drugs - The Federal Government's role. Retrieved 8 January 2007 from, http://www.oag-bvg.gc.ca.

Babbie, E. \& Benaquisto, L. (2002). Qualitative Data Analysis, In Fundamentals of social research. (chap. 14, pp.374-394). Canada: Nelson, Ltd.

Back, Dansky, Carroll, Foa, \& Brady (2001). Concurrent treatment of PTSD and cocaine dependence.

Back, S.E., Brady, K.T., Jaanimagi, U. \& Jackson, J.L. (2006). Cocaine dependence and PTSD: A pilot study of symptom interplay and treatment preferences. Addictive Behaviors, 31 351-354.

Baker, T.B., Piper, M.E., McCarthy, D.E., Majeskie, M.R., \& Fiore, M.C. (2004). Addiction motivation reformulated: An affective processing model of negative reinforcement. Psychological Review, 111 33-51. 
Bandura, A. (1977). Self-efficacy: Toward a unifying theory of behavioral change. Psychological Review, 84 191-215.

Beck, A.T. (1963). Thinking and depression: Idiosyncratic content and cognitive distortions. Arch Gen Psychiatry, 9, 36-46.

Beck, A.T. (1967). Depression: Clinical, experimental and theoretical aspects. New York: Harper \& Row.

Beck, J.S. (1995). Cognitive Therapy: Basics and Beyond. New York: The Guilford Press.

Bentler, Newcomb \& Zimmerman (2002). Cigarette use and drug use progression: Growth trajectory and lagged effect hypothesis. In D.B. Kandel (Ed.), Stages and pathways of drug involvement: Examining the gateway hypothesis (chap. 10, pp.223-253). USA: Cambridge University Press.

Blinder, B.J., Cumella, E.J., \& Sanathara, V.A. (2006). Psychiatric comorbidities of female patients with eating disorders. Psychosomatic Medicine, 68, 454 462.

Blume, A.W. (2005). Treating drug problems. Hoboken, New Jersey: John Wiley \& Sons.

Bolam, B., Murphy, S., \& Gleeson, K. (2004). Individualisation and inequalities in health: a qualitative study of class identity and health. Social science and medicine, 59, 1355-1365.

Briere, J. (2002). Treating adult survivors of severe childhood abuse and neglect: Further development of an integrative model. In J.E.B. Myers, L. Berliner, J. Briere, C.T. Hendrix, T. Reid \& C. Jenny (Eds.), The APSAC handbook on child maltreatment, $\left(2^{\text {nd }}\right.$ ed.). Newbury Park, CA: Sage Publications.

Briere, J. \& Elliott, D.M. (2003). Prevalence and psychological sequelae of self-reported childhood physical and sexual abuse in a general population sample of men and women. Child Abuse \& Neglect 27, 1205-1222.

Briere, J., Elliott, D.M., Harris, K., \& Cotman, A. (1995). Trauma Symptom Inventory: Psychometrics and association with childhood and adult trauma in clinical samples. Journal of Interpersonal Violence, 10, 387-401.

Briere, J. (1995). Trauma Symptom Inventory. Florida: Psychological Assessment Resources, Inc.

Brun, C.F. (2005). A practical guide to service evaluation. Chicago, Illinois: Lyceum Books, Inc. 
Byrne, P. (2005). Psychometric properties of the trauma symptom inventory (TSI; Briere, 1995). Retrieved November 17, 2006 from, http://www.swin.edu.au/victims/resources/assessment/ptsd/tsi.html

Capponi, P. (1997). Dispatches from the poverty line. Toronto: Penguin Books.

Carlson, N.R., Buckist, W., Enzle, M.E., \& Heth, C.D. (2000). Psychology: The science of behavior (Cdn ed.). Scarborough: Prentice-Hall Canada Inc.

Carroll, K.M., Nich, C. \& Ball, S.A. (2005). Practice makes progress? Homework assignments and outcome in treatment of cocaine dependence. Journal of Consulting and Clinical Psychology, 73(4), 749-755.

Catanzaro, S.J. \& Laurent, J. (2004). Perceived family support, negative mood regulation expectancies, coping, and adolescent alcohol use: Evidence of mediation and moderation effects. Addictive Behaviors, 29, 1779-1797.

Catherall, D.R. (Ed.). (2004). Handbook of stress, trauma, and the family. NewYork: Bruner-Routledge.

Collin, C. (2006). Substance abuse and public policy in Canada: I. Canada's federal drug strategy. Library of Parliament. Pp.1-15.

Coombs, R.H. \& Howatt, W.A. (2005). The addiction counselor's desk reference. Hoboken, New Jersey: John Wiley \& Sons, Inc.

Corbin, J. \& Strauss, A. (1990). Grounded theory research: Procedures, canons, and evaluative criteria. Qualitative Sociology, 13(1), 3-21.

Creswell, J.W. (1998). Data analysis and representation, In Qualitative inquiry and research design: Choosing among five traditions. Thousand Oaks: SAGE Publications. (chap 8., pp.139-165).

Csiernik, R. (2003). Many paths to prohibition: Drug policy in Canada. In R. Csiernik \& W.S. Rowe (Eds.). Responding to the oppression of addiction: Canadian social work perspectives (chap. 18, pp. 273-291). Toronto: Canadian Scholar's Press Inc.

Csiernik, R. \& Rowe, W.S. (2003). Creating a social work understanding of addiction. In R. Csiernik \& W.S. Rowe (Eds.). Responding to the oppression of addiction: Canadian social work perspectives (chap. 1, pp. 3-15). Toronto: Canadian Scholar's Press Inc.

Davies, J.B. (1998). Pharmacology versus social process: Competing or complementary views on the nature of addiction. Pharmacology and Therapeutics, 80, 265-75. 
Davis, M., Rhodes, T., \& Martin, A. (2004). Preventing hepatitis C: 'Common sense', 'the bug' and other perspectives from the risk narratives of people who inject drugs. Social Science and Medicine, 59, 1807-1818.

Denning, P. (2000). Practicing harm reduction psychotherapy: An alternative approach to addictions. New York: The Guilford Press.

DeWitt, D.J., Adlaf, E.M., Offord, D.R., \& Ogborne, A.C. (2000). Age at first alcohol use: A risk factor for the development of alcohol disorders. American Journal Psychiatry, 157, 745-750.

DiClemente, C.C. (2003). Addiction and change: How addictions develop and addicted people recover. New York: The Guilford Press.

Dodes, L. (2003). The heart of addiction: A new approach to understanding and managing alcoholism and other addictive behaviors. New York: Harper.

Donovan, B., Padkin-Rivera, E., \& Kowaliw, S. (2007, under review). Transcend: Initial outcomes from a posttraumatic stress disorder/substance abuse treatment program.

Doweiko, H.E. (2002). Concepts of chemical dependency $\left(5^{\text {th }}\right.$ ed.). Canada: Brooks/Cole.

Dziegielewski, S.F. (Ed.). (2005). Understanding substance addictions. Chicago, Illinois: Lyceum Books, Inc.

Eisenberg, L. The social construction of the human brain. Am J Psychiatry, 152(11), 1563-1575.

Elhai, J.D., Gray, M.J., Kashdan, T.B., \& Franklin, C.L. (2005). Which instruments are most commonly used to assess traumatic event exposure and posttraumatic effects?: A survey of traumatic stress professionals. Journal of Traumatic-Stress, $18(5), 541-545$.

Engel, G. (1960). A unified concept of health and disease. Perspectives in Biology and Medicine 3 (Summer), 459-85.

Enock, M.A, Goldman, D. (2002). Molecular and Cellular Genetics of Alcohol Addiction. In K.Davis, D. Charney, J.Coyle, \& C. Nemeroff (Eds.), Neuropharmacology: The Fifth Generation of Progress (pp. 1413-1423). Philadelphia, PA: Lippincott, Williams, and Wilkins.

Ferentzy, P. (2002). Foucault and Addiction. Telos, 167-191. 
Fingarette, H. (1988). Heavy drinking: The myth of alcoholism as a disease. Berkeley: University of California Press.

Foa, E.B. \& Rothbaum, B.O. (1998). Treating the trauma of rape: Cognitivebehavioral therapy for PTSD. New York: The Guilford Press.

Fields, R. (2007). Drugs in perspective: A personalized look at substance use and abuse $\left(6^{\text {th }}\right.$ ed.). New York: McGraw-Hill.

Fraser, G.A. (2003). Epidemiology and neurobiology of PTSD - An overview. The Canadian Journal of Diagnosis, 2-4.

Freud, S. (1939). An outline of psychoanalysis, 23, (standard ed.). London: Hogarth Press.

Gallop, R.J., Crits-Christoph, P., Ten Have, T.R., Barber, J.P., Frank, A., Griffin, M.L. \& Thase, M.E. (2007). Differential transitions between cocaine use and abstinence for men and women. Journal of Consulting and Clinical Psychology, 75(1), 95103.

Gerzon, R. (1997). Finding serenity in the age of anxiety. Toronto: Bantam Books.

Goldstein, A. (2001). Addiction: From biology to drug policy (2 $2^{\text {nd }}$ ed.). New York: Oxford University Press.

Gonzalez, V.M., Schmitz, J.M. \& DeLaune, K.A. (2006). The role of homework completion in cognitive-behavioral therapy for cocaine dependence. Journal of Consulting and Clinical Psychology, 74(3) 633-637.

Goodman, S. \& Levy, S.J. (n.d.). The biopsychosocial model revisited: A psychodynamic view of addiction. Retrieved 9 May 2007 from, http://www.rocklandpsych.com.

Grant, B.F. (1997). Barriers to alcoholism treatment: Reasons for not seeking treatment in a general population sample. Journal of Studies on Alcohol, 58, 365-371.

Graziano, A.M. \& Raulin, M.L. (2007). Research methods: A process of inquiry (6 $6^{\text {th }}$ ed.). Boston: Pearson Education Inc..

Harris, M., Fallot, R.D., \& Berley, R.W. (2005). Qualitative interviews on substance abuse relapse and prevention among female trauma survivors. Psychiatric Services, 56(10). 
Hayes, S.C. (2004). Acceptance and commitment therapy and the new behavior therapies: Mindfulness, acceptance, and relationship. In S.C., Hayes, V.M. Follette, \& M.M. Linehan (Eds.). Mindfulness and acceptance: Expanding the cognitive-behavioral tradition. New York: The Guilford Press.

Hebb, A.L.O., Zacharko, R.M., Dominguez, H., LaForest, S., Gauthier, M., Drolet, G. (2003). Changes in brain cholecystokinin and anxiety-like behavior following exposure of mice to predator odor. Neuroscience, 116, 539-551.

Herman, J. (1997). Trauma and recovery: The aftermath of violence - from domestic abuse to political terror. New York: Basic Books.

Hien, D.A., Cohen, L.R., Miele, G.M., Litt, L.C., \& Capstick, M.A. (2004). Promising treatments for women with comorbid PTSD and substance use disorders. $A m J$ Psychiatry, 161, 1426-1432.

Holmes, J. (2002). All you need is cognitive behaviour therapy? Education and debate. Retrieved November 18, 2006 from, http://www.bmj.com/cgi/reprint/324/7332/288

Hyucksun Shin, S. \& Amodeo, M. (2007). Injection drug use among adolescents and young adults: Scope of the problem and recommendations. Families in Society: The Journal of Contemporary Social Services, 88 (1), 95-103.

Jellnick (1952). Phases of alcohol addiction. Quarterly Journal of Studies on Alcohol, 13(4), 673-684.

Jellinek, E.M. (1960). The disease concept of alcoholism. College \& University Press: New Haven, Conn., in association with Hillhouse Press: New Brunswick, N.J.

Johns, C.J. (1992). Power, ideology, and the war on drugs: Nothing succeeds like failure. New York: Praegar.

Kabat-Zinn, J. (2005). Full catastrophe living: Using the wisdom of your body and mind to face stress, pain and illness ( $2^{\text {nd }}$ ed.). New York: Dell Publishing.

Kaminer, W. (1993). I'm dysfunctional you're dysfunctional: The recovery movement and other self-help fashions. New York: Vintage Books.

Kandel, D.B., Yamaguchi, K., \& Chen, K. (1992). Stages of progression in drug involvement from adolescence to adulthood: Further evidence for the gateway theory. Journal of Studies on Alcohol, 53, 447-457.

Kendall, D. Murray, J.L., \& Linden, R. (2000). Sociology in our times ( $2^{\text {nd }}$ Cdn ed.). Canada: Nelson Thompson Learning. 
Kertesz, S.G., Horton, N.J., Friedmann, P.D., Saitz, R., \& Samet, J.H. (2003). Slowing the revolving door: Stabilization programs reduce homeless persons' substance use after detoxification. Journal of substance abuse treatment, 24 197-207.

Kessler, R.C., Sonnega, A., Bromet, E., Hughes, M., \& Nelson, (1995). Posttraumatic stress disorder in the national comorbidity survey. Archives of General Psychiatry, 52, 1048-1060.

Kingdon, D.G. \& Turkington, D. (1994). Cognitive-behavioral therapy of schizophrenia. New York: Guilford Press.

Koval, J.J. and Pederson, L.L. (1999). Stress-coping and other psychosocial risk factors: A model for smoking in grade 6 students. Addictive Behaviors, 24(2), 207-218.

LaFond, V. (2002). Grieving mental illness: A guide for patients and their caregivers $\left(2^{\text {nd }}\right.$ ed.). Toronto: University of Toronto Press.

Larimer, M.E., Palmer, R.S., \& Marlatt, G.A. (1999). Relapse prevention: An overview of Marlatt's cognitive-behavioral model. Alcohol Research \& Health, 23(2), 151160.

Leigh, J., Bowen, S., \& Marlatt, G. A. (2005). Spirituality, mindfulness, and substance abuse. Addictive Behaviors, 30(7), 1335-1341.

Levine, H.G. (1978). The discovery of addiction: Changing conceptions of habitual drunkenness in America. Journal of Studies on Alcohol, 39, 143-174.

Lysaker, P.H., Davis, L.W., Gatton, M.J., \& Herman, S.M. (2005). Associations of anxiety-related symptoms with reported history of childhood sexual abuse in schizophrenia spectrum disorders. Journal of Clinical Psychiatry, 66, 1279-1284.

Marlatt, G.A. \& Donovan, D.M. (Eds.). (2005). Relapse Prevention: Maintenance strategies in the treatment of addictive behaviors (2nd ed.). New York: Guilford Press.

Marlow, C. (2001). Research Methods for Generalist Social Work (3 ${ }^{\text {rd }}$ ed.). Canada: Wadsworth.

Martin, P.R., Weinberg, B.A., \& Bealer, B.K. (2007). Healing Addiction: An integrated pharmacopsychosocial approach to treatment. Hoboken, New Jersey: John Wiley \& Sons, Inc.

Massing, M. (2000). The Fix. Berkley: University of California Press.

McCann, I.L. \& Coletti, J. (1994). The dance of empathy: A Hermeneutic formulation of countertransference, empathy, and understanding in the treatment of 
individuals who have experienced early childhood trauma. In J.P. Wilson \& J.D. Lindy (Eds.), Countertransference in the treatment of PTSD (chap. 4, pp. 87-121). New York: The Guilford Press.

McCutcheon, V.V. (2006). Toward an integration of social and biological research. Social Service Review, 159-178.

McDevitt-Murphy, M.E., Weathers, F.W., \& Adkins, J.W. (2005). The use of the trauma symptom inventory in the assessment of PTSD symptoms. Journal of Traumatic Stress, 18(1), 63-67.

Morrissey, J.P., Jackson, E.W., Ellis, A.R., Amaro, H., Brown, V.B., \& Najavits, L.M. (2005). Twelve-month outcomes of trauma-informed interventions for women with co-occuring disorders. Psychiatric Services, 56(10), 1213-1222.

Mullen, Hammersley, \& Marriott, (2005). After you've ran with the rats the mice are a bore: Cessation of heroin use among men entering midlife. In W.R. Palacios (Ed.) Cocktails and dreams: Perspectives on drug and alcohol use. New Jersey: Pearson / Prentice Hall.

Muller, R.T., Kraftcheck, E.R., \& McLewin, L.A. (2004). Adult attachment and trauma. In D.R. Catherall (Ed.), Handbook of stress, trauma, and the family (chap. 10, pp. 203-229) New York: Bruner-Routledge.

Miller, W.R. \& Rollnick, S. (1991). Motivational interviewing: Preparing people to change addictive behavior. New York: Guilford Press.

Najavits, L.M., Gastfriend, D.R., Barber, J.P., Reif, S., Muenz, L.R., Blaine, J., Frank, A., Crits-Christoph, P., Thase, M., \& Weiss, R.D. (1998). Cocaine dependence with and without PTSD among subjects in the National Institute on Drug Abuse collaborative cocaine treatment study. American Journal of Psychiatry, 155, 214219.

Najavits, L. (2002a). Seeking Safety. New York: The Guilford Press.

Najavits, L.M. (2002b). Seeking Safety: Therapy for trauma and substance abuse. Corrections Today, 136-141.

Najavits, L.M. (1997). Therapists' implicit theories of psychotherapy. Journal of Psychotherapy Integration, 7, 1-16.

Najavits, L.M. (2004). Assessment of trauma, PTSD, and substance use disorder: A practical guide. In J.P. Wilson \& T. Keane (Eds.), Assessing psychological trauma and PTSD ( $2^{\text {nd }}$ ed., chap. 16, pp. 466-491). New York: Guilford Press. 
Najavits, L.M. (2007, in press). Seeking Safety: A new psychotherapy for posttraumatic stress disorder and substance use disorder. In P. Ouimette \& P. Brown (Eds.), Trauma and substance abuse: Causes, consequences, and treatment of comorbid disorders. Washington, DC: American Psychological Association Press.

Najavits, L.M., Liese, B.S., \& Harned, M.S. (2004). Cognitive and behavioural therapies. In J.H., Lowinson, R.B. Millman, P. Ruiz \& J.G. Langrod (Eds.), Substance abuse: A comprehensive textbook (4h ed., chap. 4, pp. 723-732). Baltimore: Williams and Wilkins.

Najavits, L.M., Schmizt, M., Gotthardt, \& Weiss, (2005). Seeking Safety plus exposure therapy: An outcome study on dual diagnosis men. Journal of Psychoactive Drugs, 27(4), 425-435.

Najavits, L.M., Weiss, R.D., Shaw, S.R., \& Muenz, L.R. (1998). "Seeking Safety": Outcome of a new cognitive-behavioral psychotherapy for women with posttraumatic stress disorder and substance dependence. Journal of Traumatic Stress, 11(3), 437-456.

O'Brien, C.P. (2005). Anticraving medications for relapse prevention: A possible new class of psychoactive medications. American Journal of Psychiatry, 162(8), 1423-1431.

Peele, S. (1989). Diseasing of America. Toronto: Lexington Books.

Peele, S. (1985). The meaning of addiction: Compulsive experience and its interpretation. Toronto: Lexington Books.

Pitman, R.K. (1997). Overview of biological themes in PTSD. In R. Yehuda \& A.C. McFarlane (Eds.), Psychobiology of posttraumatic stress disorder (Vol. 821). New York: The New York Academy of Sciences.

Prochaska, J.O., Norcross, J.C., \& Di-Clemente, C.C. (1994). Changing for good. New York: William Morrow.

Reinarman, C. (2005). Addiction as accomplishment: The discursive construction of disease. Addiction Research and Theory, 13(4): 307-320.

Rimondini, R., Sommer, W., \& Heilig, M. (2003). A temporal threshold for induction of persistent alcohol preference: Behavioural evidence in a rat model of intermittent intoxication. Journal of Studies on Alcohol, 64, 445-449.

Rosenthal, B.S. \& Wilson, W.C. (2003). Impact of and exposure to community violence and psychological symptoms on college performance among students of color. Adolescence, 38 239-249. 
Rothery, M., Richard, M., Grinnell, Jr., \& Tutty, L.M. (1996). Qualitative research for social workers: Phases, steps \& tasks. Allyn \& Bacon.

Rothschild, B. (2000). The body remembers: The psychophysiology of trauma and trauma treatment. New York: W.W. Norton \& Company, Inc.

Royse, D., Leukefeld, C., Logan, T.K., Dennis, M., Wechsberg, W., Hoffman, J., Cottler, L., \& Inciardi, J. (2000). Homelessness and gender in out-of-treatment drug users. American Journal of Drug and Alcohol Abuse, 26(2), 283-296.

Rubin, A. \& Babbie, E. (1993). Research methods for social work ( $2^{\text {nd }}$ ed.). Pacific Grove, CA: Wadsworth, Inc.

Schaler, J.A. (2007). Addiction is a choice. Chicago: Open Court.

Schore, A. (1994). Affect regulation and the origin of the self. Hillsdale, New Jersey: Lawrence Erlbaum.

Schukit. M.A. (2002). Vulnerability Factors for Alcoholism. In K. Davis, D. Charney, J. Coyle, \& C. Nemeroff (Eds.), Neuropharmacology: The Fifth Generation of Progress (pp.1399-1412). Philadelphia, PA: Lippincott, Williams, and Wilkins.

Sedgewick, E.K. (1993). Epidemics of the will. In Tendencies. (pp.130-142). Durham: Duke University Press.

Shulman, L. (1999). The skills of helping individuals, families, groups, and communities $\left(4^{\text {th }}\right.$ ed. $)$. USA: Brooks/Cole.

Sofuoglu, M., Dudish-Poulsen, S., Poling, J., Mooney, M. \& Hatsukami, D.K. (2005). The effect of individual cocaine withdrawal synptoms on outcomes in cocaine users. Addictive Behaviors, 30 1125-1134.

Spanos, N. (2001). Multiple identities \& false memories: A sociocognitive perspective. Washington: American Psychological Association.

Statistics Canada (2004a). Mospitalizations for mental disorders, by cause. Retrieved November 21, 2006 from Statistics Canada.

Statistics Canada (2004b). Hospitalizations for mental disorders, by cause. Retrieved November 21, 2006 from Statistics Canada.

Strean, H.S. (1996). Psychoanalytic theory an social work treatment. In F.J. Turner (Ed.), Social work treatment: Interlocking theoretical approaches $\left(4^{\text {th }} \mathrm{ed}.\right)$. New York: The Free Press. 
Streatfeild, D. (2001). Cocaine [an unauthorized biography]. New York: St. Martin's Press.

Summerfield, D. (2001). The invention of post-traumatic stress disorder and the social usefulness of a psychiatric category. BMJ, 322, 95-8. Retrieved 25 January 2007 from, BMJ.com.

Teasdale, J. (2000). Prevention of relapse/recurrence in manic depressive psychosis by mindfulness-based cognitive therapy. Journal of Counseling and Clinical Psychology, 68, 615-621.

Tew, J. (Ed.). (2005). Social perspectives in mental health: Developing social models to understand and work with mental distress. London, UK: Jessica Kingsley Publishers.

Thompson, T. \& Hopton, J. (2006, unpublished data). LifeHouse Seeking Safety Pilot Project. The Ottawa Mission.

Tjepkema, M. (2004). Alcohol and illicit drug dependence. Supplement to Health Reports, Vol. 15, 2004., (catalogue 82-003). Retrieved November 21, 2006 from, Statistics Canada.

Triffleman, E., Carroll, K., \& Kellogg, S. (1999). Substance dependence, posttraumatic stress disorder therapy: An integrated cognitive-behavioral approach. Journal of Substance Abuse Treatment, 17, 3-14.

Truan, F. (1993). Addiction as a social construction: A postempirical view. Journal of Psychology, 127(5), 489-500.

True, W.R., Rice, J., Eisen, S.A., Heath, A.C., Goldberg, J., Lyons, M.J., \& Nowak, J. (1993). A twin study of genetic and environmental contributions to liability for posttraumatic stress symptoms. Arch. Gen. Psychiatry 50, 257-264.

Tutty, L.M., Rothery, M.A., Grinnell, R.M. (1996). Qualitative research for social workers: Phases, steps and tasks. Toronto: Allyn \& Bacon.

Vallant,G.E. (1995). The natural history of alcoholism revisited. London, England: Harvard University Press.

VWSAC (2004). VWSAC Seeking Safety evaluation report. Advancing the health of girls and women: A women's health strategy for British Columbia. Vancouver, British Columbia: BC Women's Hospital and Health Centre and British Columbia Centre of Excellence for Women's Health.

Weller, L.A. (2005). Group therapy to treat substance use and traumatic symptoms in female veterans. Federal Practitioner, 22, 27-38. 
Weinberg, D. (2000). "Out there": The ecology of addiction in drug abuse treatment discourse. Social Problems, 47(4), 606-621.

Wilson, C.W. \& Rosenthal, B.S. (2004). Psychological effects of attacks on the World Trade Centre: Analysis before and after. Psychological Reports, 94, 587-606.

Woodiwiss, M. (1998). Reform, racism and rackets: Alcohol and drug prohibition in the United States. In R. Coomber (Ed.). The control of drugs and drug users: Reason or reaction? United Kingdom: Harwood Academic Publishers.

Wolfe, D.A., Francis, K.J. \& Straatman, A. (2006). Child abuse in religiously-affiliated institutions: longterm impact on men's mental health. Child Abuse and Neglect, 30, 205-212.

Witkiewitz, K. and Marlatt, G.A. (2004). Relapse prevention for alcohol and drug problems: That was Zen, this is Tao. American Psychologist, 59(4), 224-235.

Yehuda, R., Teicher, M.H., Levengood, R., \& Seiver, L.J. (1996). Cortisol regulation in posttraumatic stress disorder and major depression: A chronobiological analysis. Biological Psychiatry, 40, 79-88.

Zanis, D.A., Cohen, E., Meyers, K., \& Cnaan, R.A. (1997). Brief Report: HIV risks among homeless men differentiated by cocaine use and psychiatric distress. Addictive Behaviors 22(2), 287-292.

Zlotnick, C., Najavits, L.M., Rohsenow, D.J., \& Johnson, D.M. (2003). A cognitivebehavioral treatment for incarcerated women with substance abuse disorder and posttraumatic stress disorder: Findings from a pilot study. Journal of Substance Abuse Treatment, 25, 99-105. 


\section{Appendix A}

\section{Seeking Safety: Treatment Topics}

1. Introduction to Treatment / Case Management

2. Safety

3. PTSD: Taking Back your Power

4. Detaching from Emotional Pain (Grounding)

5. When Substances Control You

6. Asking for Help

7. Taking Good Care of Yourself

8. Compassion

9. Red and Green Flags

10. Honesty

11. Recovery Thinking

12. Integrating the Split Self

13. Commitment

14. Creating Meaning

15. Community Resources

16. Setting Boundaries in Relationships

17. Discovery

18. Getting Others to Support Your Recovery

19. Coping with Triggers

20. Respecting Your Time

21. Healthy Relationships

22. Self-Nurturing

23. Healing from Anger

24. The Life Choices Game (Review)

25. Termination 


\section{Appendix B: Research Instrument \\ Homeless Men Seeking Safety from Trauma and Substance Use: \\ Findings from a Pilot Study}

\section{I would like to emphasize that you may decline to answer any of the following questions. You may also ask to stop the interview at any time.}

(Referring to the posttest evaluation) I see you completed the LifeHouse Seeking Safety classes on...

The following questions apply to your current situation.

1. Where are you living now?

2. Are you clean and/or sober today? (Probe: I need to ask you this question for ethical reasons - it would not be appropriate for me to interview you if you were under the influence).

3. Have you remained clean and/or sober since completing the program? (Probe: Your personal response will not be revealed to LifeHouse counselors).

4. Are you currently attending aftercare?

5. Approximately how many AA/NA meetings do you attend each week?

6. Are you currently volunteering or working or attending school or retraining?

7. How do you see yourself today?

The following questions refer to your past experience.

8. Describe your first experience with alcohol and/or drugs.

9. Describe how you were first introduced to alcohol or drugs (Probe: friends, family, peers)?

For the following questions, you don't need to go into detail about your traumatic experience, but rather explain how the traumatic experience may have influenced your substance use.

(Probe: Definition of trauma and substance abuse) Trauma includes physical and/or sexual and/or emotional abuse as outlined in the LifeHouse assessment form. In other words, you self-identified whether a substance was problematic and/or self-determined whether a life experience was traumatic.

10. Did your experience with trauma occur before and/or after your substance use?

11. Describe how you lived with the effects of trauma prior to coming to LifeHouse.

12. How do you see that your traumatic experience influenced your substance use?

13. What other factors may have contributed to your substance use?

The following questions pertain to the LifeHouse Seeking Safety Pilot Project.

14. Describe your experience with the LifeHouse trauma and substance abuse classes. 
15. How do you think participating in Seeking Safety classes influenced your stabilization?

16. Did you attend each of the twelve week classes?

17. Describe the class that you found most useful.

18. Which class was the least helpful?

19. Did you have the opportunity to address both trauma and substance abuse?

20. Describe your experience addressing both trauma and substance abuse.

21. Did you feel safe exploring trauma and substance abuse in the LifeHouse class environment?

22. What might have helped you to feel safer exploring trauma and substance abuse?

23. Did you feel a connection or a bond with others attending the Seeking Safety classes?

24. Were the classes helpful in breaking any feelings of isolation?

25. Has your experience with Seeking Safety classes helped reduce any feelings of shame or stigma associated with trauma and/or substance abuse?

26. Did you learn about the effects of trauma?

27. What skills (if any) have you learned for managing effects of trauma without using substances?

28. (Probe), I see you attended Bible study and the chapel as part of the LifeHouse program. What relevance, if any does religion have for your recovery and/or sobriety? 29. (Probe), I also see that you were required to attend Alcoholics Anonymous (AA) and/or Narcotics Anonymous (NA) meetings while living at LifeHouse. How has attending AA and/or NA meetings influenced your recovery?

30. (Probe), I see you were also asked to work in the community as a volunteer. How have you found performing volunteer work has influenced your recovery?

31. Have you had previous experiences with substance abuse recovery programs? (If answered "yes" please answer questions 32 through 35 , otherwise skip to number 36).

32. How were the LifeHouse Seeking Safety classes different from other addiction treatment programs?

33. How has the LifeHouse program been different than previous addiction treatment experiences?

34. What has been your longest continuous period of clean and/or sober time?

35. What skills did you learn that helped you stay clean and sober?

36. What motivates you to stay clean and/or sober?

The following questions pertain to the future.

37. What other supports or resources do you think might be helpful towards sustaining sobriety and/or clean time?

38. How do you see your life changing as a result of experiencing the LifeHouse Seeking Safety classes? 
39. Is there anything in particular that you would like to tell me that is related to the LifeHouse program or your recovery that I haven't asked you about?

Thank you very much for sharing your recovery experience, strength and insight with others. 


\section{Appendix C: Thematic Diagram (Themes \& Subcategories)}

\section{Control}
i. Disease
ii. Progression
iii. Choice
iv. Acceptance

\section{Trauma}

3. Safety

i. Trust

\section{Seeking Safety}

i. Feedback for Increased Effectiveness

ii. Program Intensity

iii. Program Initiation / Timing

iv. Memory

\section{Anger Management}

\section{Skills}

i. Grounding to the Here and Now

ii. Asking for Help

iii. Self-Care

iv. Thought-Stopping

v. Self-Awareness

vi. Relaxation

\section{Motivation}

i. Willingness

ii. Practice

iii. Routine

iv. Desperation / Hitting Bottom

v. Relationships

vi. Higher Power / Church

vii. Fellowship

viii. Change

ix. Education / Work

x. Hobbies

xi. Volunteerism

xii. Growing / Growth 


\section{Appendix D}

\section{Participant One}

\begin{tabular}{|l|l|l|}
\hline Subscale Name & Pretest (trauma score) & Posttest \\
\hline Anxious-Arousal (AA) & 64 & 57 \\
\hline Depression (D) & 60 & 57 \\
\hline Anger-Irritability (AI) & 60 & 54 \\
\hline Intrusive Experiences (IE) & $65^{*}$ & $79^{*}$ \\
\hline Defensive-Avoidance (DA) & $65^{*}$ & $73^{*}$ \\
\hline Disassociation (DIS) & 60 & 49 \\
\hline Sexual Concerns (SC) & 59 & 63 \\
\hline $\begin{array}{l}\text { Dysfunctional Sexual } \\
\text { Behavior (DSB) }\end{array}$ & $90^{*}$ & 61 \\
\hline $\begin{array}{l}\text { Impaired Self-Reference } \\
\text { (ISR) }\end{array}$ & 59 & 59 \\
\hline $\begin{array}{l}\text { Tension-Reduction } \\
\text { Behavior (TRB) }\end{array}$ & $76^{*}$ & 49 \\
\hline
\end{tabular}

* indicates significance

IE and DA were significant at pretest and the symptoms worsened at posttest. Yet DSB diminished at posttest.

\section{Participant Two}

\begin{tabular}{|l|l|l|}
\hline Subscale Name & Pretest (trauma score) & Posttest \\
\hline Anxious-Arousal (AA) & 58 & 53 \\
\hline Depression (D) & 55 & 50 \\
\hline Anger-Irritability (AI) & $65^{*}$ & 55 \\
\hline Intrusive Experiences (IE) & $81^{*}$ & $75^{*}$ \\
\hline Defensive-Avoidance (DA) & $68^{*}$ & $70^{*}$ \\
\hline Disassociation (DIS) & 49 & 49 \\
\hline
\end{tabular}




\begin{tabular}{|l|l|l|}
\hline Sexual Concerns (SC) & 63 & 59 \\
\hline $\begin{array}{l}\text { Dysfunctional Sexual } \\
\text { Behavior (DSB) }\end{array}$ & 59 & 49 \\
\hline $\begin{array}{l}\text { Impaired Self-Reference } \\
\text { (ISR) }\end{array}$ & 59 & 54 \\
\hline $\begin{array}{l}\text { Tension-Reduction } \\
\text { Behavior (TRB) }\end{array}$ & 61 & 55 \\
\hline
\end{tabular}

* indicates significance

Significant IE and DA results are indicative of classic post traumatic stress presentation. Intrusive experiences and avoidance meet two of three criteria for PTSD as defined by the DSM-IV.

\section{Participant Three}

\begin{tabular}{|l|l|l|}
\hline Subscale Name & Pretest (trauma score) & Posttest \\
\hline Anxious-Arousal (AA) & $75^{*}$ & 49 \\
\hline Depression (D) & $73^{*}$ & 41 \\
\hline Anger-Irritability (AI) & 60 & 42 \\
\hline Intrusive Experiences (IE) & $69^{*}$ & 50 \\
\hline Defensive-Avoidance (DA) & $68^{*}$ & 41 \\
\hline Disassociation (DIS) & 62 & 43 \\
\hline Sexual Concerns (SC) & 57 & 44 \\
\hline $\begin{array}{l}\text { Dysfunctional Sexual } \\
\text { Behavior (DSB) }\end{array}$ & $68^{*}$ & 47 \\
\hline $\begin{array}{l}\text { Impaired Self-Reference } \\
\text { (ISR) }\end{array}$ & $80^{*}$ & 45 \\
\hline $\begin{array}{l}\text { Tension-Reduction } \\
\text { Behavior (TRB) }\end{array}$ & $70^{*}$ & 43 \\
\hline
\end{tabular}

* indicates significance

Participant 3 rated significant scores on seven of ten scales at pretest. However, posttest results demonstrate improvement across all scales. 


\section{Participant Four}

\begin{tabular}{|l|l|l|}
\hline Subscale Name & Pretest (trauma score) & Posttest \\
\hline Anxious-Arousal (AA) & $77^{*}$ & 58 \\
\hline Depression (D) & $76^{*}$ & 62 \\
\hline Anger-Irritability (AI) & $74^{*}$ & 59 \\
\hline Intrusive Experiences (IE) & $69^{*}$ & 56 \\
\hline Defensive-Avoidance (DA) & 62 & 57 \\
\hline Disassociation (DIS) & $81^{*}$ & $72^{*}$ \\
\hline Sexual Concerns (SC) & $73^{*}$ & 65 \\
\hline $\begin{array}{l}\text { Dysfunctional Sexual } \\
\text { Behavior (DSB) }\end{array}$ & $73^{*}$ & $66^{*}$ \\
\hline $\begin{array}{l}\text { Impaired Self-Reference } \\
\text { (ISR) }\end{array}$ & $80^{*}$ & $75^{*}$ \\
\hline $\begin{array}{l}\text { Tension-Reduction } \\
\text { Behavior (TRB) }\end{array}$ & $88^{*}$ & 64 \\
\hline
\end{tabular}

* indicates significance

Participant 4 scored significantly on nine of ten scales. DIS and ISR suggests the individual is unsure of their identity. DIS and DSB indicates dissociation to avoid shame associated behaviour.

\section{Participant Five}

\begin{tabular}{|l|l|l|}
\hline Subscale Name & Pretest (trauma score) & Posttest \\
\hline Anxious-Arousal (AA) & 64 & 55 \\
\hline Depression (D) & $67^{*}$ & 60 \\
\hline Anger-Irritability (AI) & 54 & 46 \\
\hline Intrusive Experiences (IE) & 48 & 58 \\
\hline Defensive-Avoidance (DA) & 60 & $65^{*}$ \\
\hline Disassociation (DIS) & 62 & 53 \\
\hline
\end{tabular}




\begin{tabular}{|l|l|l|}
\hline Sexual Concerns (SC) & $78^{*}$ & $76^{*}$ \\
\hline $\begin{array}{l}\text { Dysfunctional Sexual } \\
\text { Behavior (DSB) }\end{array}$ & 54 & 51 \\
\hline $\begin{array}{l}\text { Impaired Self-Reference } \\
\text { (ISR) }\end{array}$ & 62 & 62 \\
\hline $\begin{array}{l}\text { Tension-Reduction } \\
\text { Behavior (TRB) }\end{array}$ & 43 & 43 \\
\hline
\end{tabular}

* indicates significance

SC continued to be clinically significant at posttest, which indicates sexual distress and/or associated shame.

\section{Participant Six}

\begin{tabular}{|l|l|l|}
\hline Subscale Name & Pretest (trauma score) & Posttest \\
\hline Anxious-Arousal (AA) & $66^{*}$ & 55 \\
\hline Depression (D) & $67^{*}$ & 59 \\
\hline Anger-Irritability (AI) & $79^{*}$ & 62 \\
\hline Intrusive Experiences (IE) & $73^{*}$ & $71^{*}$ \\
\hline Defensive-Avoidance (DA) & $71^{*}$ & 63 \\
\hline Disassociation (DIS) & $76^{*}$ & 62 \\
\hline Sexual Concerns (SC) & 57 & $65^{*}$ \\
\hline $\begin{array}{l}\text { Dysfunctional Sexual } \\
\text { Behavior (DSB) }\end{array}$ & $83^{*}$ & $71^{*}$ \\
\hline $\begin{array}{l}\text { Impaired Self-Reference } \\
\text { (ISR) }\end{array}$ & $73^{*}$ & $71^{*}$ \\
\hline $\begin{array}{l}\text { Tension-Reduction } \\
\text { Behavior (TRB) }\end{array}$ & $79^{*}$ & $70^{*}$ \\
\hline
\end{tabular}

* indicates significance

Participant 6 experienced significant scores across all of the clinical scales. The posttest indicates improvement across five scales. Taken together the IE, DSB, ISR, TRB predict for intrusive thoughts, avoidance, dissociation, and a possible personality disorder. 
Participant Seven

\begin{tabular}{|l|l|l|}
\hline Subscale Name & Pretest (trauma score) & Posttest \\
\hline Anxious-Arousal (AA) & 60 & 46 \\
\hline Depression (D) & $67^{*}$ & 47 \\
\hline Anger-Irritability (AI) & 54 & 47 \\
\hline Intrusive Experiences (IE) & 61 & 52 \\
\hline Defensive-Avoidance (DA) & 60 & 63 \\
\hline Disassociation (DIS) & 55 & 49 \\
\hline Sexual Concerns (SC) & $69^{*}$ & $71^{*}$ \\
\hline $\begin{array}{l}\text { Dysfunctional Sexual } \\
\text { Behavior (DSB) }\end{array}$ & 47 & 47 \\
\hline $\begin{array}{l}\text { Impaired Self-Reference } \\
\text { (ISR) }\end{array}$ & $75^{*}$ & 61 \\
\hline $\begin{array}{l}\text { Tension-Reduction } \\
\text { Behavior (TRB) }\end{array}$ & 61 & 49 \\
\hline
\end{tabular}

* indicates significance

Significant scores regarding SC were noted at pretest and were higher at posttest.

\section{Participant Eight}

\begin{tabular}{|l|l|l|}
\hline Subscale Name & Pretest (trauma score) & Posttest \\
\hline Anxious-Arousal (AA) & 46 & 44 \\
\hline Depression (D) & 52 & 45 \\
\hline Anger-Irritability (AI) & 51 & 54 \\
\hline Intrusive Experiences (IE) & 52 & 48 \\
\hline Defensive-Avoidance (DA) & 49 & 49 \\
\hline Disassociation (DIS) & 43 & 43 \\
\hline Sexual Concerns (SC) & 42 & 42 \\
\hline
\end{tabular}




\begin{tabular}{|l|l|l|}
\hline $\begin{array}{l}\text { Dysfunctional Sexual } \\
\text { Behavior (DSB) }\end{array}$ & 56 & 47 \\
\hline $\begin{array}{l}\text { Impaired Self-Reference } \\
\text { (ISR) }\end{array}$ & 52 & 41 \\
\hline $\begin{array}{l}\text { Tension-Reduction } \\
\text { Behavior (TRB) }\end{array}$ & 49 & 43 \\
\hline
\end{tabular}

* indicates significance

Participant 8 did not present any clinically significant scores at pretest nor at posttest.

\section{Participant Nine}

\begin{tabular}{|l|l|l|}
\hline Subscale Name & Pretest (trauma score) & Posttest \\
\hline Anxious-Arousal (AA) & 55 & 51 \\
\hline Depression (D) & 48 & 50 \\
\hline Anger-Irritability (AI) & $67^{*}$ & 62 \\
\hline Intrusive Experiences (IE) & 56 & 52 \\
\hline Defensive-Avoidance (DA) & 49 & 52 \\
\hline Disassociation (Dis) & 60 & 55 \\
\hline Sexual Concerns (SC) & 46 & 46 \\
\hline $\begin{array}{l}\text { Dysfunctional Sexual } \\
\text { Behavior (DSB) }\end{array}$ & 54 & 44 \\
\hline $\begin{array}{l}\text { Impaired Self-Reference } \\
\text { (ISR) }\end{array}$ & 57 & 59 \\
\hline $\begin{array}{l}\text { Tension-Reduction } \\
\text { Behavior (TRB) }\end{array}$ & 52 & 49 \\
\hline
\end{tabular}

* indicates significance

Participant 9 attained a clinically significant AI score at pretest, but significant scores were absent at posttest. 


\section{Participant Ten}

\begin{tabular}{|l|l|l|}
\hline Subscale Name & Pretest (trauma score) & Posttest \\
\hline Anxious-Arousal (AA) & 58 & 51 \\
\hline Depression (D) & $66^{*}$ & 50 \\
\hline Anger-Irritability (AI) & $72^{*}$ & 55 \\
\hline Intrusive Experiences (IE) & $65^{*}$ & 56 \\
\hline Defensive-Avoidance (DA) & 62 & 49 \\
\hline Disassociation (DIS) & 66 & 53 \\
\hline Sexual Concerns (SC) & $88^{*}$ & 61 \\
\hline $\begin{array}{l}\text { Dysfunctional Sexual } \\
\text { Behavior (DSB) }\end{array}$ & $100^{*}$ & $66^{*}$ \\
\hline $\begin{array}{l}\text { Impaired Self-Reference } \\
\text { (ISR) }\end{array}$ & $71^{*}$ & 62 \\
\hline $\begin{array}{l}\text { Tension-Reduction } \\
\text { Behavior (TRB) }\end{array}$ & $91^{*}$ & 52 \\
\hline
\end{tabular}

* indicates significance

DSB ranked the highest possible clinical score at pretest and while it had diminished at posttest, the score remained significant. Similarly SC was also significant. Such a combination is not uncommon in clinical practice.

\section{Participant Eleven}

\begin{tabular}{|l|l|l|}
\hline Subscale Name & Pretest (trauma score) & Posttest \\
\hline Anxious-Arousal (AA) & 51 & 60 \\
\hline Depression (D) & 59 & 57 \\
\hline Anger-Irritability (AI) & $69^{*}$ & 60 \\
\hline Intrusive Experiences (IE) & $73^{*}$ & 61 \\
\hline Defensive-Avoidance (DA) & 60 & 63 \\
\hline Disassociation (DIS) & 55 & 60 \\
\hline
\end{tabular}




\begin{tabular}{|l|l|l|}
\hline Sexual Concerns (SC) & 44 & 48 \\
\hline $\begin{array}{l}\text { Dysfunctional Sexual } \\
\text { Behavior (DSB) }\end{array}$ & 59 & 47 \\
\hline $\begin{array}{l}\text { Impaired Self-Reference } \\
\text { (ISR) }\end{array}$ & 61 & $66^{*}$ \\
\hline $\begin{array}{l}\text { Tension-Reduction } \\
\text { Behavior (TRB) }\end{array}$ & 61 & 58 \\
\hline
\end{tabular}

* indicates significance

$\mathrm{AI}$ and IE indicate flashbacks and nightmares. ISR was significant at posttest which indicates some confusion regarding self-knowledge and self-confidence. 


\section{Appendix E: Information Letter \\ Homeless Men Seeking Safety from Trauma and Substance Use: Findings from a Pilot Study}

Dear (name of individual participant),

My name is Juliet Haynes and I am currently a graduate student attending the School of Social Work at Carleton University. I am performing this research study in partial fulfillment for my Masters Degree.

I would like to interview you about your experiences with the Lifehouse Seeking Safety Addiction Program.

To be able to participate in this study it is required that you have completed the Lifehouse twelve-week Seeking Safety Addiction Program and are currently clean and/or sober.

The research study will include two parts:

1. Troy and Jennifer will seek your permission for release of the evaluations you previously completed (at assessment and before and after you completed the Lifehouse Seeking Safety program).

2. I will interview you. I am interested in your recovery experience. I will not focus on trauma or drug use. The interview will last approximately sixty minutes. With your permission, I would like to tape record the interviews. I would also like to take notes.

Participation in this study is entirely voluntary and you may withdraw your agreement to participate at any time during the interview or up to seven days following completion of the interview. You may ask me to remove any information that you do not want revealed.

While I will focus on your trauma and substance abuse recovery experience, some uncomfortable memories may arise, which may be stressful. You may stop the interview at any time and Lifehouse addiction counselors will be available for counseling support and/or services.

The interviews will be conducted at the Ottawa Mission, in a private location, at a date and time which is convenient for you. Transportation costs (i.e., parking costs or bus tickets) will be reimbursed.

All interview recordings (i.e., audio tapes, notes and working documents) will be retained and secured in a locked filing cabinet located at the researcher's personal residence. Access to this information will be limited to Juliet L. Haynes, Dr. Hanes and Dr. van de Sande (i.e., the research team). I plan to complete my research by August 2007. All data will be destroyed following completion of my Master of Social Work degree requirements, which is forecasted no later than December 2007. 


\section{Appendix F: Informed Consent \\ Homeless Men Seeking Safety from Trauma and Substance Use: Findings from a Pilot Study}

- The purpose of this form is to outline my participation in the research project being conducted by Juliet Haynes.

- I have been asked to participate in an interview regarding my trauma and substance abuse recovery program. I am aware that the interview will focus on what $I$ have found to be useful in my recovery.

- The interview will last approximately 60 minutes.

- My participation is voluntary and I may refuse to answer any questions and I may withdraw from the study.

- I may withdraw from the study up to 7 days after the interview after which time the information I have provided will be used in a manner that cannot be distinguished from interviews with other participants.

- If I decide to withdraw from the study, I may decide at that time whether the researcher may keep the interview audio tape recording and/or notes taken to that point or I may ask to have them destroyed.

- I understand that even if I end the interview early, I will still receive $\$ 10.00$ in Tim Horton gift certificates and $\$ 5.00$ cash for my participation.

- I acknowledge the potential minimal risk associated with participating in this interview. I understand some uncomfortable memories may arise, which may be stressful. I may stop the interview at any time and Lifehouse addiction counselors will be available for counseling support and/or services.

- I understand that I can be quoted or paraphrased in the final report; however the report will not refer to me or identify me by name without my prior permission.

- I am aware a final report will be presented to Lifehouse Addiction Staff.

I I agree to be tape recorded. $\quad \square$ I do not agree to be tape recorded.

$[$ I agree to note-taking. $\quad[$ I do not agree with note-taking.

I understand that this project has been approved by the Carleton University Ethics Committee, which adheres to the Tri-Council Policy Statement: Ethical Conduct for Research Involving Humans. If I have any concerns or questions about involvement in the study or about how the research has been conducted, I know that I may contact the Carleton University Ethics Committee through the Chairperson, Prof. Antonio Gualtieri, by telephone, at 613-520-2517 or ethics@carleton.ca

I have read the above letter and understand and agree with its contents. I have signed this letter and have received a copy of it for my personal files. The researcher is not anticipating any mental health issues that would interfere with competence in signing this consent.

Signed: Date:

Name:

Signed (researcher): Date: 